NASA CONTRACTOR R E P O R T

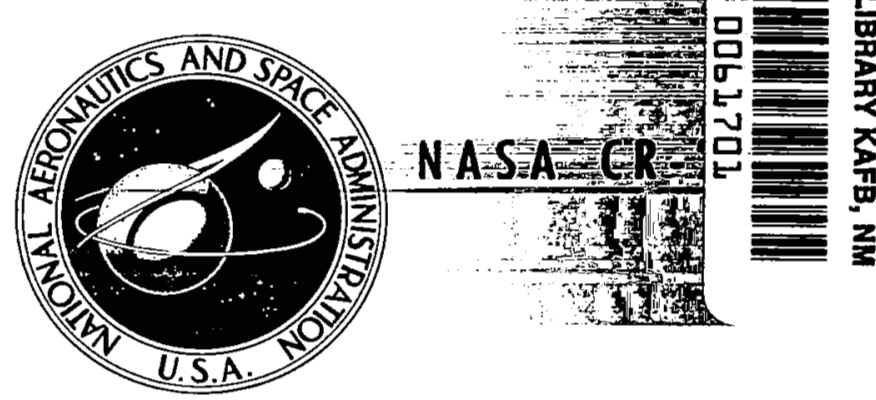

LOAN COPY: RETURN TO AFWL TECHPICAL LIERAEM KIRTLAND AFB, N. M.

\title{
INVESTIGATION OF \\ REFRACTING FLOWS \\ FOR ACOUSTIC SUPPRESSION
}

Denis Sloan, Robert B. Purves, and Bannister W. Farqubar

Prepared by

THE BOEING COMMERCIAL AIRPLANE COMPANY

Seattle, Wash. 98124

for Langley Researcb Center

NATIONAL AERONAUtics AND SPACE ADMINISTRATION - WASHINGTON, D. C. - APRIL 1977 


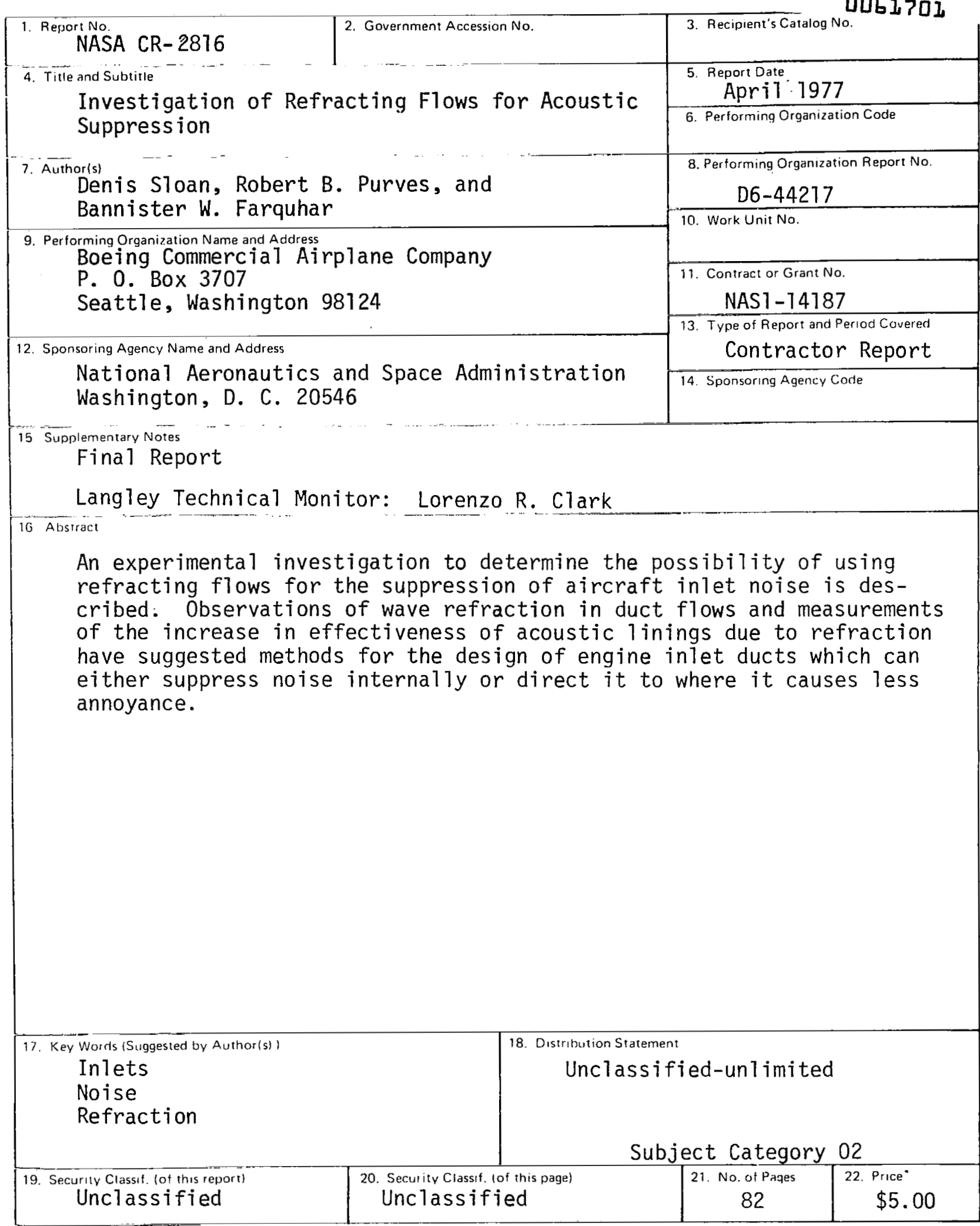

-For sale by the National Technical Information Service, Springfield, Virgina 22151 
SUMMARY . . . . . . . . . . . . . . . . . . . . . . 1 INTRODUCTION . . . . . . . . . . . . . . . . . . . 1 SYMBOLS ......................... 4

PHASE I: OBSERVATIONS OF WAVE BEHAVIOR IN REFRACTING FLOWS . . . . 5 General Description . . . . . . . . . . . 5 The Test Facility ............... 5 Model Design................. . . 7 Part 1................. 7 Part 2 ................. . . 17

Part 3 .................. 17

Part 4................. 17

Test Conditions and 0bjectives.............. 17

Part 1................. . 18

Part 2................. . . 20

Part 3.................. 21

Part 4 ................. . . 24

Results .................. 26

Part 1................ 26

Part 2................. 38

Part 3 ................. . . 47

Part 4 .................. . . 50

PHASE II: THE INFLUENCE OF REFRACTION ON THE EFFECTIVENESS

OF ACOUSTIC LININGS . . . . . . . . . . . . . . 51

General Description ............. . 51

The Test Facility . . . . . . . . . . . . . 51

Model Design ................ . . 54

Duct contours . . . . . . . . . . . . . . 54

Acoustic lining materials ........... 56

Test Conditions ................. . 63 


\section{CONTENTS (Continued)}

\section{Page}

Results ........................ . . 63

Aerodynamic data .................. 63

Acoustic data . . . . . . . . . . . . . . 63

CONCLUSIONS . . . . . . . . . . . . . . . . . . . . 76

RECOMMENDATIONS . . . . . . . . . . . . . . . . . . 79

REFERENCES . . . . . . . . . . . . . . . . . . . 80 


\title{
INVESTIGATION OF REFRACTING FLOWS FOR ACOUSTIC SUPPRESSION
}

\author{
By Denis SToan*, Robert B. Purves ${ }^{\dagger}$ \\ and Bannister W. Farquhar*
}

\section{SUMMARY}

An experimental investigation to determine the possibility of using refracting flows for the suppression of aircraft inlet noise is described. Observations of wave refraction in duct flows and measurements of the increase in effectiveness of acoustic linings due to refraction have suggested methods for the design of engine inlet ducts which can either suppress noise internally or direct it to where it causes less annoyance.

\section{INTRODUCTION}

Many types of inlet configurations have been proposed which would suppress the engine inlet noise of commercial transport aircraft: Among those are inlets containing acoustic linings as well as inlets containing grids, vanes, inflatable lips, translating rings, etc. which can be generally classified as sonic inlets. However, the noise reduction attributable to acoustically lined inlets is not as great as desirable, while the use of sonic inlets would be likely to impose unacceptable performance penalties due to their weight and/or associated pressure recovery losses and distortion effects. More recently (ref. 1), a concept for inlet noise suppression was described which used the effects of wave refraction within the inlet duct to enhance the effectiveness of acoustic linings. Test results at model scale showed that this "refracting inlet" had potential

*Research Engineer, Propulsion Research Group, Boeing Commercial Airplane Co., Renton, Washington.

tResearch Engineer, Noise Research Group, Boeing Conmercial Airplane Co., Renton, Washington. 
for providing a useful reduction in inlet noise. An alternative application of refraction effects in inlet design is to control the directivity pattern of the radiated noise. This involves the use of wave refraction to establish a bias in the direction of propagation of the acoustic waves, the objective being to asymmetrically radiate more acoustic energy forward or above the aircraft rather than towards the ground.

The utilization of acoustic wave refraction in inlets offers several distinct advantages over alternate methods such as acoustic linings or high Mach number inlets. Compared to conventional lined inlets, wave refraction could increase acoustic 1 ining effectiveness or substantially change the inlet directivity with little penalty in the inlet aerodynamic performance, length, or weight. Also, an acoustically refracting inlet offers the possibility of a fixed inlet geometry, a trait lacking in most sonic inlet concepts.

The present work describes the results of an experimental program to obtain information on the use of refracting flows for acoustic suppression. The program is comprised of two phases.

In Phase I, the behavior of weak shock waves propagating upstream against a duct flow were observed using Schlieren photography. Various wall liners or flow dividers were installed in the duct to generate the flow conditions of interest. This phase of the program was divided into four parts. The objective of Part 1 was to determine the relationship between the amount of refraction and the shape of the wall contour. Parts 2 and 3 examined the influence of the profiles of simulated inlet configurations on the direction of propagation of waves leaving the inlet. The Part 2 configurations were symmetrical about the centerline and the Part 3 configurations were nonsymmetrical. In Part 4, some basic information concerning the required length of refracting inlet configurations was obtained. 
Phase II was an investigation to determine the influence of refraction on the effectiveness of acoustic linings. The experiment was conducted using an Acoustic Flow Duct facility in which suitably contoured walls were installed to generate the required flow conditions. A range of acoustic lining materials were located along the duct walls. Results show the acoustic performance of the linings at a variety of flow conditions. 


\section{SYMBOLS}

$A_{R} \quad$ approach length ratio (length of the duct upstream of the contraction section divided by the throat height for configurations N4-01 through N4-06)

c velocity of sound

$D_{R} \quad$ contraction ratio (upstream duct height or distance between hilites divided by throat height)

$\mathrm{D}_{\mathrm{TH}} \quad$ throat height

DU

duct height upstream of contraction

d distance

$k$ wave number

$L_{C} \quad$ contraction length

$L_{R}$

contraction length ratio (contraction length divided by throat height)

M Mach number

$M_{T H} \quad$ mean Mach number at the throat

$M_{P}$

particle Mach number

resistance

$X$ distance along the duct or reactance

$Y$ distance across the duct

$Z$ acoustic impedance

$\alpha \quad$ angular deviation of the direction of wave propagation

$\rho$ density of air

IL insertion loss

SPL sound pressure leve? 
PHASE I: OBSERVATIONS OF WAVE BEHAVIOR IN REFRACTING FLOWS

\section{Genera1 Description}

This phase of the program was an experimental investigation to observe the behavior of waves in flows similar to those which can be generated in aircraft gas turbine engine inlets. Because of the difficulty of observing acoustic waves using optical methods, the bulk of the observations were conducted using weak shock waves produced by the discharge of a spark across electrodes located in the flow. The behavior of these waves was recorded photographically using a Schlieren apparatus and variable timedelay generator as they propagated against the flow in a duct. The flow conditions of interest were generated by using various wall contours in the test section or by locating flow dividers across the duct.

The Test Facility

A schematic of the test facility is shown in figure 1. Air was drawn into the test section from the atmosphere through a bellmouth (not shown) and ducted to a vacuum pump downstream. The duct cross-section was $102 \times$ $102 \mathrm{sq} \mathrm{mm}$ and $609 \mathrm{~mm}$ long, having glass sidewalls, and had the capability for inserting contoured liners along both the upper and lower surfaces or for locating flow dividers across the entire width of the duct between the glass sidewal1s. Static pressure taps located along the upper and lower surfaces were used to determine the flow conditions. The electrodes of the spark discharge system were located at the center of the duct $150 \mathrm{~mm}$ downstream of the test section and the shock waves were generated by the discharge of a $5 \mu \mathrm{F}$ capacitor at $8000 \vee$ across the 3-rm gap separating the electrodes. After a selected time delay of up to several milliseconds, the spark 1 ight source of the $150-\mathrm{mm}$-diameter Schlieren system was discharged and the location of the shock wave recorded photographically. 
Schematic of the test section for part 1 of phase $I$ (pressure taps at $X=0.025,0.229,0.419,0.584 \mathrm{~m}$ )

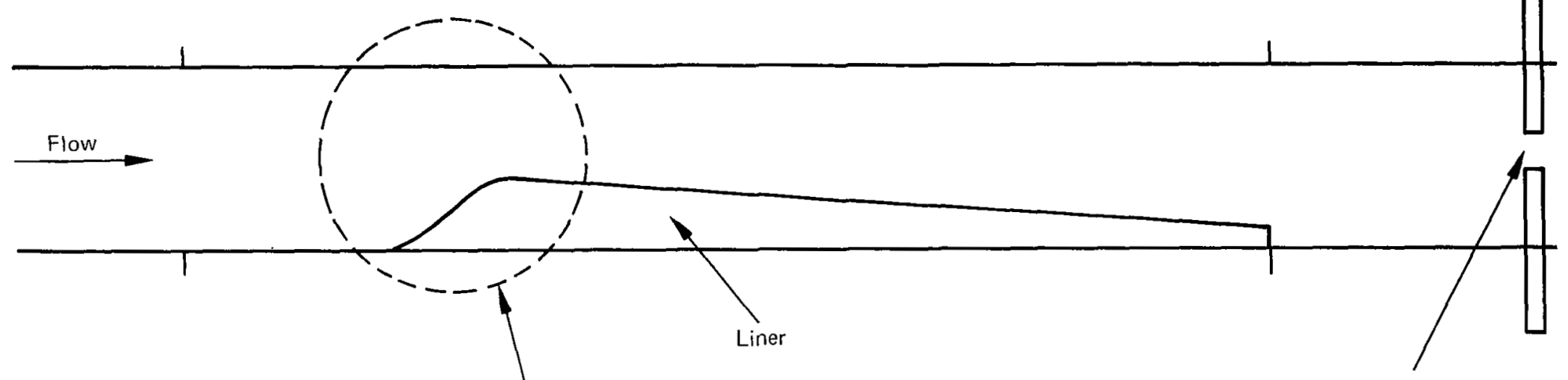

Viewing area of schlieren apparatus

Schematic of the test

section for parts $2,3 \& 4$ of phase 1

(pressure taps on both walls at $\mathrm{X}=$

$0.025,0.102,0.152,0.203,0.254,0.305,0.406,0.508 \mathrm{~m}$ )

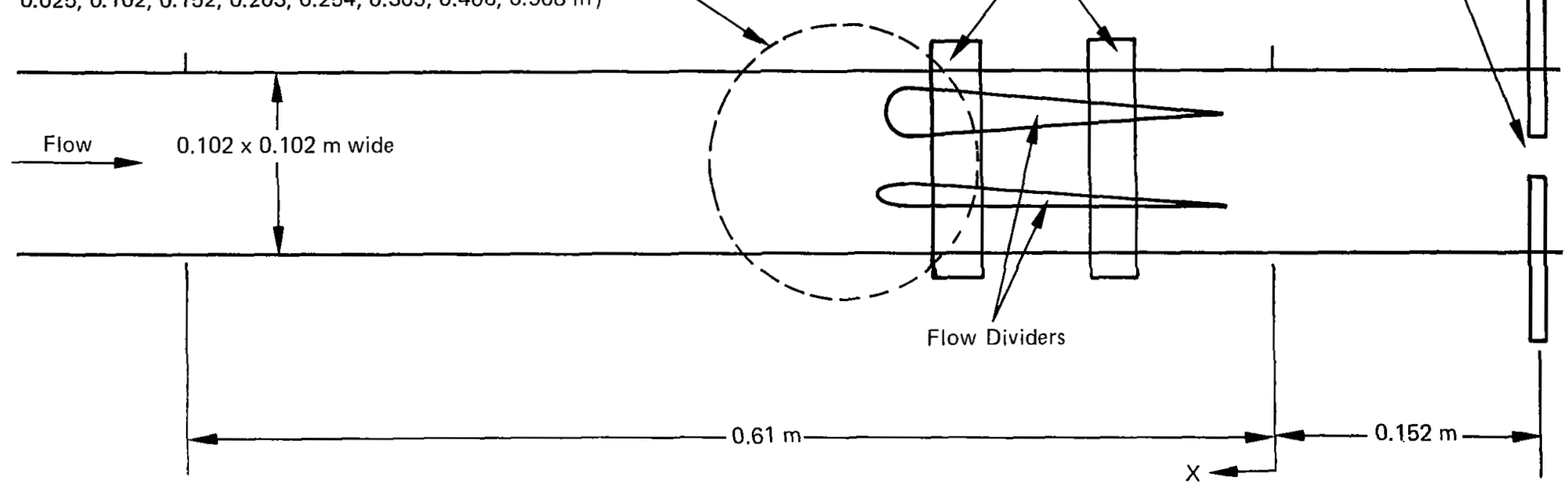

Figure 1. Schematic of the Test Section for Phase I 
Mode1 Design

This phase of the program was divided into four parts, each part using different arrangements of wall liners or flow dividers. The general installation is shown schematically in figure 1 , with the details of the liners and dividers shown in figures 2 through 7.

Part 1.--Seven configurations (designated N1-01 through N1-07) were used in this part of the investigation and are shown in figures 2(a) and 2(b). The throat was located at the same position of the duct for each configuration, and in every case the contraction portion of the contour was described by a cubic curve. Downstream of the throat, the flow discharged to the pump through a gentle diffuser faired smoothly at the throat. Both the contraction ratio, $D_{R}$ (upstream duct height divided by throat height), and the contraction length ratio, $L_{R}$ (contraction length divided by throat height)*, are indicated on figures $2(a)$ and $2(b)$.

In addition to the above seven configurations, two other configurations were tested and are shown in figure 3(a). These were designated $N 1-$ 03-A and N1-04-A and had identical contours to configurations N1-03 and N104, respectively. However, these configurations also contained a Hartmann whistle located downstream of the throat and midway across the duct, which was designed to generate high-intensity acoustic waves in the vicinity of $22 \mathrm{kHz}$. Details of the Hartmann whistle are shown in figure 3(b) with the underexpanded jet flow discharging into a cup containing a stabilizing needle. Information on the operation of the Hartmann whistle is contained in references 2 and 3. A flush-mounted microphone was located in the wal1 of the duct to facilitate tuning of the whistle (this was accomplished by varying the location of the cup in the jet flow until the sound pressure level recorded by the microphone was a maximum).

*Because only one wall was 1 ined in configurations N1-01 through N1-06, the effective throat height used to calculate $L_{R}$ was twice that shown in figures $2(a)$ and $2(b)$. 

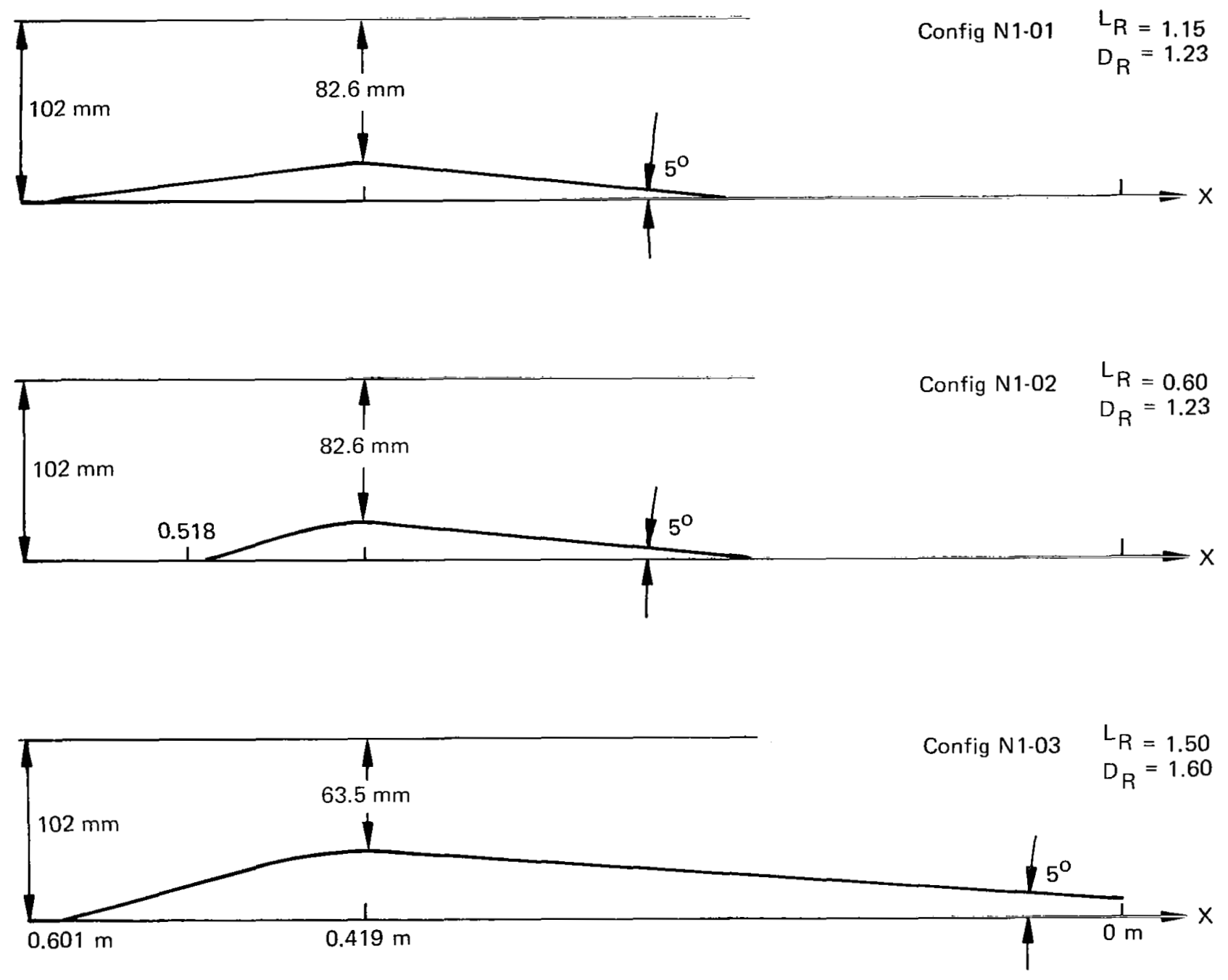

$\left.\begin{array}{ll}\text { All contraction contours are defined by, } Y=a X^{3}+b X^{2}+c X+d \\ Y \text { inere the coefficients are evaluated using: at } X_{\text {initial }} \\ X_{\text {throat }}\end{array}\right\} \begin{aligned} & Y=0 \\ & Y^{\prime}=0 \\ & Y_{\text {throat }} \\ & Y^{\prime}=0\end{aligned}$

The $5^{\circ}$ diffuser is faired smoothly at the throat

Figure 2(a). Test Configurations NASI - 14187 Phase I - Part 1 (Cont'd) 

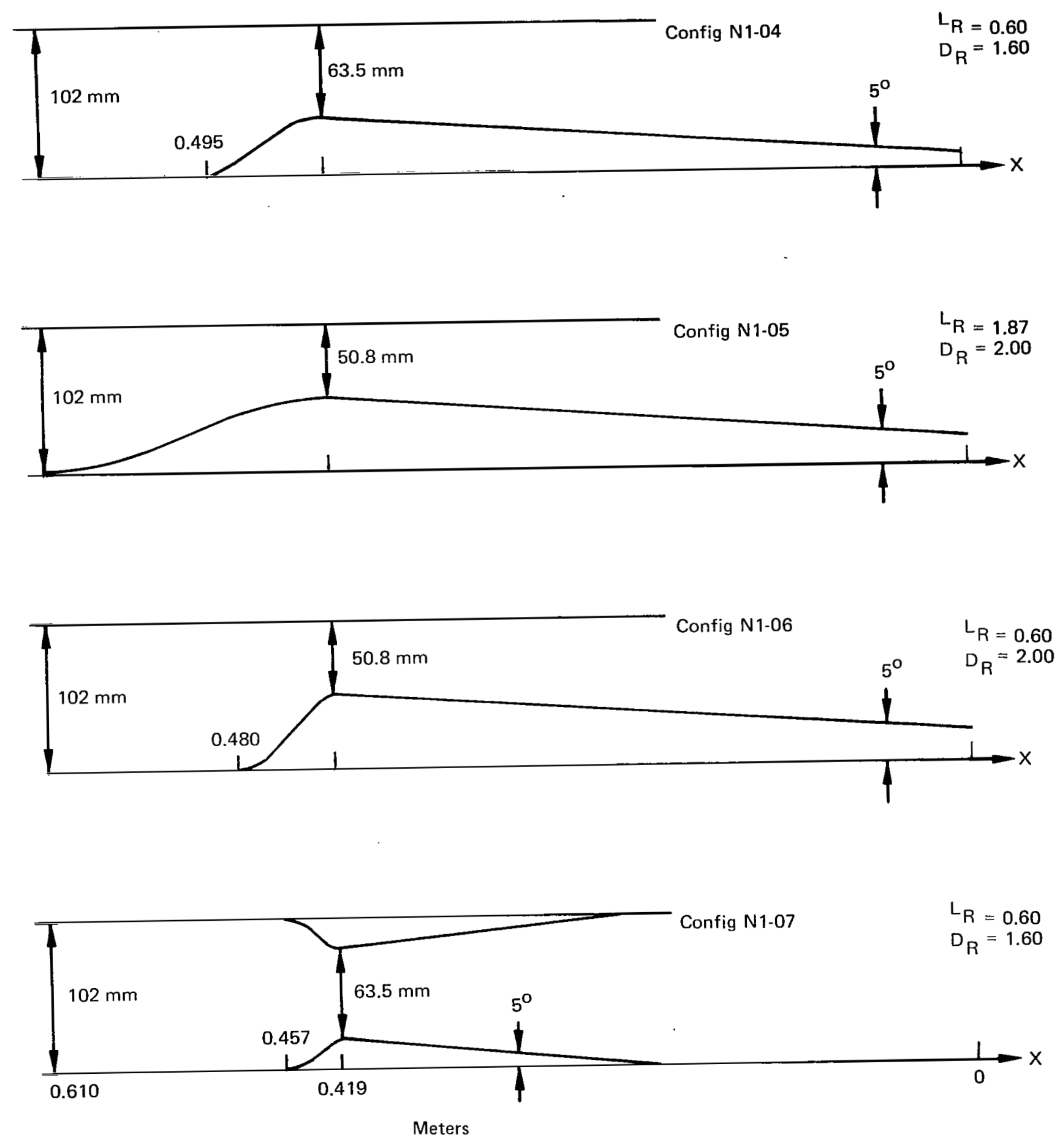

Figure 2(b). Test Configurations NASI - 14187 Phase I-Part 1 (Conc'd) 


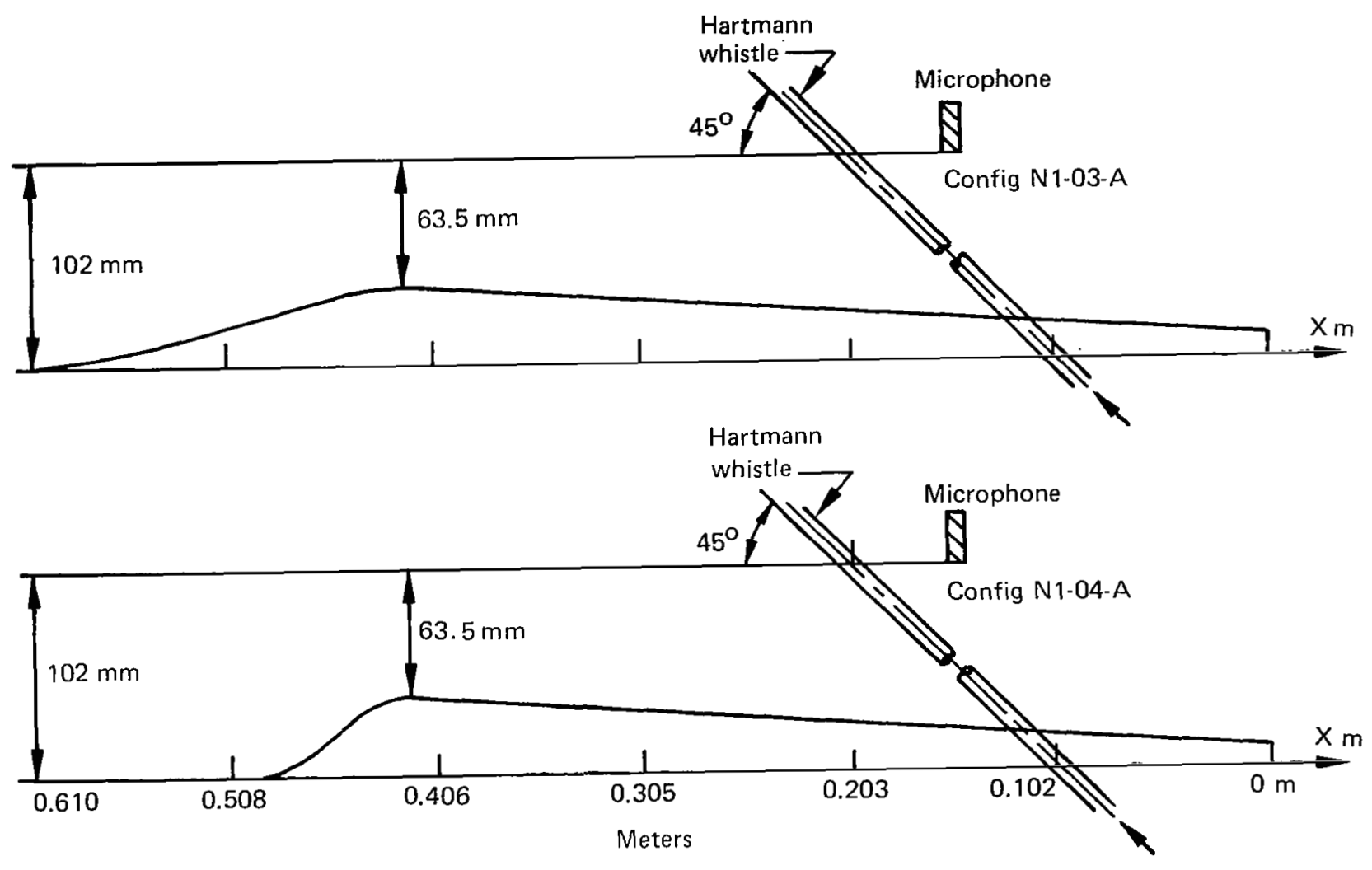

The contour of config N1-03-A was identical to that of config N1-03.

The contour of config N1-04-A was identical to that of config N1-04.

Figure 3(a). Test Configurations NASI-14187 Phase / - Part 1 (Cont'd) 


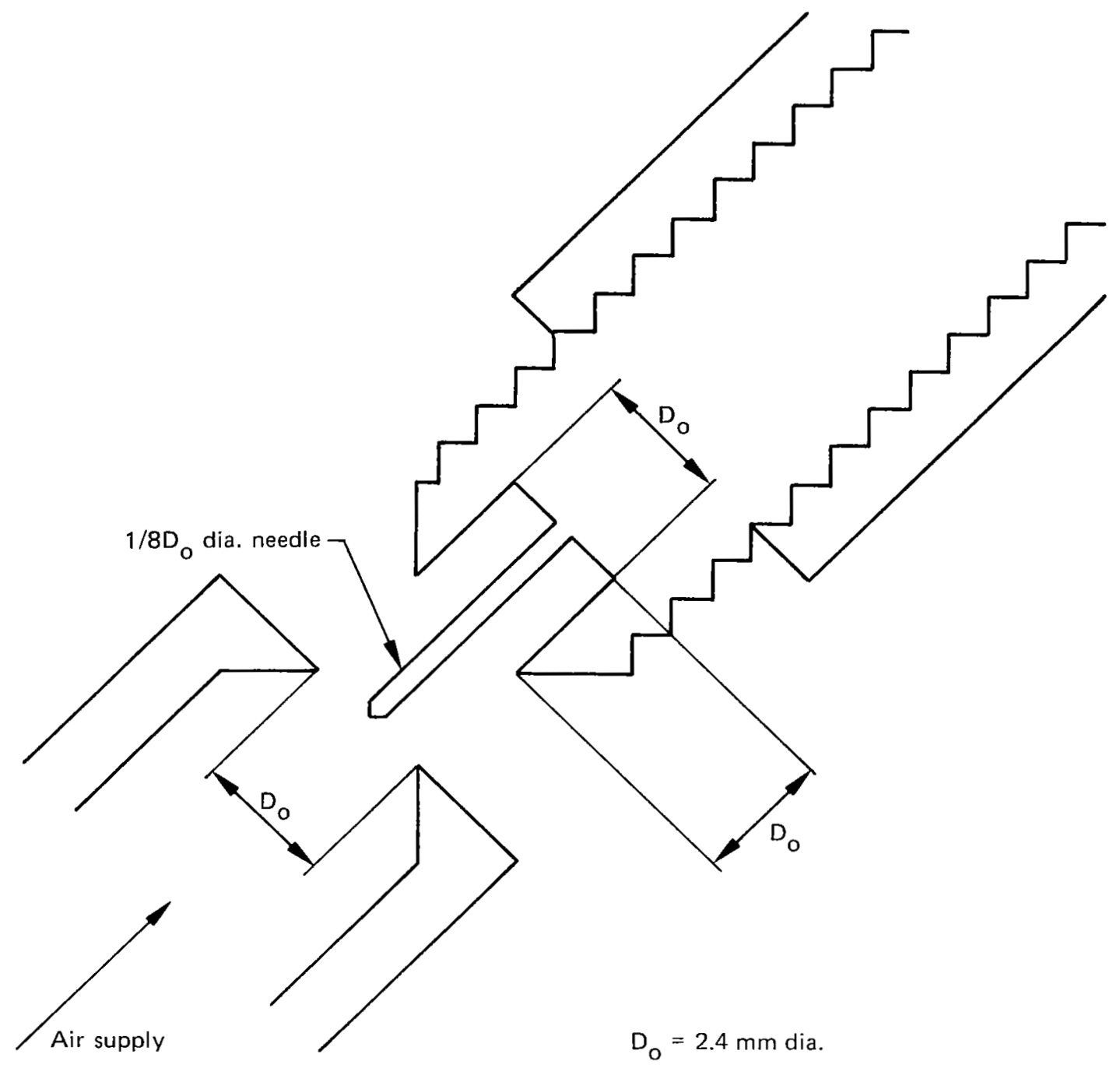

Figure 3(b). Details of the Hartmann whistle 
Profile P-01

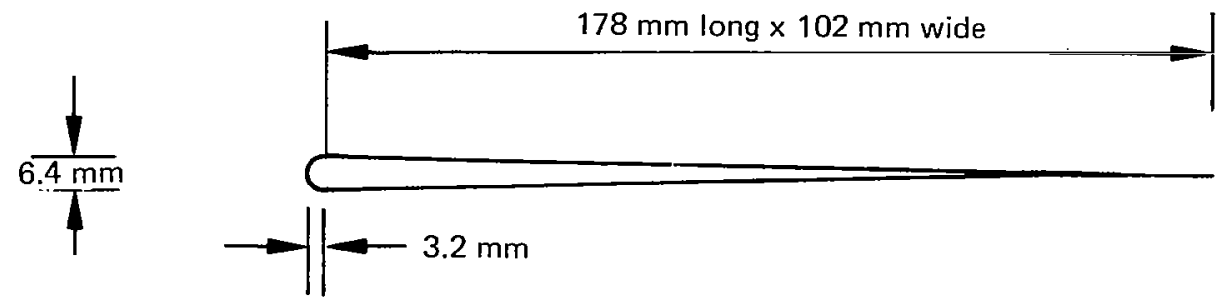

Profile P-02
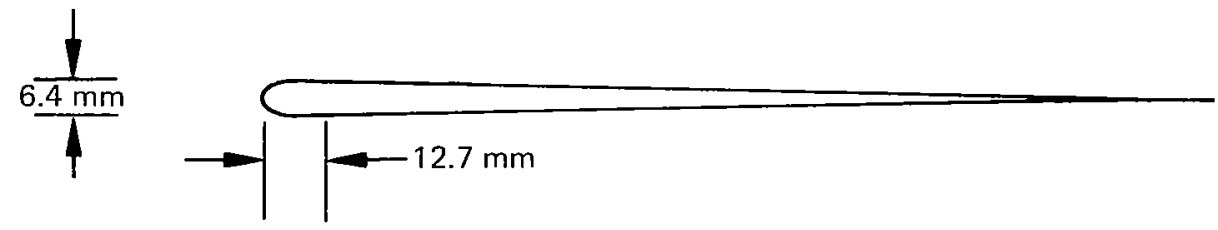

Profile P-03
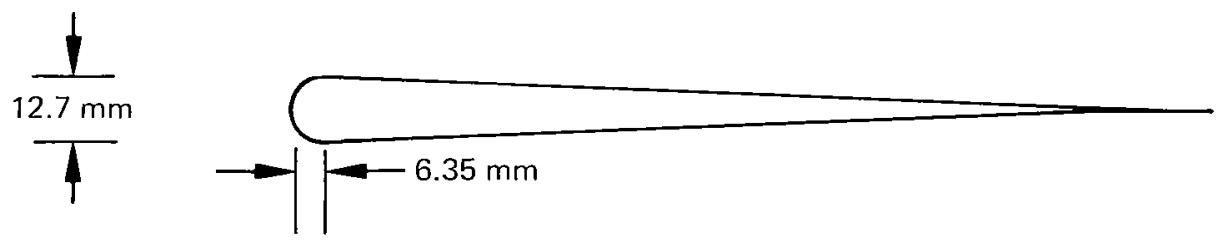

Profile P-04
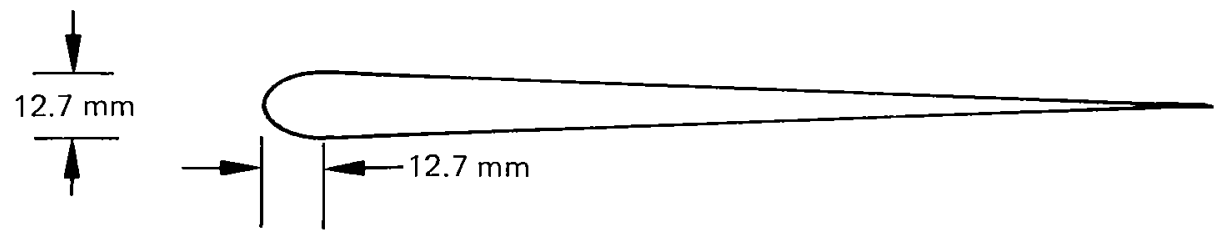

Profile P-05
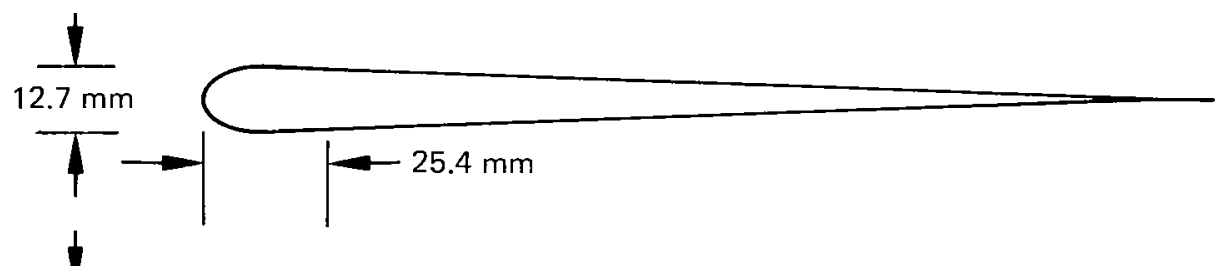

Profile P-06

$25.4 \mathrm{~mm}$
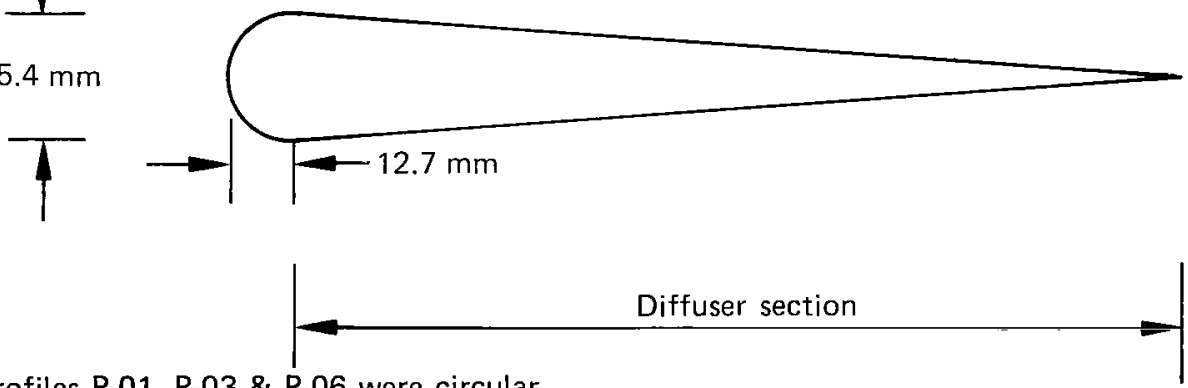

The leading edges of profiles P-01, P-03 \& P-06 were circular.

The leading edges of profiles P-02, P-04 \& P-05 were elliptical.

Each linear diffuser section was faired smoothly with the leading edge.

Figure 4(a). Flow Divider Profiles for Parts 2 \& 3 of Phase I - NAS/-14187 
Profile P-07

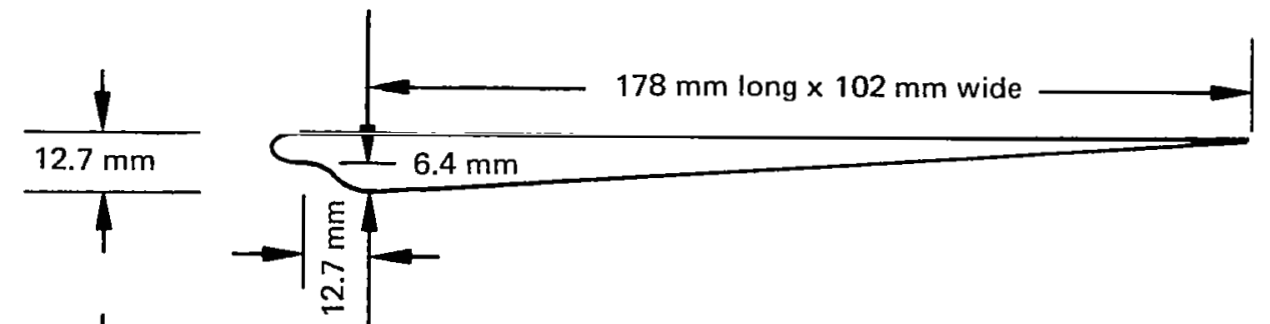

Profile P-08

Profile'P:09-

Profile P-10
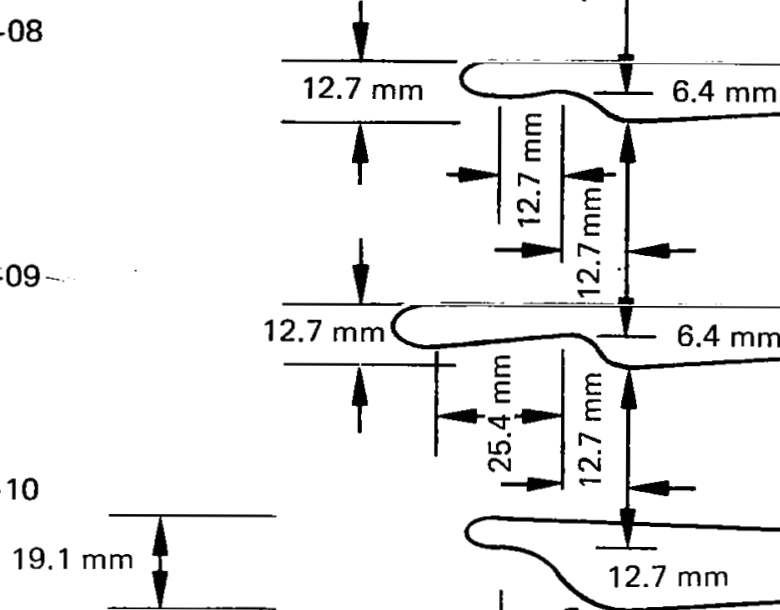

$6.4 \mathrm{~mm}$

Profile P-11

$19.1 \mathrm{~mm}$

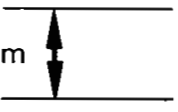

Profile P-12
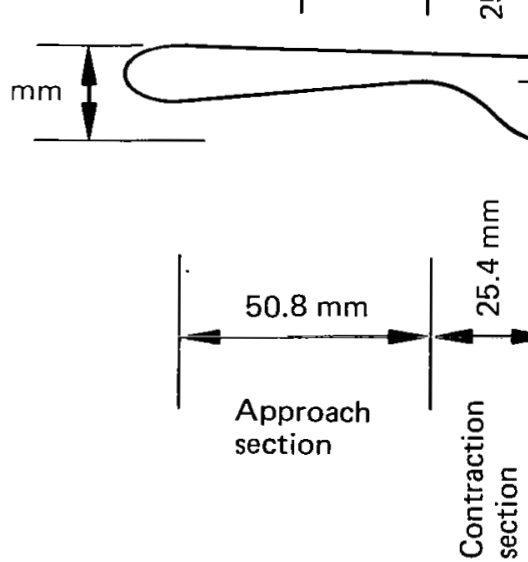

Diffuser section

The leading edge of each profile was a 2:1 ellipse.

Each approach section was a cubic curve at mean slope 1:14.

Each contraction section was a cubic curve.

The linear diffuser section was faired smoothly with the contraction section.

Figure 4(b). Flow Divider Profiles for Part 4 of Phase I - NAS/-14187 

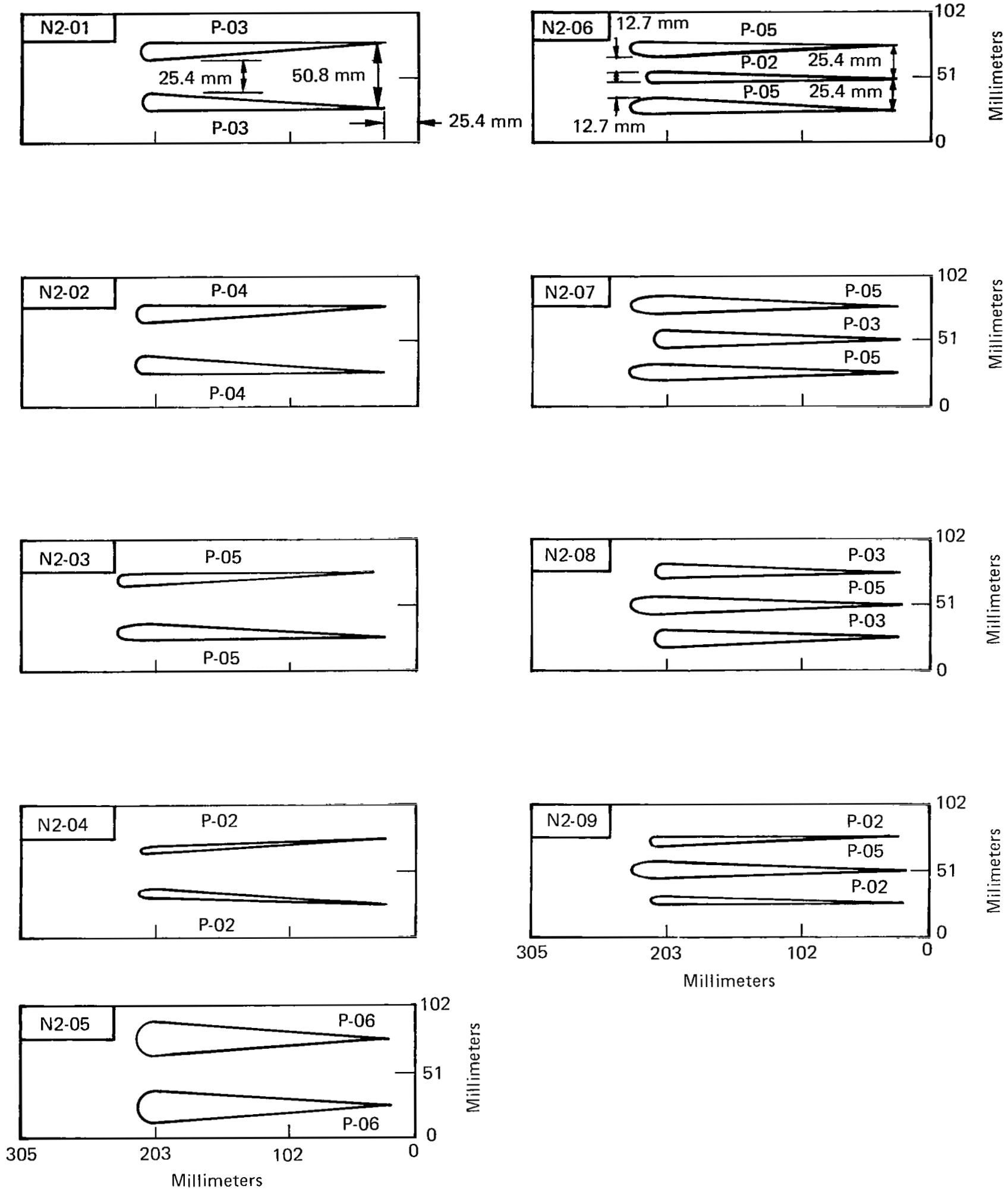

Figure 5. Configurations for Part 2 of Phase I, NAS/-14187 

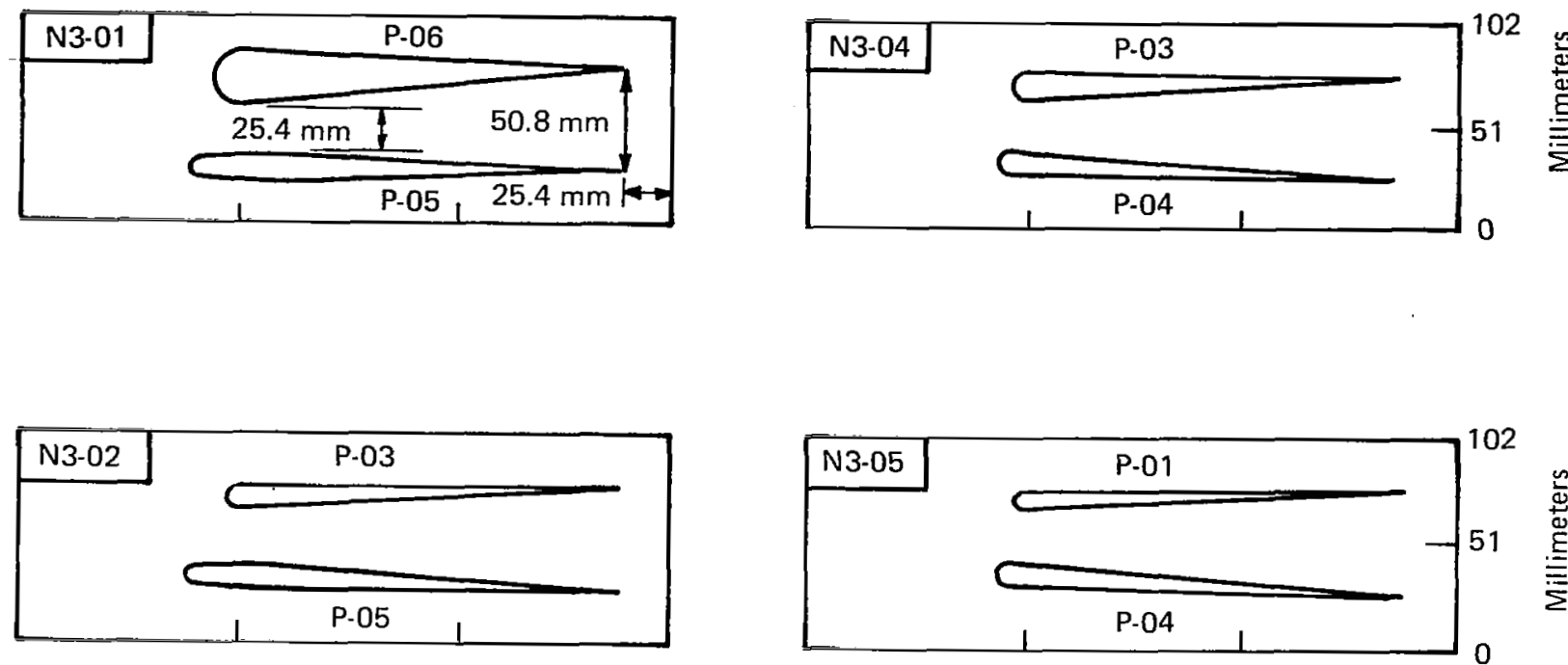

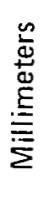
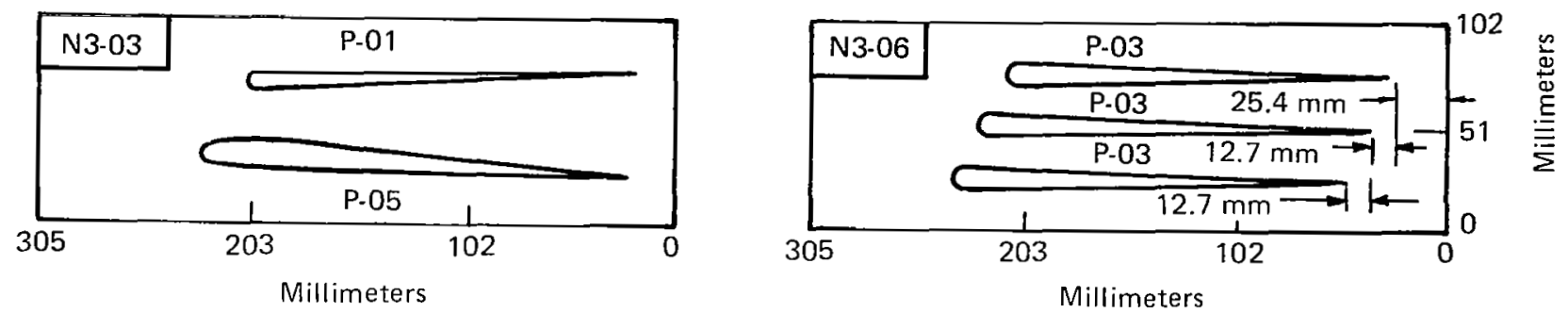

Figure 6. Configurations for Part 3 of Phase I 

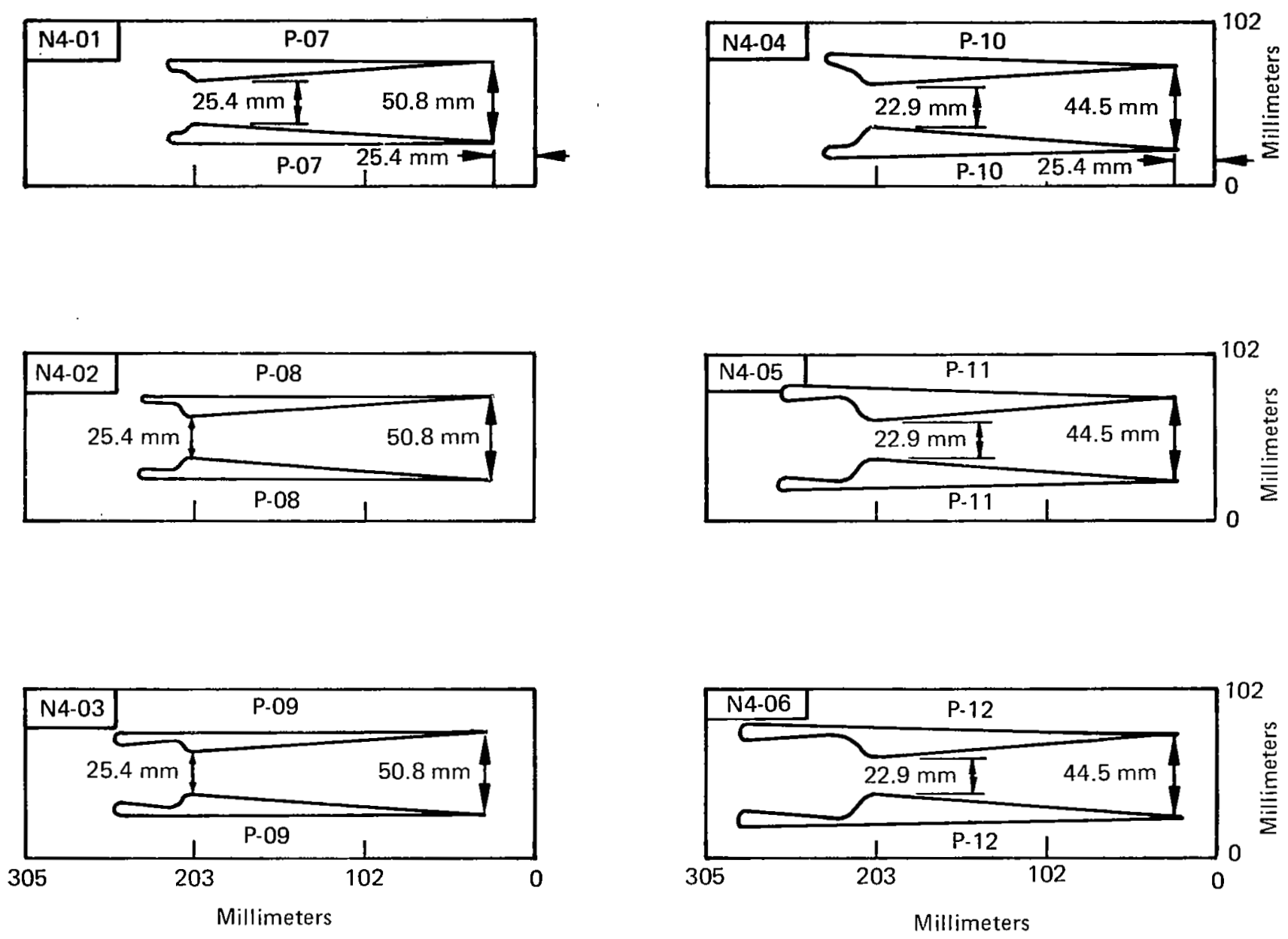

Figure 7. Configurations for Part 4 of Phase I 
Part 2. --Nine configurations designated N2-01 through N2-09 were tested in this part of the investigation. Each of these contained either two or three flow dividers installed across the full width of the duct between the glass sidewails. The details of the divider contours, labeled P-01 through P-06, are shown in figure $4(\mathrm{a})$, and the arrangements of these dividers in each of the nine configurations are shown in figure 5 . The total height of the flow area between the dividers was $25.4 \mathrm{~mm}$ at the throat and opened up to $50.8 \mathrm{~mm}$ at the trailing edge.

Part 3.--The six configurations N3-01 through N3-06 tested in this part of the investigation are shown in figure 6 and are comprised of different combinations of the flow dividers shown in figure 4(a). For each configuration, the total height of the flow area between the airfoils was $25.4 \mathrm{~mm}$ at the throat opening up to $50.8 \mathrm{~mm}$ at the trailing edge.

Part 4.--The details of the flow dividers P-07 through P-12 used in this part of the test are shown in figure $4(\mathrm{~b})$, and the arrangements of these dividers in the six configurations N4-01 through N4-06 are shown in figure 7 .

Test Conditions and Objectives

In each part of Phase I, the motion of the spark-generated shock wave moving upstream against the flow was recorded photographically using the Schiieren apparatus. Each of the four parts of Phase I had distinct and separate objectives, which are described below. 
Part 1.--Previous work (ref. 1) has demonstrated that significant refraction effects can be produced in flowfields representative of the inlet flow in aircraft gas turbine engines. The scope of this work was not broad enough, however, to provide the basic information needed to design inlets which utilize refraction effects. Consequently, the objective of Part 1 of this investigation was to provide sufficient data to relate the level of refraction to the flow conditions which cause the refraction. For convenience, all the velocity gradients in the flow were generated using cubic contraction profiles, which made it possible to relate the level of refraction to the contraction ratio, $D_{R}$, and length ratio, $L_{R}$, describing the contour. The values of $D_{R}$ and $L_{R}$ for the seven configurations are tabulated below.

\begin{tabular}{|l|l|l|l|l|}
\hline & & & & \\
\hline & 0.60 & 1.15 & 1.50 & 1.87 \\
\hline 1.00 & $N 1-06$ & $x$ & $x$ & $N 7-05$ \\
\hline 1.60 & $\begin{array}{l}N 1-04 \\
N 1-07\end{array}$ & $x$ & $N 1-03$ & $x$ \\
\hline 1.23 & $N 1-02$ & $N 1-01$ & $x$ & $x$ \\
\hline
\end{tabular}

The values of $L_{R}$ and $D_{R}$ for these configurations were considered sufficient to cover the range which may conceivably be used in an actual inlet design (due to limitations on inlet length and nacelle diameter to restrict weight and drag). The configurations N1-04 and N1-07 were geometrically similar, but as can be seen in figure 2(b), the centerline of configuration N1-07 was effectively replaced by a straight wall to form configuration N1-04. Therefore, it was intended that a comparison of the results of these two configurations could be used to assess the influence of boundary layer growth on the observed refraction effects. Each of the configurations was tested at nominal mean Mach numbers in the throat of $0.40,0.55$, and 0.70 , the exact values being shown in table 1 together with the Mach number of the approach flow in the upstream parallel portion of the duct. 
TABLE 1

FLOW CONDITIONS FOR PART I OF PHASE I

\begin{tabular}{|c|c|c|c|c|}
\hline Configuration & Run No. & $\begin{array}{l}\text { Throat } \\
\text { Mach No. }\end{array}$ & $\begin{array}{l}\text { Approach } \\
\text { Mach No. }\end{array}$ & Comments \\
\hline$N 1-01$ & $\begin{array}{l}\text { A007 } \\
\text { A008 } \\
\text { A006 }\end{array}$ & $\begin{array}{l}0.71 \\
0.55 \\
0.41\end{array}$ & $\begin{array}{l}0.53 \\
0.43 \\
0.33\end{array}$ & $\begin{array}{l}\text { Shock wave } \\
\text { photographs }\end{array}$ \\
\hline $\mathrm{N} 1-02$ & $\begin{array}{l}\text { A014 } \\
\text { A015 }\end{array}$ & $\begin{array}{l}0.72 \\
0.55\end{array}$ & $\begin{array}{l}0.54 \\
0.44\end{array}$ & $\begin{array}{l}\text { Shock wave } \\
\text { photographs }\end{array}$ \\
\hline N1 -03 & $\begin{array}{l}\mathrm{A} 021 \\
\mathrm{~A} 022 \\
\mathrm{~A} 023\end{array}$ & $\begin{array}{l}0.72 \\
0.56 \\
0.41\end{array}$ & $\begin{array}{l}0.39 \\
0.33 \\
0.26\end{array}$ & $\begin{array}{l}\text { Shock wave } \\
\text { photographs }\end{array}$ \\
\hline N1-04 & $\begin{array}{l}\text { A029 } \\
\text { A030 } \\
\text { A031 }\end{array}$ & $\begin{array}{l}0.70 \\
0.54 \\
0.41\end{array}$ & $\begin{array}{l}0.39 \\
0.32 \\
0.26\end{array}$ & $\begin{array}{l}\text { Shock wave } \\
\text { photographs }\end{array}$ \\
\hline N1-05 & $\begin{array}{l}\text { A036 } \\
\text { A037 } \\
\text { A038 }\end{array}$ & $\begin{array}{l}0.76 \\
0.58 \\
0.41\end{array}$ & $\begin{array}{l}0.30 \\
0.26 \\
0.20\end{array}$ & $\begin{array}{l}\text { Shock wave } \\
\text { photographs }\end{array}$ \\
\hline N1-06 & $\begin{array}{l}\text { A043 } \\
\text { A044 } \\
\text { A045 }\end{array}$ & $\begin{array}{l}0.71 \\
0.56 \\
0.41\end{array}$ & $\begin{array}{l}0.28 \\
0.25 \\
0.19\end{array}$ & $\begin{array}{l}\text { Shock wave } \\
\text { photographs }\end{array}$ \\
\hline N1-07 & $\begin{array}{l}\text { A050 } \\
\text { A051 } \\
\text { A052 }\end{array}$ & $\begin{array}{l}0.68 \\
0.55 \\
0.40\end{array}$ & $\begin{array}{l}0.38 \\
0.33 \\
0.26\end{array}$ & $\begin{array}{l}\text { Shock wave } \\
\text { photographs }\end{array}$ \\
\hline N1-03-A & $\begin{array}{l}\text { HW004 } \\
\text { HW005 } \\
\text { HW006 } \\
\text { HW007 }\end{array}$ & $\begin{array}{l}0 \\
0.43 \\
0.57 \\
0.72\end{array}$ & $\begin{array}{l}0 \\
0.26 \\
0.32 \\
0.37\end{array}$ & $\begin{array}{l}\text { Acoustic wave } \\
\text { photographs }\end{array}$ \\
\hline NT-04-A & $\begin{array}{l}\text { HW009 } \\
\text { HW010 } \\
\text { HW011 } \\
\text { HW012 }\end{array}$ & $\begin{array}{l}0 \\
0.41 \\
0.56 \\
0.68\end{array}$ & $\begin{array}{l}0 \\
0.25 \\
0.33 \\
0.38\end{array}$ & $\begin{array}{l}\text { Acoustic wave } \\
\text { photographs }\end{array}$ \\
\hline
\end{tabular}


Because some doubt had been raised concerning the validity of using the observed behavior of the shock wave to describe the behavior of acoustic waves, two of the configurations were selected to observe the motions of trains of acoustic waves generated by a Hartmann whistle. As shown in table 1, these configurations, N1-03-A and N1-04-A, were tested at nominally the same conditions as the configurations N1-03 and N1-04. The behavior of the acoustic waves was recorded photographically using the Schlieren apparatus.

Part 2.--The objective in testing configurations N2-01 through N2-09 was to determine the extent to which the direction of propagation of waves leaving these symmetrical simulated inlet configurations was influenced by the flow conditions generated by the divider profiles. As shown in figure $4(a)$, the leading edge of each profile was either circular or elliptical, which permitted each of the configurations shown in figure 5 to be described by a contraction ratio, $D_{R}$ (distance between the hilites* divided by the throat height), and a length ratio, $L_{R}$ (the axial distance from the throat section to the hilite* section divided by throat height). The range of values of $D_{R}$ and $L_{R}$ for configurations N2-01 through N2-05 is shown below.

\begin{tabular}{|l|l|l|l|}
\hline$D_{R}$ & & & \\
\hline 2.00 & 0.25 & 0.50 & 1.00 \\
\hline 1.50 & $x$ & $N 2-05$ & $x$ \\
\hline 1.25 & $N 2-01$ & $N 2-02$ & $N 2-03$ \\
\hline
\end{tabular}

The remaining configurations, N2-06 through N2-09, were also symmetrical about the centerline of the duct, but contained a third divider midway between the outer two, which was representative of a contoured inlet centerbody. The values of $D_{R}$ and $L_{R}$ based on the 12.7-mm separation between the flow dividers are shown below.

*The "hilite" location was at the nose of each flow divider. 


\begin{tabular}{|l|l|l|l|l|}
\hline \multirow{2}{*}{ Configuration } & \multicolumn{2}{|c|}{ Outer Dividers } & \multicolumn{2}{c|}{ Center Divider } \\
\cline { 2 - 5 } & $\mathrm{D}_{\mathrm{R}}$ & $\mathrm{L}_{\mathrm{R}}$ & $\mathrm{D}_{\mathrm{R}}$ & $\mathrm{L}_{\mathrm{R}}$ \\
\hline $\mathrm{N} 2-06$ & 2.0 & 2.0 & 1.5 & 1.0 \\
\hline $\mathrm{N} 2-07$ & 2.0 & 2.0 & 2.0 & 0.5 \\
\hline $\mathrm{N} 2-08$ & 2.0 & 0.5 & 2.0 & 2.0 \\
\hline N2-09 & 1.5 & 1.0 & 2.0 & 2.0 \\
\hline
\end{tabular}

Because of the low curvature of the outer dividers in the throat region of configurations $\mathrm{N} 2-06$ and N2-07, it was hoped that results from these configurations would provide examples of how waves could be propagated along or even across the centerline. Conversely, because of the low curvature of the inner dividers of configurations N2-08 and N2-09, it was intended that these results would demonstrate how waves could be propagated away from the axis of a centerbody inlet.

Each of these configurations was run at nominal mean Mach numbers of 0.4 to 0.8 in 0.1 increments, the precise values being shown in table 2 . Also shown are the values of the approach Mach number in the parallel section of the duct upstream of the flow dividers.

Part 3.--The objective in testing the configurations N3-07 through N306 was to determine which types of divider contour would generate flow conditions to cause the waves to be refracted in a specified direction away from the duct centerline. Thus, each of the configurations shown in figure 6 was expected to refract the waves towards the upper wall of the duct. The lower dividers of configurations N3-01, N3-02, and N3-03 were identical and the leading edges of the upper profiles were circular arcs. Configurations N3-04 and N3-05 were tested to determine the extent to which shortening of the leading edge of the lower divider changed the direction of propagation by influencing the flowfield in the throat region. The results from configuration N3-06 were required to demonstrate how a centerbody inlet could also be used to refract waves in a selected direction. 
TABLE 2

FLOW CONDITIONS FOR PART 2 OF PHASE I

\begin{tabular}{|c|c|c|c|c|}
\hline Configuration & Run No. & $\begin{array}{l}\text { Throat } \\
\text { Mach No. }\end{array}$ & $\begin{array}{l}\text { Approach } \\
\text { Mach No. }\end{array}$ & Comments \\
\hline $\mathrm{N} 2-01$ & $\begin{array}{l}\mathrm{N} 2-01.0 \\
\mathrm{~N} 2-01.4 \\
\mathrm{~N} 2-01.5 \\
\mathrm{~N} 2-01.6 \\
\mathrm{~N} 2-01.7 \\
\mathrm{~N} 2-01.8\end{array}$ & $\begin{array}{l}0 \\
0.40 \\
0.50 \\
0.60 \\
0.70 \\
0.81\end{array}$ & $\begin{array}{l}0 \\
0.19 \\
0.22 \\
0.25 \\
0.28 \\
0.30\end{array}$ & $\begin{array}{l}\text { Shock wave } \\
\text { photographs }\end{array}$ \\
\hline $\mathrm{N} 2-02$ & $\begin{array}{l}\mathrm{N} 2-02.0 \\
\mathrm{~N} 2-02.4 \\
\mathrm{~N} 2-02.5 \\
\mathrm{~N} 2-02.6 \\
\mathrm{~N} 2-02.7 \\
\mathrm{~N} 2-02.8\end{array}$ & $\begin{array}{l}0 \\
0.40 \\
0.50 \\
0.60 \\
0.70 \\
0.82 \\
\end{array}$ & $\begin{array}{l}0 \\
0.19 \\
0.22 \\
0.25 \\
0.28 \\
0.30\end{array}$ & $\begin{array}{l}\text { Shock wave } \\
\text { photographs }\end{array}$ \\
\hline $\mathrm{N} 2-03$ & $\begin{array}{l}N 2-03.0 \\
N 2-03.4 \\
N 2-03.5 \\
N 2-03.6 \\
N 2-03.7 \\
N 2-03.8\end{array}$ & $\begin{array}{l}0 \\
0.40 \\
0.51 \\
0.67 \\
0.71 \\
0.84\end{array}$ & $\begin{array}{l}0 \\
0.19 \\
0.22 \\
0.25 \\
0.28 \\
0.30\end{array}$ & $\begin{array}{l}\text { Shock wave } \\
\text { photographs }\end{array}$ \\
\hline$N 2-04$ & $\begin{array}{l}\text { N2-04.0 } \\
\text { N2-04.4 } \\
\text { N2-04.5 } \\
\text { N2-04.6 } \\
\text { N2-04.7 } \\
\text { N2-04.8 }\end{array}$ & $\begin{array}{l}0 \\
0.40 \\
0.50 \\
0.61 \\
0.71 \\
0.82\end{array}$ & $\begin{array}{l}0 \\
0.18 \\
0.22 \\
0.25 \\
0.28 \\
0.29\end{array}$ & $\begin{array}{l}\text { Shock wave } \\
\text { photographs }\end{array}$ \\
\hline$N 2-05$ & $\begin{array}{l}\mathrm{N} 2-05.0 \\
N 2-05.4 \\
N 2-05.5 \\
N 2-05.6 \\
N 2-05.7 \\
N 2-05.8\end{array}$ & $\begin{array}{l}0 \\
0.40 \\
0.50 \\
0.61 \\
0.71 \\
0.83\end{array}$ & $\begin{array}{l}0 \\
0.19 \\
0.22 \\
0.25 \\
0.28 \\
0.29\end{array}$ & $\begin{array}{l}\text { Shock wave } \\
\text { photographs }\end{array}$ \\
\hline N2-06 & $\begin{array}{l}\text { N2 }-06.0 \\
\text { N2 }-06.4 \\
\text { N2 }-06.5 \\
\text { N2-06.6 } \\
\text { N2 }-06.7 \\
\text { N2-06.8 }\end{array}$ & $\begin{array}{l}0 \\
0.40 \\
0.49 \\
0.59 \\
0.68 \\
0.78\end{array}$ & $\begin{array}{l}0 \\
0.19 \\
0.22 \\
0.25 \\
0.28 \\
0.30\end{array}$ & $\begin{array}{l}\text { Shock wave } \\
\text { photographs }\end{array}$ \\
\hline
\end{tabular}


TABLE 2.--Concluded

FLOW CONDITIONS FOR PART 2 OF PHASE I

\begin{tabular}{|c|c|c|c|c|}
\hline Configuration & Run No. & $\begin{array}{l}\text { Throat } \\
\text { Mach No. }\end{array}$ & $\begin{array}{l}\text { Approach } \\
\text { Mach No. }\end{array}$ & Comments \\
\hline N2-07 & $\begin{array}{l}\text { N2-07.0 } \\
\text { N2-07.4 } \\
\text { N2-07.5 } \\
\text { N2-07.6 } \\
\text { N2-07.7 } \\
\text { N2-07.8 }\end{array}$ & $\begin{array}{l}0 \\
0.39 \\
0.48 \\
0.58 \\
0.67 \\
0.76\end{array}$ & $\begin{array}{l}0 \\
0.19 \\
0.22 \\
0.25 \\
0.28 \\
0.30\end{array}$ & $\begin{array}{l}\text { Shock wave } \\
\text { photographs }\end{array}$ \\
\hline $\mathrm{N} 2-08$ & $\begin{array}{l}\text { N2-08.0 } \\
\text { N2-08.4 } \\
\text { N2-08.5 } \\
\text { N2-08.6 } \\
\text { N2-08.7 } \\
\text { N2-08.8 }\end{array}$ & $\begin{array}{l}0 \\
0.40 \\
0.49 \\
0.60 \\
0.69 \\
0.80\end{array}$ & $\begin{array}{l}0 \\
0.19 \\
0.22 \\
0.25 \\
0.28 \\
0.30\end{array}$ & $\begin{array}{l}\text { Shock wave } \\
\text { photographs }\end{array}$ \\
\hline N2-09 & $\begin{array}{l}\text { N2-09.0 } \\
\text { N2-09.4 } \\
\text { N2-09.5 } \\
\text { N2-09.6 } \\
\text { N2-09.7 } \\
N 2-09.8\end{array}$ & $\begin{array}{l}0 \\
0.40 \\
0.51 \\
0.61 \\
0.72 \\
0.85\end{array}$ & $\begin{array}{l}0 \\
0.19 \\
0.22 \\
0.25 \\
0.28 \\
0.30\end{array}$ & $\begin{array}{l}\text { Shock wave } \\
\text { photographs }\end{array}$ \\
\hline
\end{tabular}


The values of the contraction ratio, $D_{R}$, and the length ratio, $L_{R}$, for each configuration are tabulated below.

\begin{tabular}{|l|c|c|c|c|}
\hline \multirow{2}{*}{ Configuration } & \multicolumn{2}{|c|}{ Upper Divider } & \multicolumn{2}{c|}{ Lower Divider } \\
\cline { 2 - 5 } & $\mathrm{D}_{\mathrm{R}}$ & $\mathrm{L}_{\mathrm{R}}$ & $\mathrm{D}_{\mathrm{R}}$ & $\mathrm{L}_{\mathrm{R}}$ \\
\hline N3-01 & 2.0 & 0.5 & 1.5 & 1.0 \\
\hline N3-02 & 1.5 & 0.25 & 1.5 & 1.0 \\
\hline N3-03 & 1.25 & 0.125 & 1.5 & 1.0 \\
\hline N3-04 & 1.5 & 0.25 & 1.5 & 0.5 \\
\hline N3-05 & 1.25 & 0.125 & 1.5 & 0.5 \\
\hline N3-06 & 2.0 & 0.5 & \multicolumn{2}{|c|}{ Straight } \\
\hline
\end{tabular}

Each of these configurations was tested at throat mean Mach numbers nominally from 0.4 to 0.8 in 0.1 increments with the exact values shown in table 3, together with the approach Mach number in the parallel section of the duct.

Part 4.--The six configurations N4-01 through N4-06 shown in figure 7 were tested to examine the effects of variation in the "approach length ratio" of configurations resembling refracting inlets. The refracting inlet has been described in reference 1 , where the "approach length ratio" is that section of the inlet duct upstream of the throat region which intercepts sound waves propagating through the inlet. The waves are directed toward this surface via refraction by appropriate selection of the wall contour to generate the required flow conditions in the throat region. In an actual refracting inlet, the energy of these waves would be absorbed by a suitable acoustic lining material. The objective of this test was to determine the extent of the wave impingement on the upstream surface. The table below shows the contraction ratio, $D_{R}$ (the distance between the dividers at the beginning of the contraction divided by the throat height), the contraction length ratio, $L_{R}$ (the distance along the centerline from 
TABLE 3

FLOW CONDITIONS FOR PART 3 OF PHASE I

\begin{tabular}{|c|c|c|c|c|}
\hline Configuration & Run No. & $\begin{array}{l}\text { Throat } \\
\text { Mach No. }\end{array}$ & $\begin{array}{l}\text { Approach } \\
\text { Mach No. }\end{array}$ & Comments \\
\hline N3-01 & $\begin{array}{l}\text { N3-01.0 } \\
\text { N3-01.4 } \\
\text { N3-01.5 } \\
\text { N3-01.6 } \\
\text { N3-01.7 } \\
\text { N3-01.8 }\end{array}$ & $\begin{array}{l}0 \\
0.41 \\
0.51 \\
0.62 \\
0.72 \\
0.86\end{array}$ & $\begin{array}{l}0 \\
0.19 \\
0.22 \\
0.26 \\
0.28 \\
0.30\end{array}$ & $\begin{array}{l}\text { Shock wave } \\
\text { photographs }\end{array}$ \\
\hline N3-02 & $\begin{array}{l}\text { N3-02.0 } \\
\text { N3-02.4 } \\
\text { N3-02.5 } \\
\text { N3-02.6 } \\
\text { N3-02.7 } \\
N 3-02.8\end{array}$ & $\begin{array}{l}0 \\
0.40 \\
0.50 \\
0.61 \\
0.69 \\
0.80\end{array}$ & $\begin{array}{l}0 \\
0.19 \\
0.22 \\
0.25 \\
0.28 \\
0.29\end{array}$ & $\begin{array}{l}\text { Shock wave } \\
\text { photographs }\end{array}$ \\
\hline N3-03 & $\begin{array}{l}\text { N3-03.0 } \\
\text { N3-03.4 } \\
\text { N3-03.5 } \\
\text { N3-03.6 } \\
\text { N3-03.7 } \\
\text { N3-03.8 }\end{array}$ & $\begin{array}{l}0 \\
0.39 \\
0.49 \\
0.59 \\
0.68 \\
0.78\end{array}$ & $\begin{array}{l}0 \\
0.19 \\
0.22 \\
0.25 \\
0.28 \\
0.30\end{array}$ & $\begin{array}{l}\text { Shock wave } \\
\text { photographs }\end{array}$ \\
\hline N3-04 & $\begin{array}{l}\text { N3-04.0 } \\
\text { N3-04.4 } \\
\text { N3-04.5 } \\
\text { N3-04.6 } \\
\text { N3-04.7 } \\
\text { N3-04.8 }\end{array}$ & $\begin{array}{l}0 \\
0.40 \\
0.50 \\
0.60 \\
0.70 \\
0.81\end{array}$ & $\begin{array}{l}0 \\
0.19 \\
0.22 \\
0.25 \\
0.28 \\
0.30\end{array}$ & $\begin{array}{l}\text { Shock wave } \\
\text { photographs }\end{array}$ \\
\hline N3-05 & $\begin{array}{l}\text { N3-05.0 } \\
\text { N3-05.4 } \\
\text { N3-05.5 } \\
\text { N3-05.6 } \\
\text { N3-05.7 } \\
\text { N3-05.8 }\end{array}$ & $\begin{array}{l}0 \\
0.40 \\
0.49 \\
0.59 \\
0.68 \\
0.78\end{array}$ & $\begin{array}{l}0 \\
0.19 \\
0.22 \\
0.25 \\
0.28 \\
0.30\end{array}$ & $\begin{array}{l}\text { Shock wave } \\
\text { photographs }\end{array}$ \\
\hline N3-06 & $\begin{array}{l}\text { N3-06.0 } \\
\text { N3-06.4 } \\
\text { N3-06.5 } \\
\text { N3-06.6 } \\
\text { N3-06.7 } \\
\text { N3-06.8 }\end{array}$ & $\begin{array}{l}0 \\
0.40 \\
0.50 \\
0.61 \\
0.72 \\
0.84\end{array}$ & $\begin{array}{l}0 \\
0.19 \\
0.22 \\
0.25 \\
0.28 \\
0.30\end{array}$ & $\begin{array}{l}\text { Shock wave } \\
\text { photographs }\end{array}$ \\
\hline
\end{tabular}


the throat to the beginning of the contraction divided by the throat height), and the approach length ratio, $A_{R}$ (the approach length divided by throat height).

\begin{tabular}{|l|c|c|c|}
\hline Configuration & $D_{R}$ & $L_{R}$ & $A_{R}$ \\
\hline N4-01 & 1.5 & 0.5 & 0 \\
\hline N4-02 & 1.5 & 0.5 & 0.5 \\
\hline N4-03 & 1.5 & 0.5 & 1.0 \\
\hline N4-04 & 2.1 & 1.1 & 0 \\
\hline N4-05 & 2.1 & 1.1 & 1.1 \\
\hline N4-06 & 2.1 & 1.1 & 2.2 \\
\hline
\end{tabular}

Thus, it can be seen that the configurations N4-01 through N4-03 had a common contraction section, as did the remaining three configurations. Each configuration was tested at nominal mean Mach numbers in the throat of 0.4 to 0.8 in 0.1 increments, with the exact values shown in table 4 , together with the Mach number of the approach flow in the parallel portion of the duct upstream of the flow dividers.

\section{Results}

Part 1.--Figures 8(a) and 8(b) show Schlieren photographs of the shock wave as it progressed through configuration N1-06. In figure $8(a)$, the mean Mach number at the throat was 0.40 with the flow from left to right and the shock wave traveling from right to left. The wave of interest was at a location to the left of the number 18 in the photograph and can be seen to be approximately vertical but curving slightly towards the wall at its lower extremity. This wave had been only slightly influenced by the velocity gradients in the throat region and was not visible in the shadow region of the contraction section upstream of the throat. Its basic direction of travel remained generally along the duct axis. The other disturbances which are visible in figure $8(a)$ were due to reflections of the wave 
TABLE 4

FLOW CONDITIONS FOR PART 4 OF PHASE I

\begin{tabular}{|c|c|c|c|c|}
\hline Configuration & Run No. & $\begin{array}{l}\text { Throat } \\
\text { Mach No. }\end{array}$ & $\begin{array}{l}\text { Approach } \\
\text { Mach No. }\end{array}$ & Comments \\
\hline N4-01 & $\begin{array}{l}N 4-01.0 \\
N 4-01.4 \\
N 4-01.5 \\
N 4-01.6 \\
N 4-01.7 \\
N 4-01.8\end{array}$ & $\begin{array}{l}0 \\
0.40 \\
0.51 \\
0.62 \\
0.72 \\
0.86\end{array}$ & $\begin{array}{l}0 \\
0.19 \\
0.22 \\
0.25 \\
0.28 \\
0.30\end{array}$ & $\begin{array}{l}\text { Shock wave } \\
\text { photographs }\end{array}$ \\
\hline $\mathrm{N} 4-02$ & $\begin{array}{l}\text { N4-02.0 } \\
\text { N4-02.4 } \\
\text { N4-02.5 } \\
\text { N4-02.6 } \\
\text { N4-02.7 } \\
\text { N4-02.8 }\end{array}$ & $\begin{array}{l}0 \\
0.41 \\
0.51 \\
0.60 \\
0.70 \\
0.81\end{array}$ & $\begin{array}{l}0 \\
0.18 \\
0.22 \\
0.25 \\
0.27 \\
0.29\end{array}$ & $\begin{array}{l}\text { Shock wave } \\
\text { photographs }\end{array}$ \\
\hline N4-03 & $\begin{array}{l}N 4-03.0 \\
N 4-03.4 \\
N 4-03.5 \\
N 4-03.6 \\
N 4-03.7 \\
N 4-03.8\end{array}$ & $\begin{array}{l}0 \\
0.40 \\
0.51 \\
0.62 \\
0.73 \\
0.86\end{array}$ & $\begin{array}{l}0 \\
0.19 \\
0.22 \\
0.25 \\
0.28 \\
0.30\end{array}$ & $\begin{array}{l}\text { Shock wave } \\
\text { photographs }\end{array}$ \\
\hline N4-04 & $\begin{array}{l}N 4-04.0 \\
N 4-04.4 \\
N 4-04.5 \\
N 4-04.6 \\
N 4-04.7 \\
N 4-04.8\end{array}$ & $\begin{array}{l}0 \\
0.40 \\
0.50 \\
0.60 \\
0.70 \\
0.82\end{array}$ & $\begin{array}{l}0 \\
0.19 \\
0.22 \\
0.26 \\
0.28 \\
0.30\end{array}$ & $\begin{array}{l}\text { Shock wave } \\
\text { photographs }\end{array}$ \\
\hline N4-05 & $\begin{array}{l}\text { N4-05.0 } \\
\text { N4-05.4 } \\
\text { N4-05.5 } \\
\text { N4-05.6 } \\
\text { N4-05.7 } \\
\text { N4-05.8 }\end{array}$ & $\begin{array}{l}0 \\
0.40 \\
0.50 \\
0.61 \\
0.71 \\
0.83\end{array}$ & $\begin{array}{l}0 \\
0.19 \\
0.22 \\
0.25 \\
0.28 \\
0.30\end{array}$ & $\begin{array}{l}\text { Shock wave } \\
\text { photographs }\end{array}$ \\
\hline N4-06 & $\begin{array}{l}\text { N4-06.0 } \\
N 4-06.4 \\
\text { N4-06.5 } \\
N 4-06.6 \\
N 4-06.7 \\
N 4-06.8\end{array}$ & $\begin{array}{l}0 \\
0.40 \\
0.50 \\
0.60 \\
0.70 \\
0.80\end{array}$ & $\begin{array}{l}0 \\
0.19 \\
0.22 \\
0.25 \\
0.28 \\
0.29\end{array}$ & $\begin{array}{l}\text { Shock wave } \\
\text { photographs }\end{array}$ \\
\hline
\end{tabular}




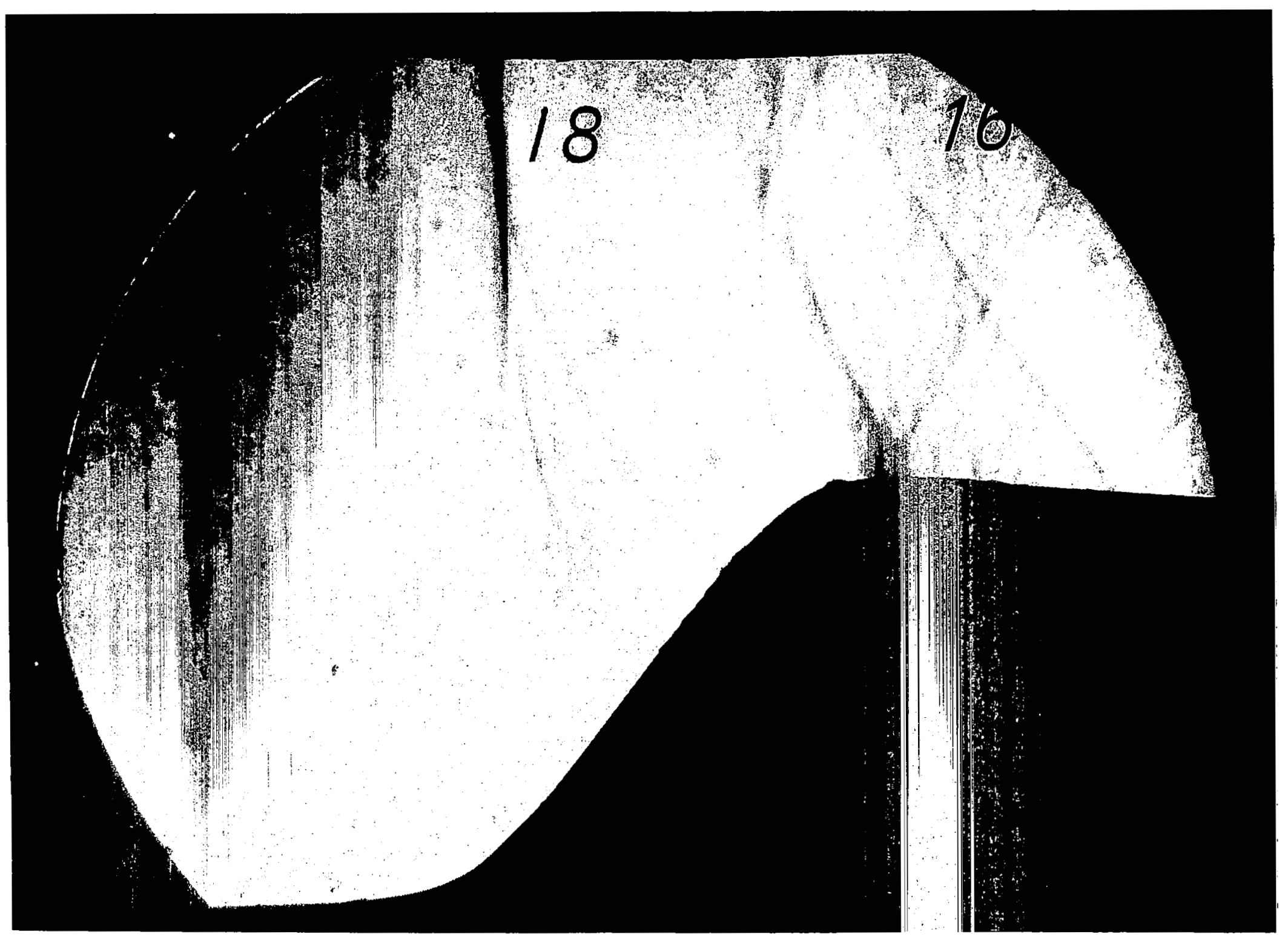

Figure 8(a). Shock Wave Location in Configuration N1-06 at $\bar{M}_{T H}=0.40$ 


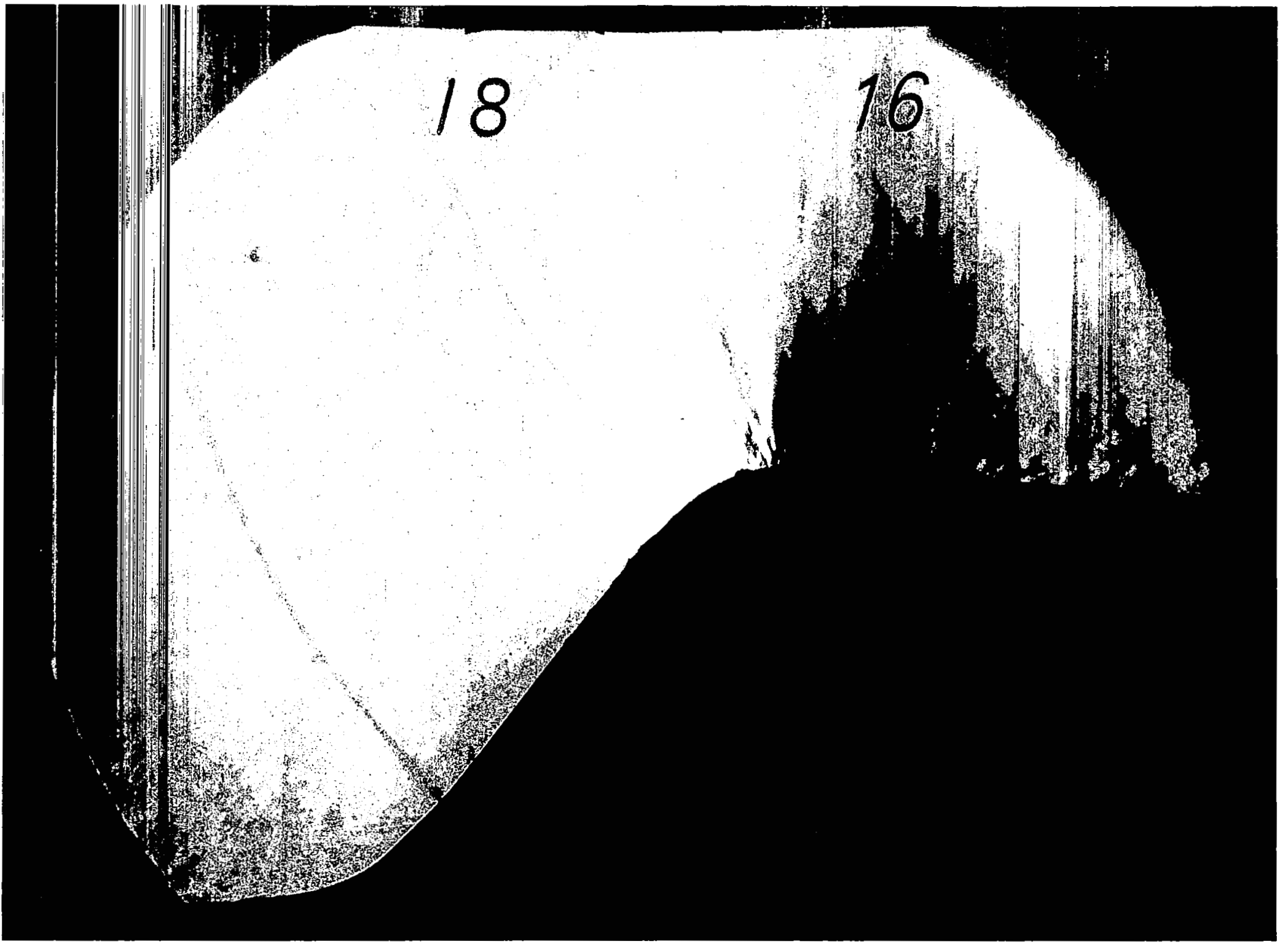


from the duct wall as it traveled from the source to the throat region, and are of no interest for the current test objectives. In figure $8(\mathrm{~b})$, the mean Mach number in the throat region was 0.71 , again with the flow traveling from left to right and the shock wave traveling from right to left. In this case, the floin conditions in the throat region were sufficient to cause very strong refraction of the wave. The wave had been directed towards the lower surface of the duct, and figure 8 (b) clearly shows both the wave itself and its reflection from the contraction surface.

From the sets of photographs similar to those in figures $8(a)$ and $8(b)$, the locations of the shock wave after varying time intervals were plotted as shown in figure 9. Also shown are the contours of Mach number, which were calculated using a potential flow analysis (ref. 4). The upper diagram of figure 9 shows the flow conditions when the mean Mach number in the throat was 0.70 and the Mach number upstream in the duct was 0.277 . As the wave approached the throat, it remained essentially vertical but was subjected to strong refraction effects as it moved upstream. This resulted in the impingement of the wave on the lower wall of the duct and its consequent reflection back towards the upper wa 17 . The center diagram of figure 9 shows the behavior of the wave when the mean Mach number in the throat was 0.55 . Even at this flow condition, refraction effects remained strong, with the wave being directed sharply towards the lower wall. The lower diagram of figure 9, however, showed that when the mean Mach number in the throat was 0.40 , the effects of refraction were only slight and the wave did not intercept the wal1. Also, it was not visible in the shadow region of the duct upstream of the throat.

Figure 10 shows the variation of Mach number along both the upper and lower walls at the three test conditions, together with the variation of Mach number across the throat. These variations were calculated using the potential flow analysis (ref. 4), and were confirmed at those positions where static pressure taps were located in the upper and lower walls. It is seen that at no flow condition did the flow locally reach sonic velocity, which was also the case for the remainder of the configurations. 


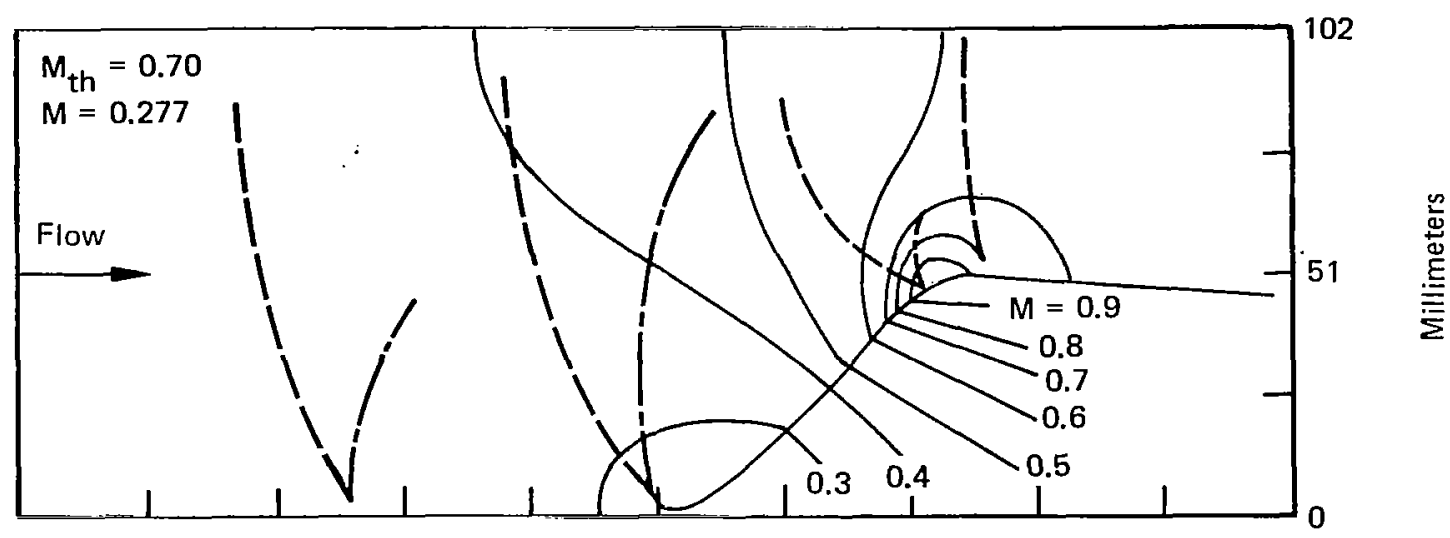

- - - Principal waves

Reflected waves

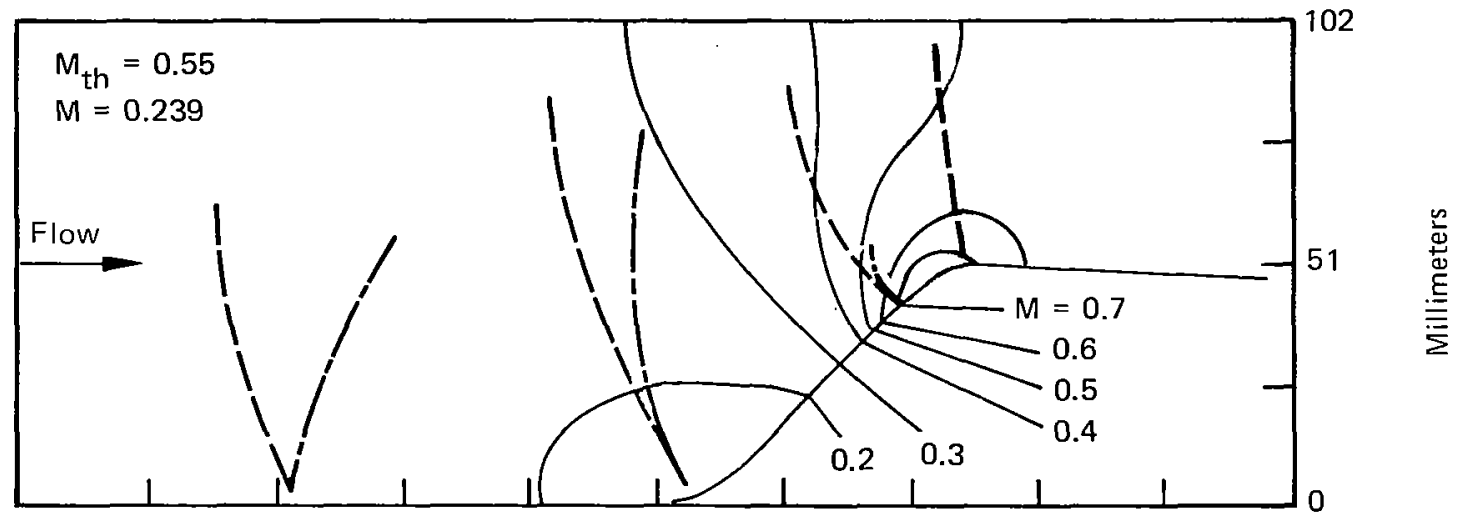

- Principal waves
- Reflected waves

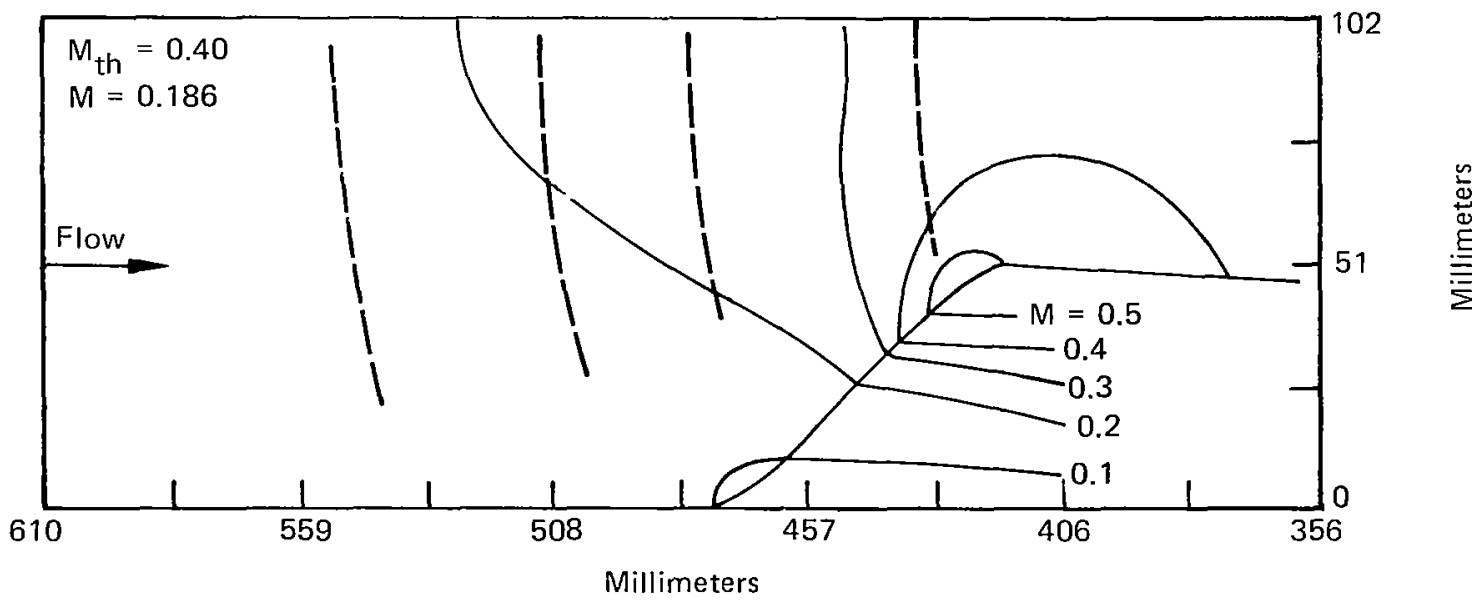

Figure 9. Observed Shock Location and Calculated Mach No.

Contours for Configuration N1-06 


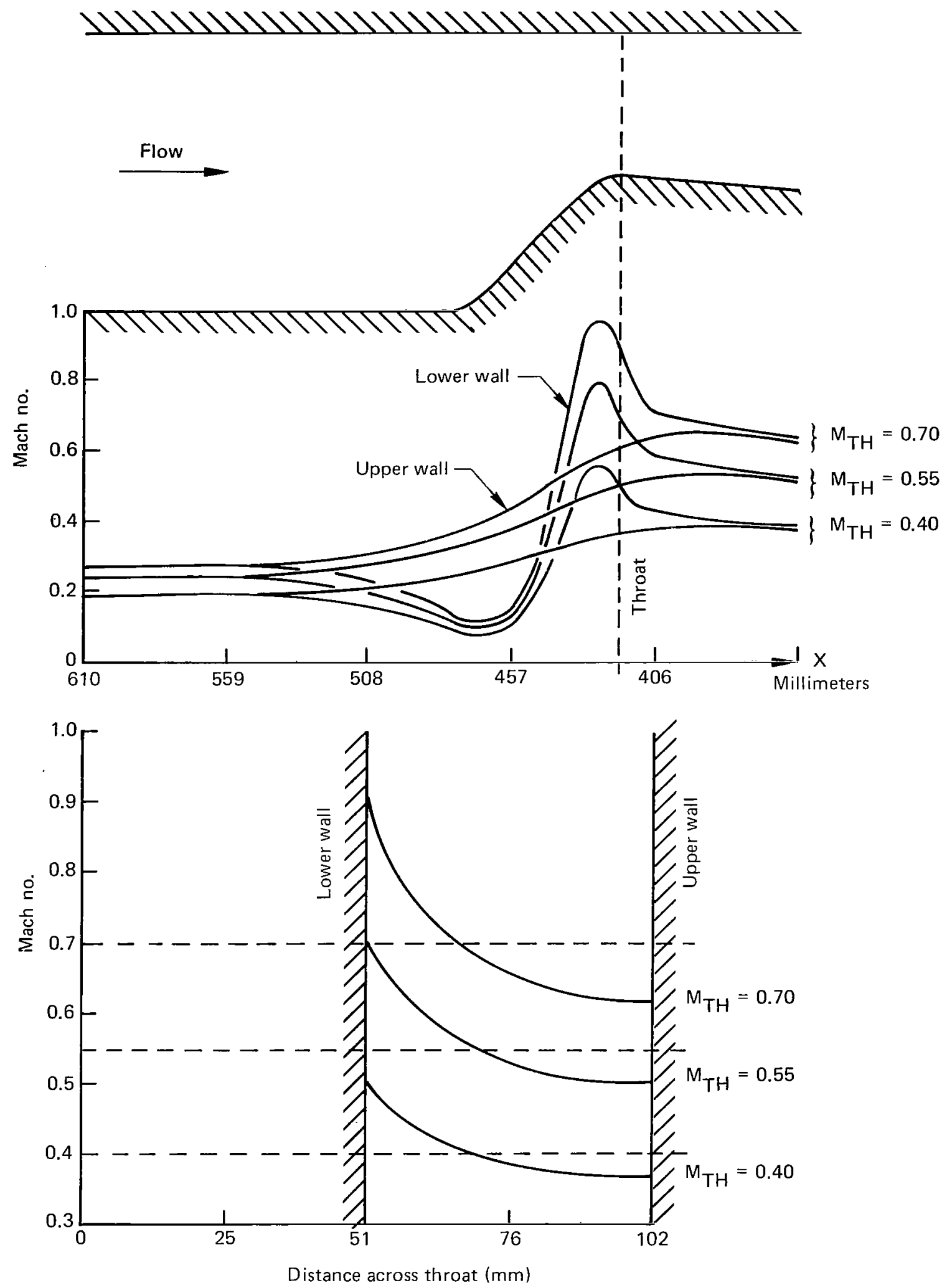

Figure 10. Mach No. Variation Along Upper and Lower Walls and Across the Throat of Configuration N1-06 
Results similar to those shown in figures 9 and 10 were obtained for each of the configurations N1-07 through N1-07. When the mean Mach number in the throat was 0.40 , no configuration caused anything greater than only slight refraction. For the remaining test conditions, the level of refraction varied depending on both the flow velocities and the contour, but all configurations showed either strong or medium refraction at the highest flow rate. Comparison of the results from the two geometrically similar configurations NT-04 and N1-07 confirmed that the behavior of the waves was not seriously affected by the boundary layer on the upper wall of configuration N7-04. This was also expected to be the case for the remainder of configurations N1-01 through N1-06. The results for configuration N1-07 did show, however, that the wave was always visible across the center region of the duct, whereas in configuration N1-04 the wave was not always visible close to the upper wall due to the presence of the boundary layer.

The results have been summarized in figure 11, which shows regions arbitrarily designated strong, medium, or weak refraction on a plot of contraction length ratio, $L_{R}$, versus contraction ratio, $D_{R}$. Whether or not any of these levels of refraction would be significant in an inlet design would depend on the specific application, and consequently it must not be assumed that the region labeled weak refraction could not provide useful changes in the direction of wave propagation.

For the first time, then, in figure 11, information is now available which relates the shape of the contraction profile to the level of wave refraction. This information is not quantitative, however, in describing the amount of refraction, and is restricted to profiles described by cubic curves. It had been hoped to use the sets of results similar to those shown in figures 9 and 10 to relate the angular change in the direction of wave propagation to a parameter describing the gradients present in the flow. Because of the complicated variation of flow properties in that region, however, it has not proved possible to obtain a parameter which concisely accounts for both the streamwise and transverse flow gradients. If such a parameter can be found, then the current test results could be applied to contours other than cubic curves. 


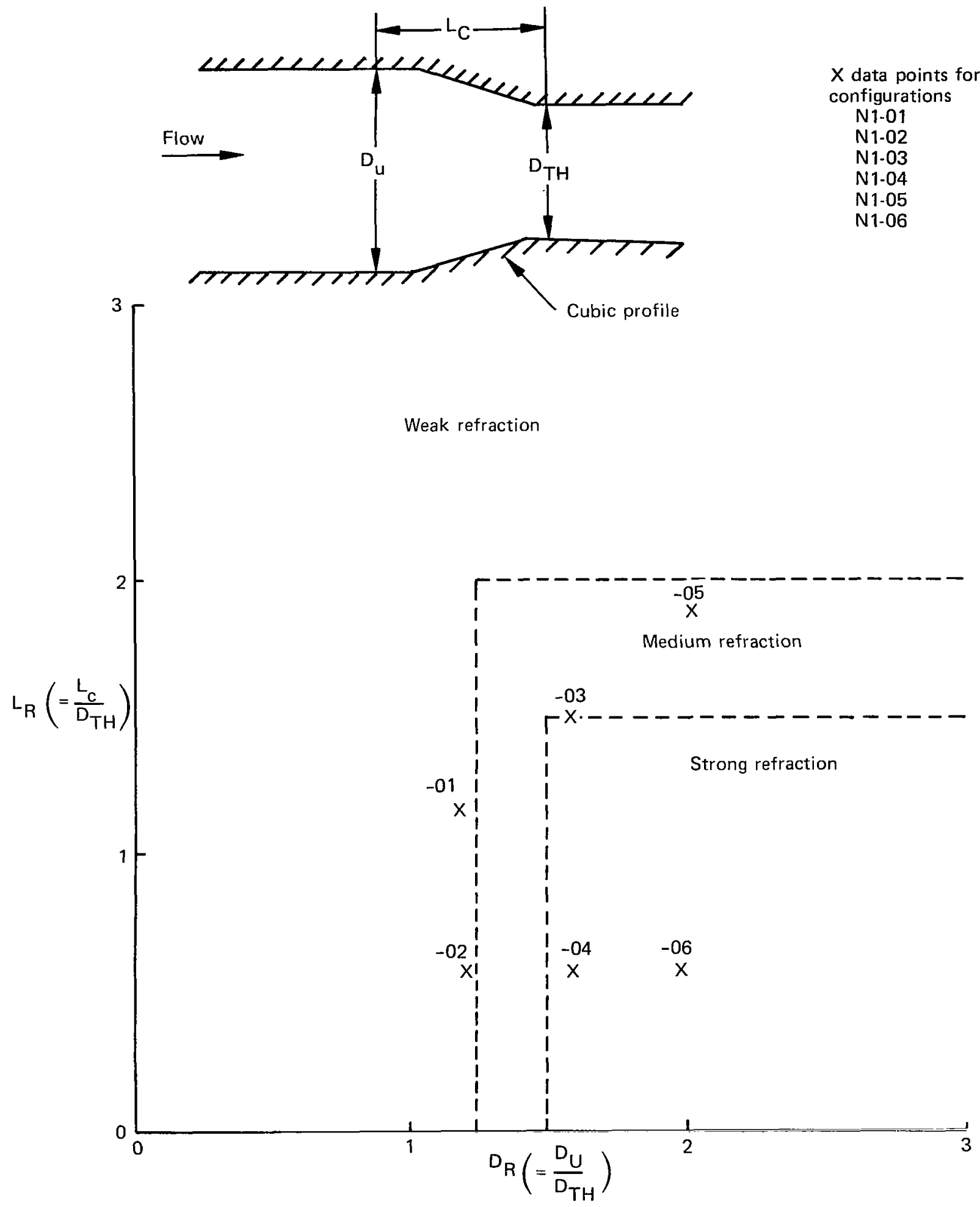

Figure 11. Measured Degree of Refraction with Varying Cubic Contraction Profiles. Phase / - Part 1 
The Hartmann whistle acoustic generator was used to examine the motions of trains of acoustic waves to complement the data obtained on refraction effects from observation of the motion of weak shock waves. The flush-mounted microphone shown in figure 3(a) located in the wall of the duct $50.8 \mathrm{~mm}$ from the source recorded a peak SPL of about $168 \mathrm{~dB}$ at $22 \mathrm{kHz}$, although both varied (insignificantly for the test objectives) depending on the mass flow rate and tuning of the whistle. The two photographs shown in figures $12(a)$ and 12(b) provide an example of the results for the configuration N1-04-A when the mean throat Mach number was 0.55 . Figure $12(a)$ clearly shows the nearly spherical wavefronts propagating away from the source with a wavelength of about $7.6 \mathrm{~mm}$ (the separation of the digits in the photographs are in inches). The wavelength of propagation in the axial direction can be seen to be a minimum and increases in directions more oblique to the flow due to the effects of the relative motion of the waves and the flow. The reflections of the waves from both the upper and lower walls of the duct are visible at approximately $\pm 45^{\circ}$ to the duct axis. Second order and higher reflections are also present, but their identification becomes increasingly difficult. The complex nature of the wave behavior was readily apparent even for this most simple of acoustic sources. Figure 12(b) shows the tendency of the principal waves to be refracted toward the lower surface of the duct as they traversed the throat region, a behavior that was also exhibited by the weak shock wave at these flow conditions. The increased wavelength as the waves passed upstream of the throat into a lower velocity region was also observed in figure $12(b)$. Comparison of this and the additional data obtained using the Hartmann whistle with the shock wave photographs confirmed the similarity in the behavior of the acoustic waves and the weak shock wave. 


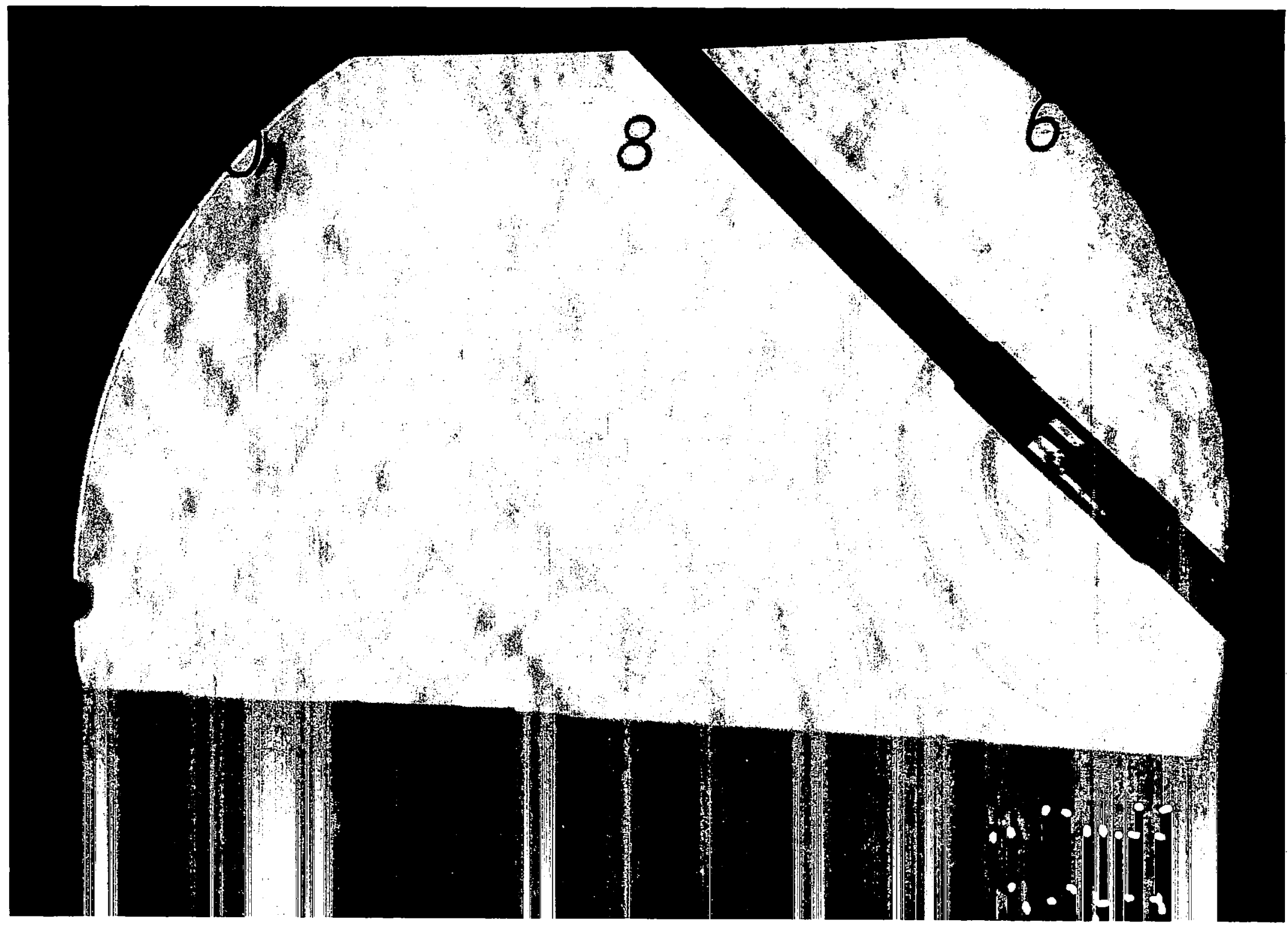

Figure 12(a). Schlieren Photograph of High Frequency Acoustic Waves in Configuration N1-04-A at $\bar{M}_{T H}=0.55$ 


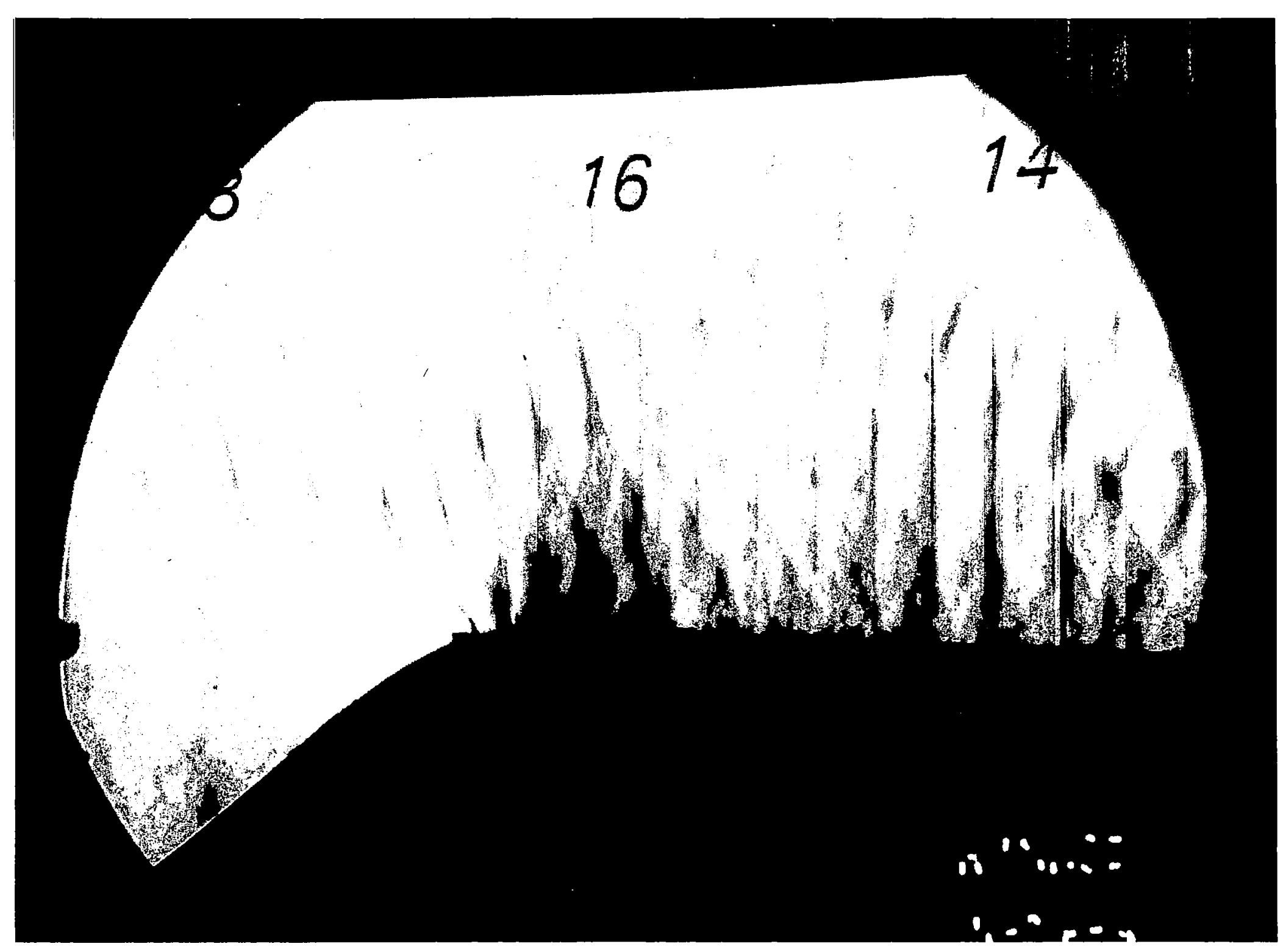


Part 2.--For each of the configurations N2-01 through N2-09, series of Schlieren photographs of the shock wave location at varying time intervals were used to plot diagrams similar to those shown in figure 13 for configuration N2-04. Moving from left to right and top to bottom, these diagrams show the path of the wave when the Mach number in the throat was $0,0.4$, $0.5,0.6,0.7$, and 0.8 , respectively. Because all these configurations were symmetrical about the duct centerline, only half the duct height is shown. In all cases, the flow was from left to right with the shock wave traveling from right to left. As can be seen top left in figure 13, with no flow the wave propagated in the direction of the duct centerline and remained essentially vertical throughout except at its extremity where some curvature was introduced due to diffraction. With increasing Mach number, the wave was refracted more and more away from the centerline until in the lower diagram, it was refracted sharply enough to be impingent on the wall within the viewing range. To provide a measure of the amount of refraction, the angular deviation from the centerline to a line connecting the lower extremity of the wave to the wall of the throat has been used. Thus, at the Mach number 0.7 (run N2-04.7) in figure 13, this angle was $35^{\circ}$. The angular deviation of the wave was also calculated for each of the configurations N2-01 through N2-05 and the results are shown in the table below.

\begin{tabular}{|c|c|c|c|}
\hline$D_{R}$ & 0.25 & 0.50 & 1.00 \\
\hline \multirow[t]{2}{*}{2.00} & \multirow[t]{2}{*}{$x$} & N2-05 & \multirow[t]{2}{*}{$x$} \\
\hline & & $\alpha=50^{\circ}$ & \\
\hline \multirow[t]{2}{*}{1.50} & $N 2-01$ & N2-02 & $\mathrm{N} 2-03$ \\
\hline & $\alpha=40^{\circ}$ & $\alpha=25^{\circ}$ & $\alpha=15^{\circ}$ \\
\hline \multirow[t]{2}{*}{1.25} & \multirow[t]{2}{*}{$x$} & $\mathrm{~N} 2-04$ & \multirow[t]{2}{*}{$x$} \\
\hline & & $\alpha=35^{\circ}$ & \\
\hline
\end{tabular}

$\alpha=$ angular deviation of the wave when ITH $=0.70$. 

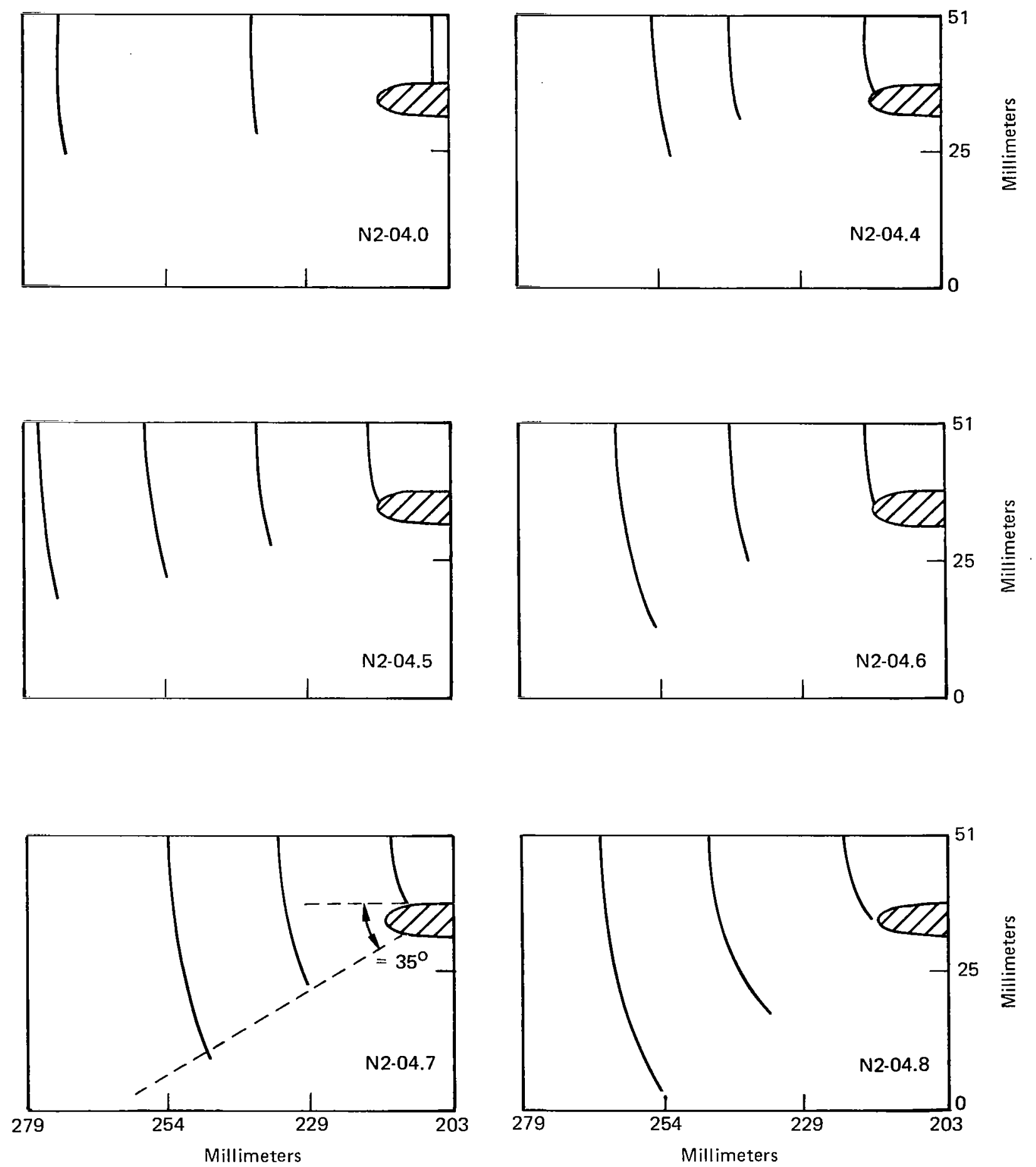

Figure 13. Observed Shock Location Thru Configuration N2-04 
This shows that for a given contraction ratio, the amount of refraction decreased as the length of the contraction section increased. This trend was to be expected because of the decreasing wall curvature in the throat region as the contraction length increased and the consequent reduction in gradients in the flow. For the given length ratio 0.50 , however, the table shows that refraction was greatest when the contraction ratio was either large or small, but reached a minimum somewhere in between. This was thought to be because the amount of refraction depended on both the transverse gradients and on the axial extent of these gradients. For the thin configuration N2-04, the transverse gradients were large but were present only over a short axial distance, whereas for the fat configuration, the transverse gradients were less but affected greater regions of the flow.

The centerbody configurations N2-06 and N2-07 showed how a centerbody could cause the waves to propagate principally in the direction of the duct centerline and in some cases to cross over the symmetrical axis of the configurations. This is shown in figure 14 for configuration N2-07. Conversely, configurations $\mathrm{N} 2-08$ and N2-09 contained centerbodies which did not prevent the waves from propagating away from the centerline. The results from the four configurations N2-06 through N2-09 provided an example of how a centerbody can influence the direction of propagation of waves leaving an inlet. This influence could be either beneficial or detrimental, depending on the design of the contour.

Part 3.--From the sets of Schlieren photographs for each of the configurations N3-01 through N3-05, the diagrams of figures 15(a) through 15(e) were obtained. Each diagram shows the location of the shock wave at varying time intervals as it passed from right to left through the throat between the dividers and into the approach flow. Figure 15(a) shows that for configuration N3-01, a change in the direction of propagation from the centerline towards the upper wall was noticeable for throat Mach numbers above 0.4. The change in propagation direction was less noticeable for configuration N3-02, as shown in figure 15(b). Refraction effects were again strong in configuration N3-03, as shown in figure $15(\mathrm{c})$, but were 

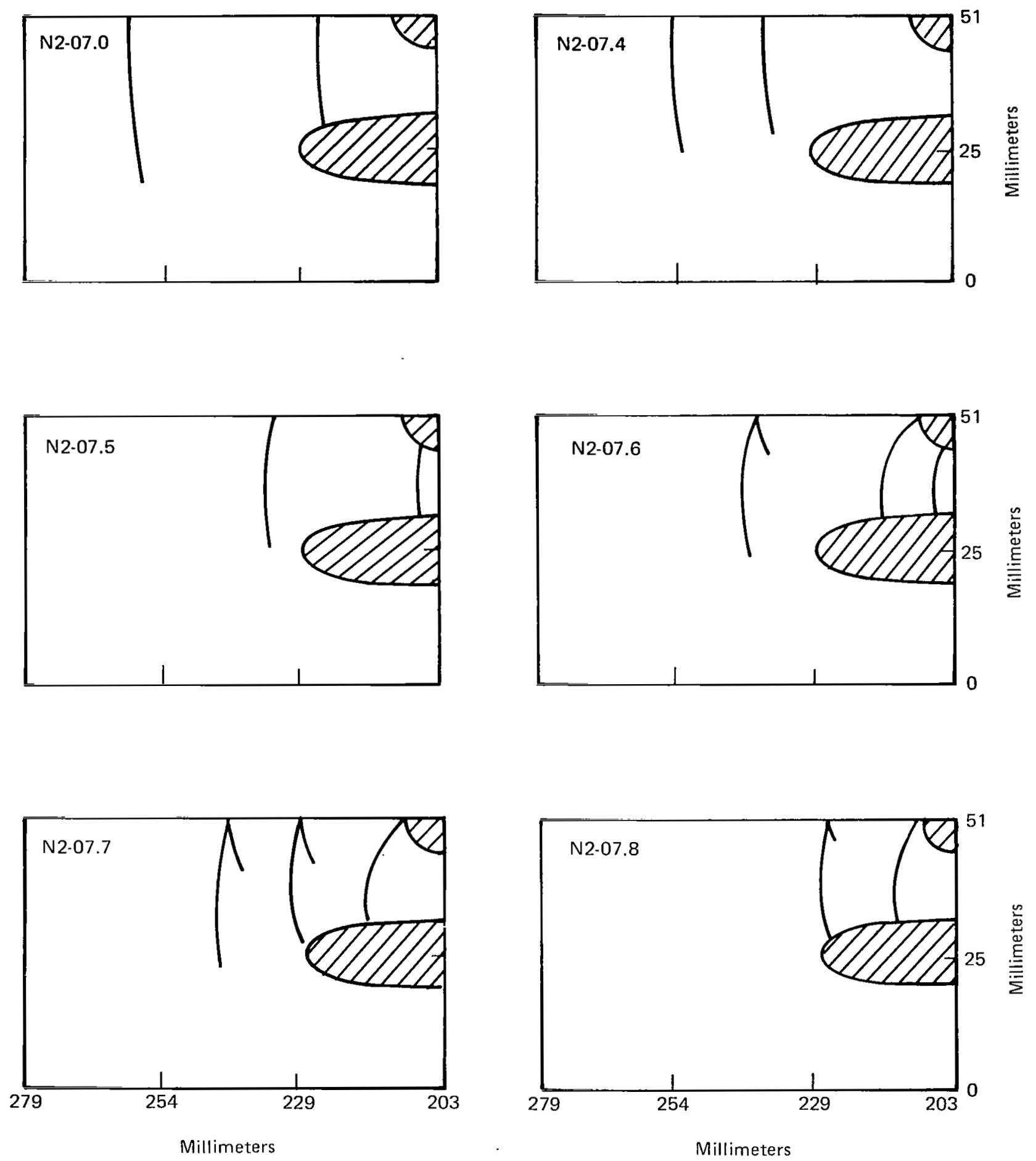

Figure 14. Observed Shock Location Thru Configuration N2-07 

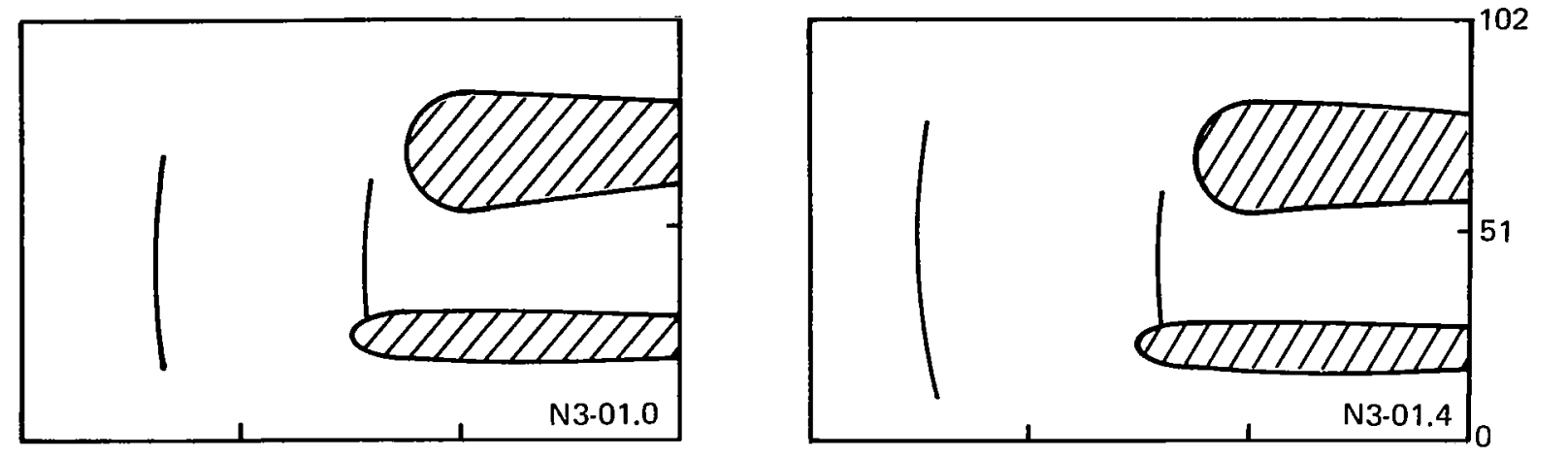

高
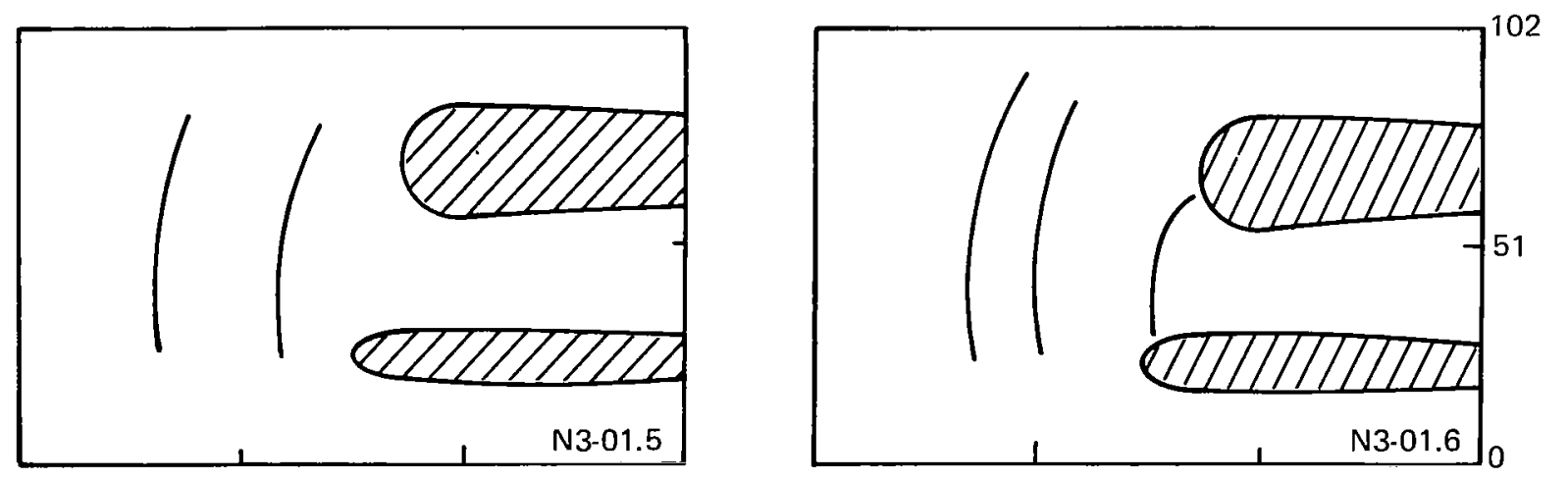

竞
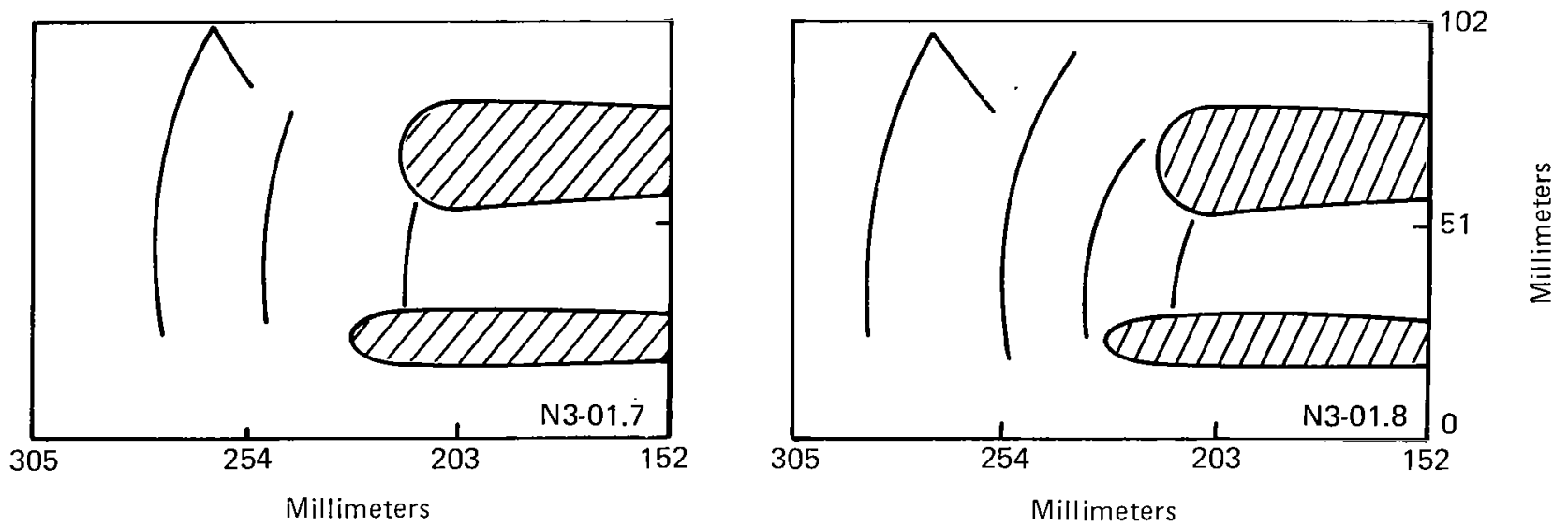

Figure 15(a). Observed Shock Location Thru Configuration N3-01 

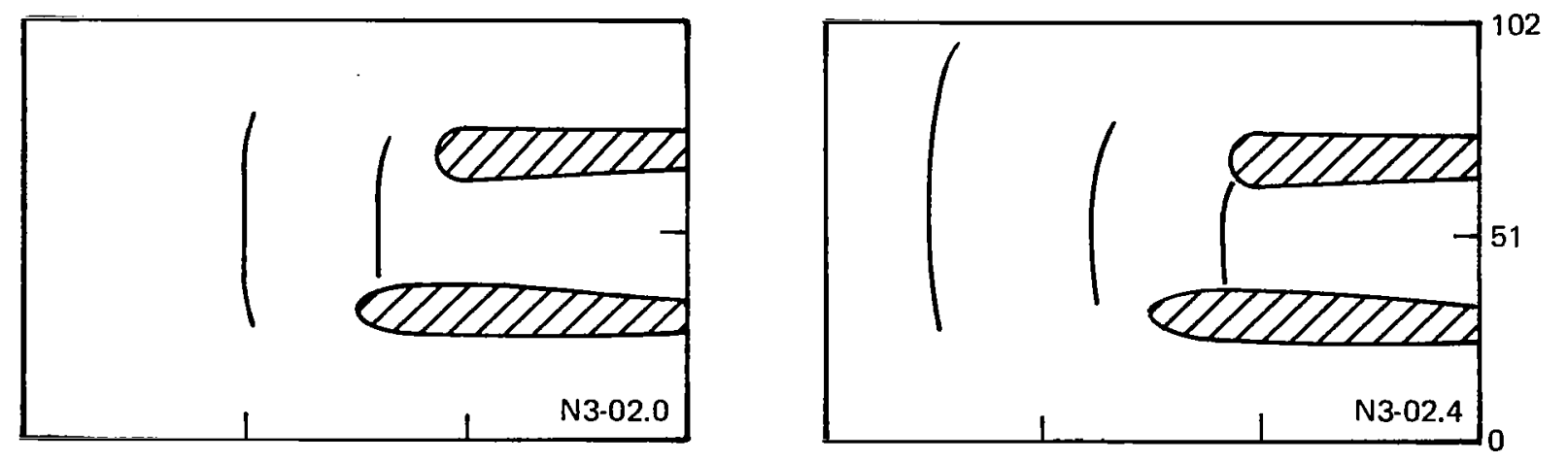

高
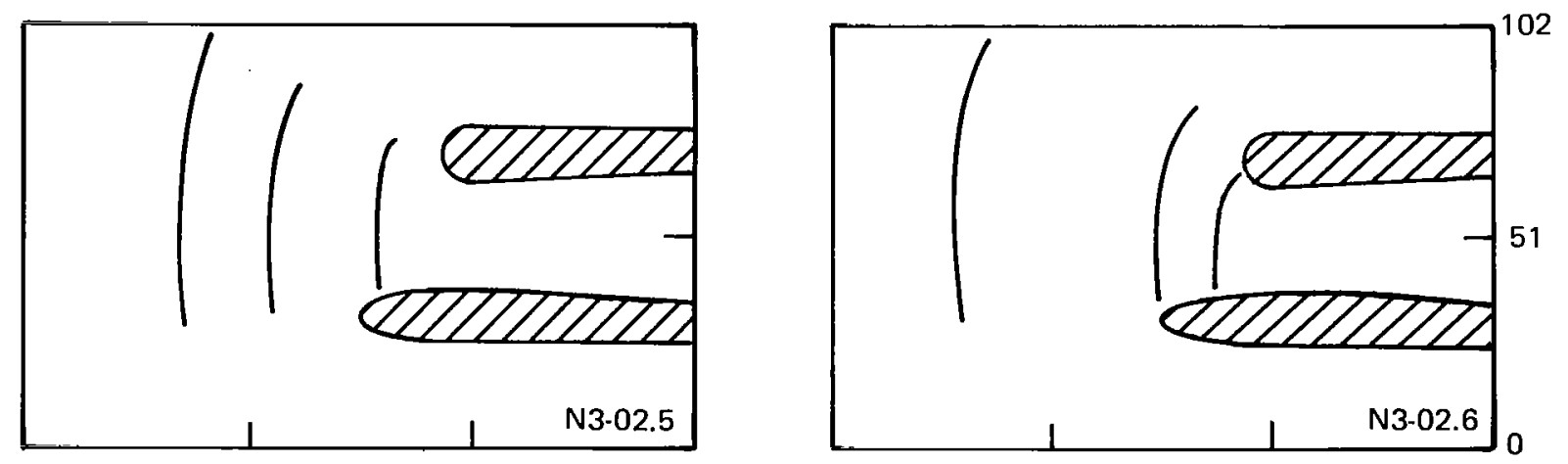

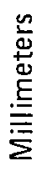
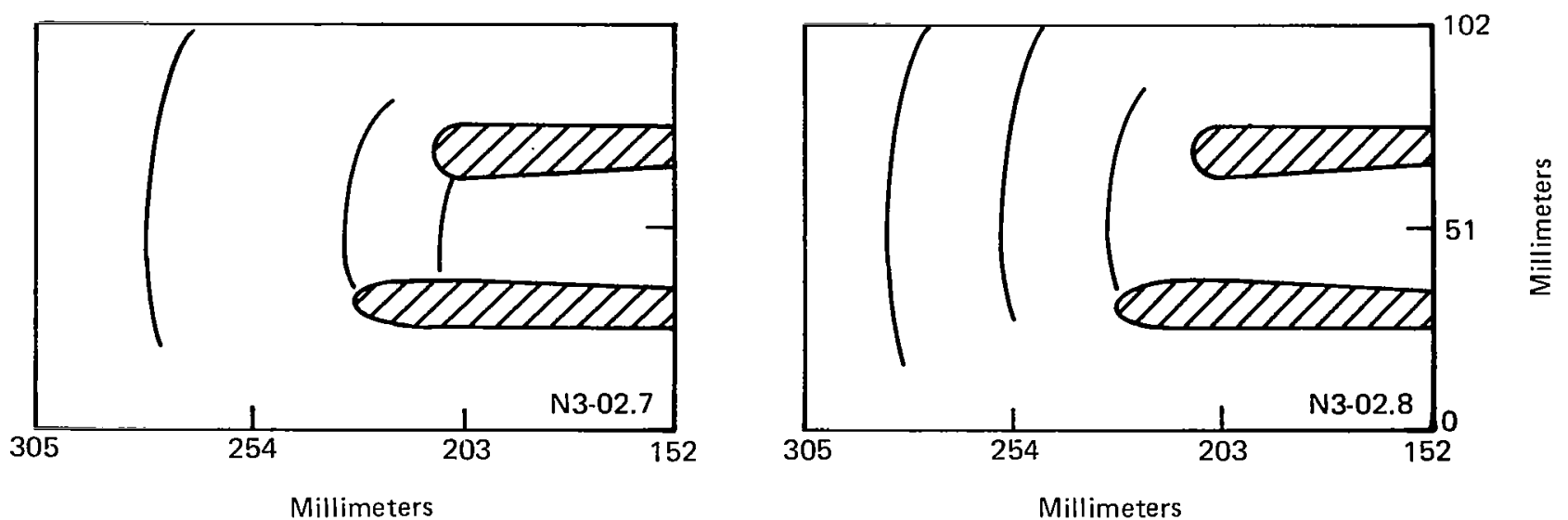

Figure 15(b). Observed Shock Location Thru Configuration N3-02 

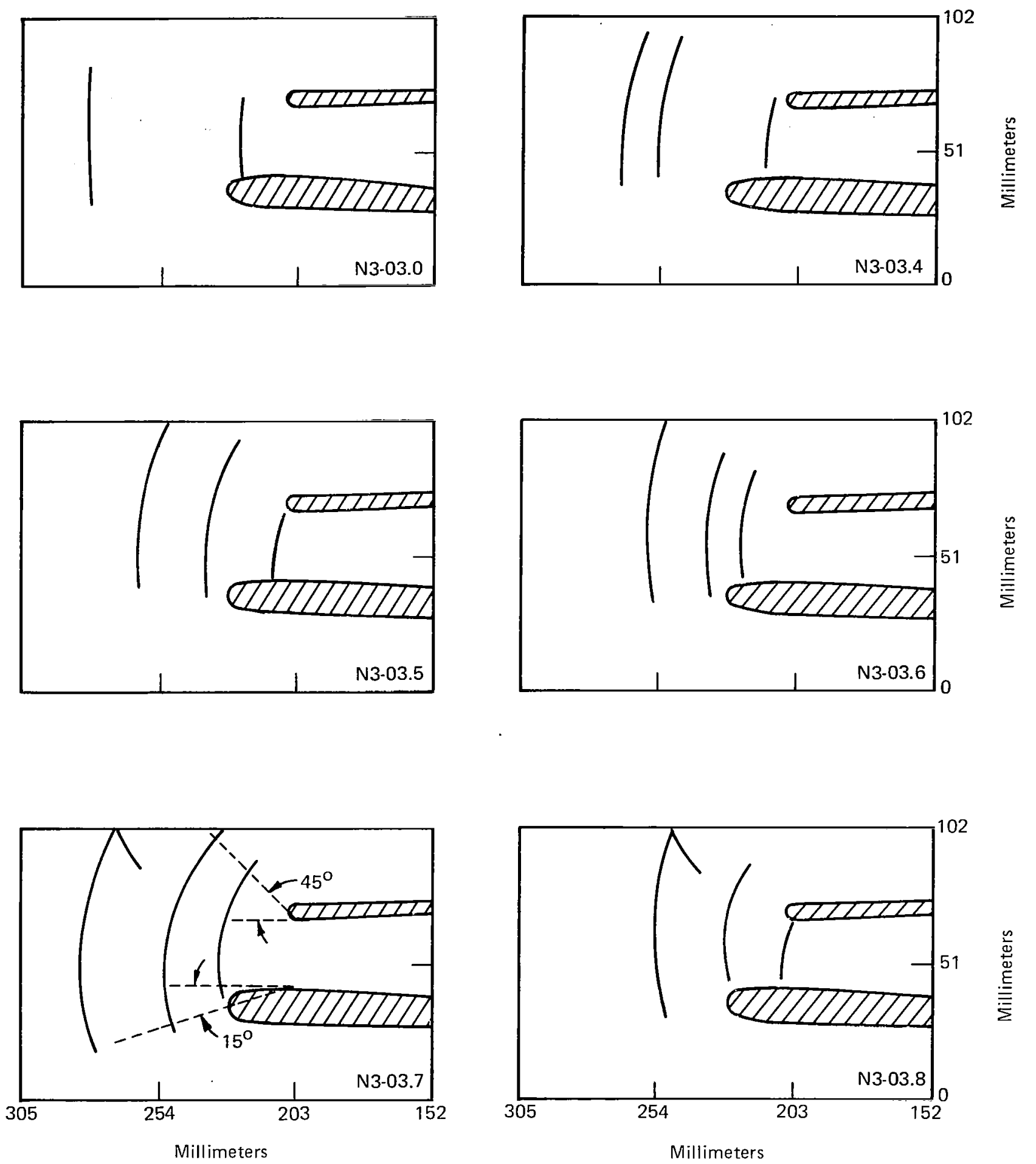

Figure 15/c). Observed Shock Location Thru Configuration N3-03. 

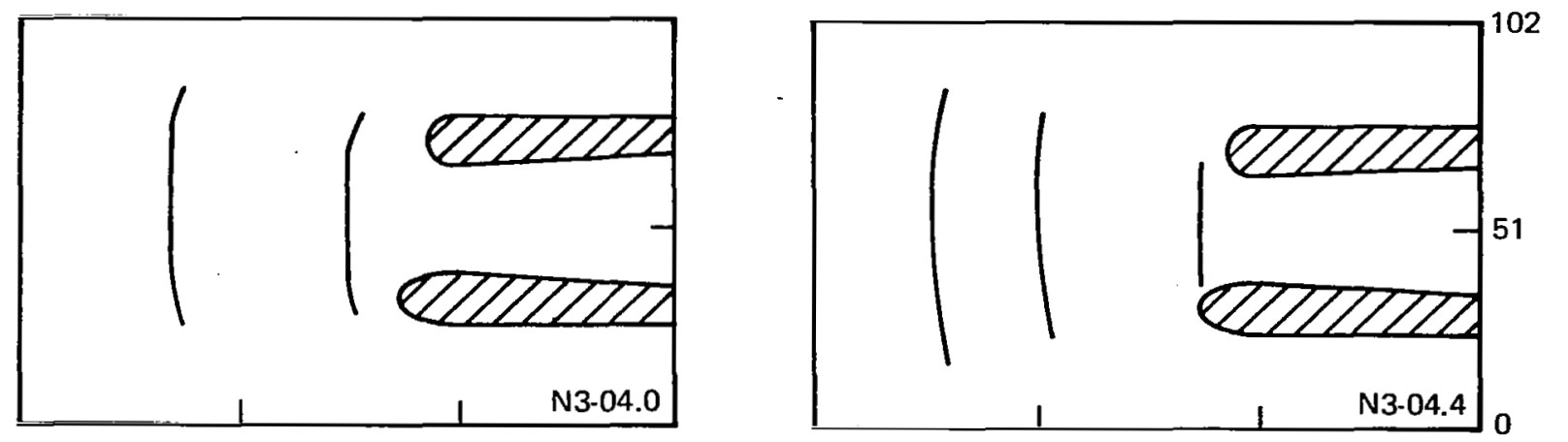

童
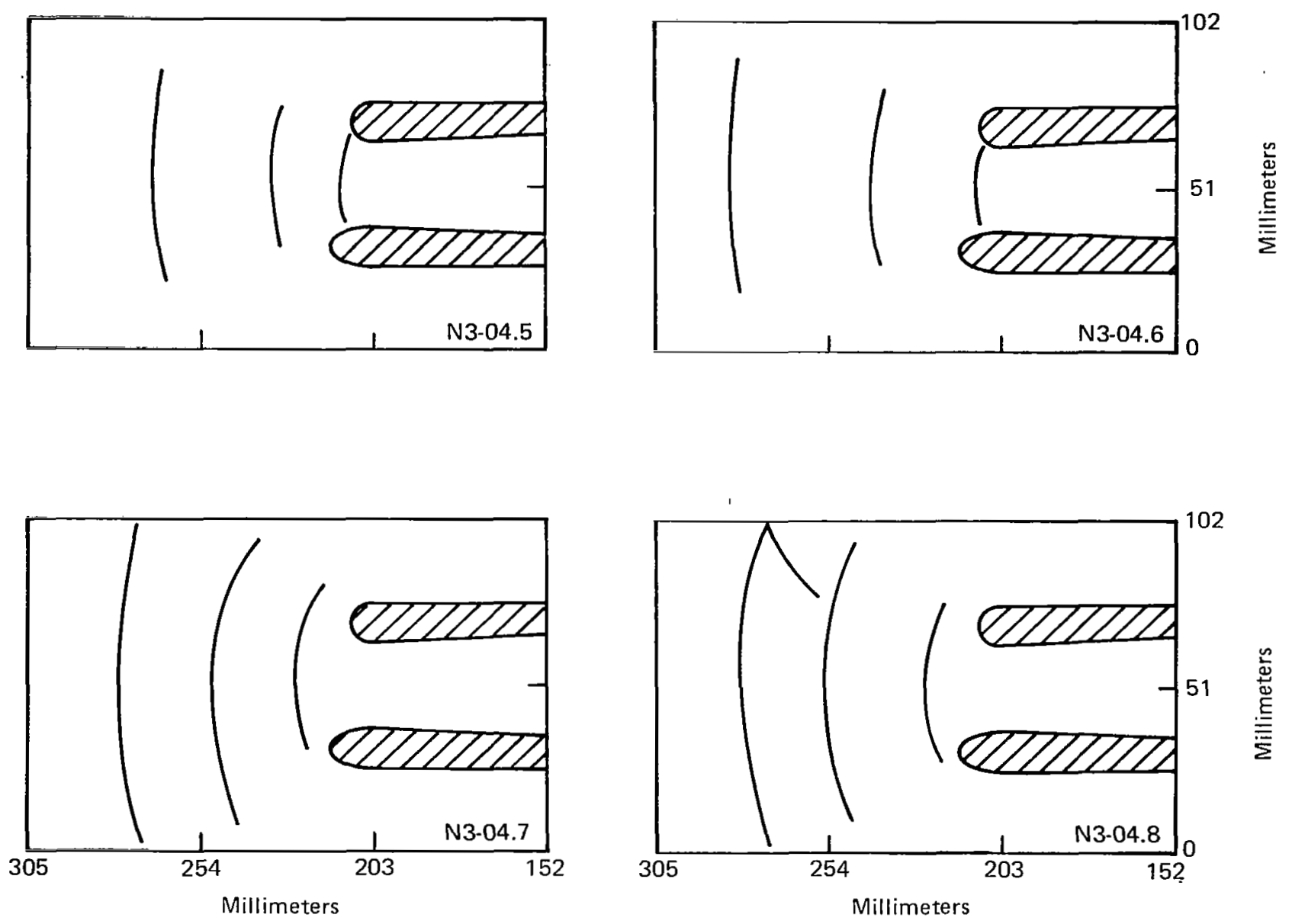

Figure 15(d). Observed Shock Location Thru Configuration N3-04 

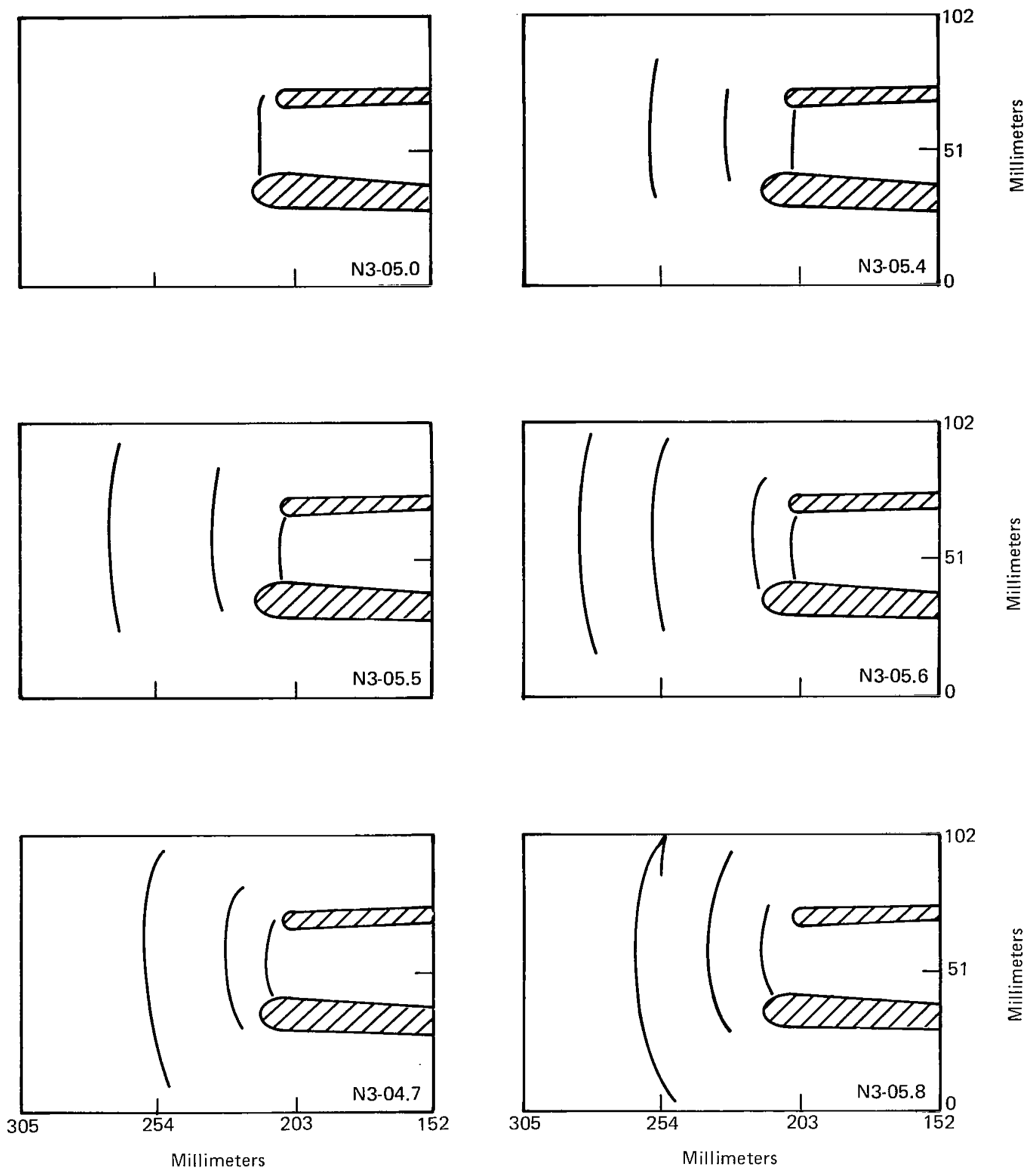

Figure 15(e). Observed Shock Location Thru Configuration N3-05 
on1y smal1 in configurations N3-04 and N3-05 shown in figures 15 (d) and 15(e), respectively. Examples of the Schlieren photographs used to construct these diagrams are shown in figure 16(a) for configuration N3-01 when the throat Mach number was 0.62 , and in figure $16(b)$ for configuration N3-03 when the throat Mach number was 0.68 .

To form a basis of comparison for the change in direction of wave propagation due to refraction effects, the angular deviation of the wavefront from the centerline was calculated as shown in figure 15(c) for Mach number 0.7 (lower left diagram). The angles between the centerline and a line drawn from the throat to the upper and lower extremities of the waves were measured. In this case, the angles were $+45^{\circ}$ and $-15^{\circ}$, respectively. The mean of these gave a direction of propagation of the wavefront of $15^{\circ}$ from the direction of the centerline of the duct. The values of the propagation direction for each of configurations N3-01 through N3-05 when the throat Mach number was 0.7 are shown below.

\begin{tabular}{|c|c|}
\hline Configuration & Direction of Wave Propagation \\
\hline N3-01 & $20^{\circ}$ \\
\hline N3-02 & $10^{\circ}$ \\
\hline N3-03 & $15^{\circ}$ \\
\hline N3-04 & $2^{\circ}$ \\
\hline N3-05 & $0^{\circ}$ \\
\hline
\end{tabular}

It is of interest to note that for the two configurations which cause the greatest change in the direction of propagation, one has a high contraction ratio, $D_{R}$, and the other a small contraction ratio. This suggests that large refraction effects can be caused by either a fat lip or a thin lip inlet, but that something in between causes less refraction. This observation supports the results described above for the Part 2 tests of Phase I. 


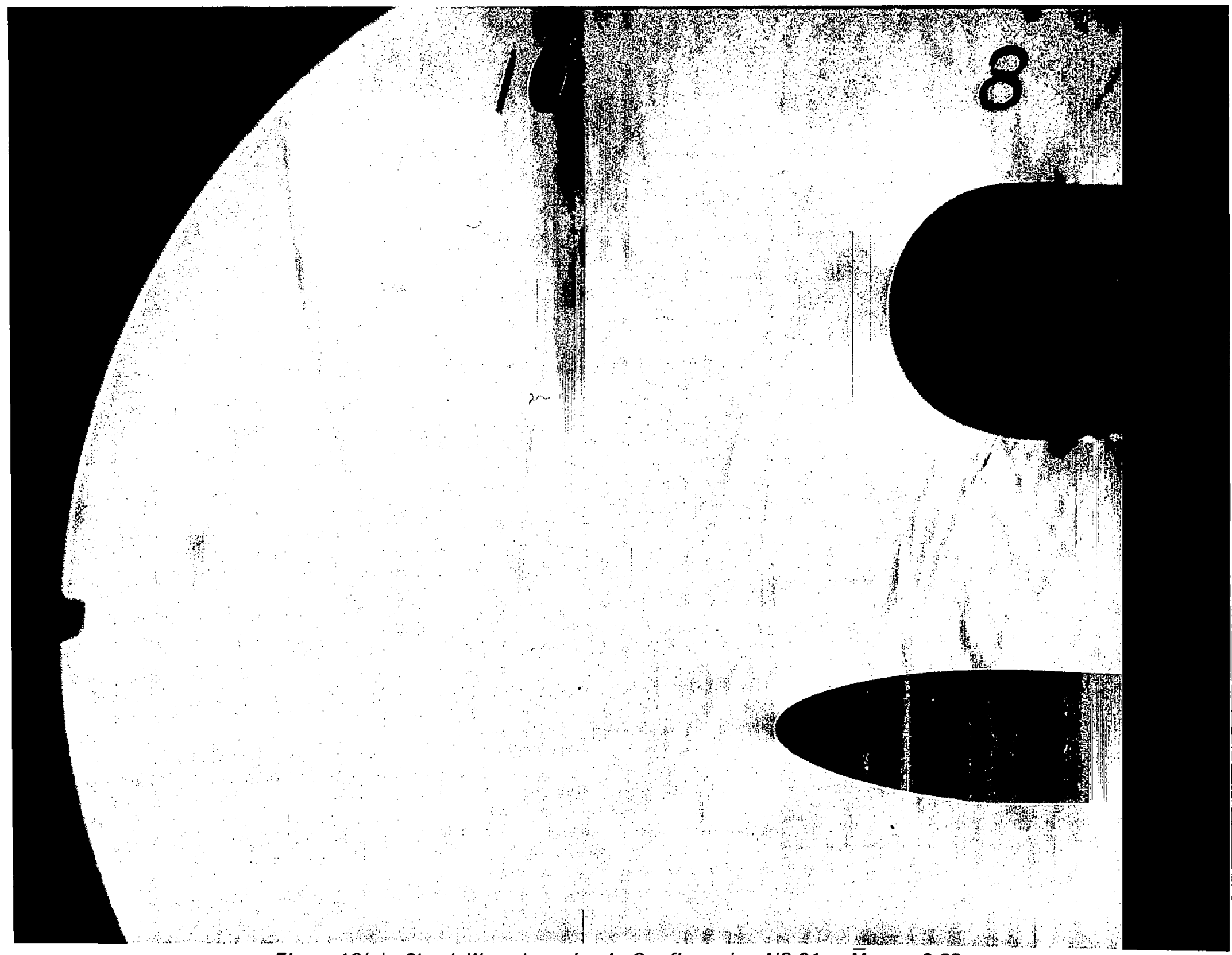

Figure 16(a). Shock Wave Location in Configuration N3-01 at $\bar{M}_{T H}=0.62$ 


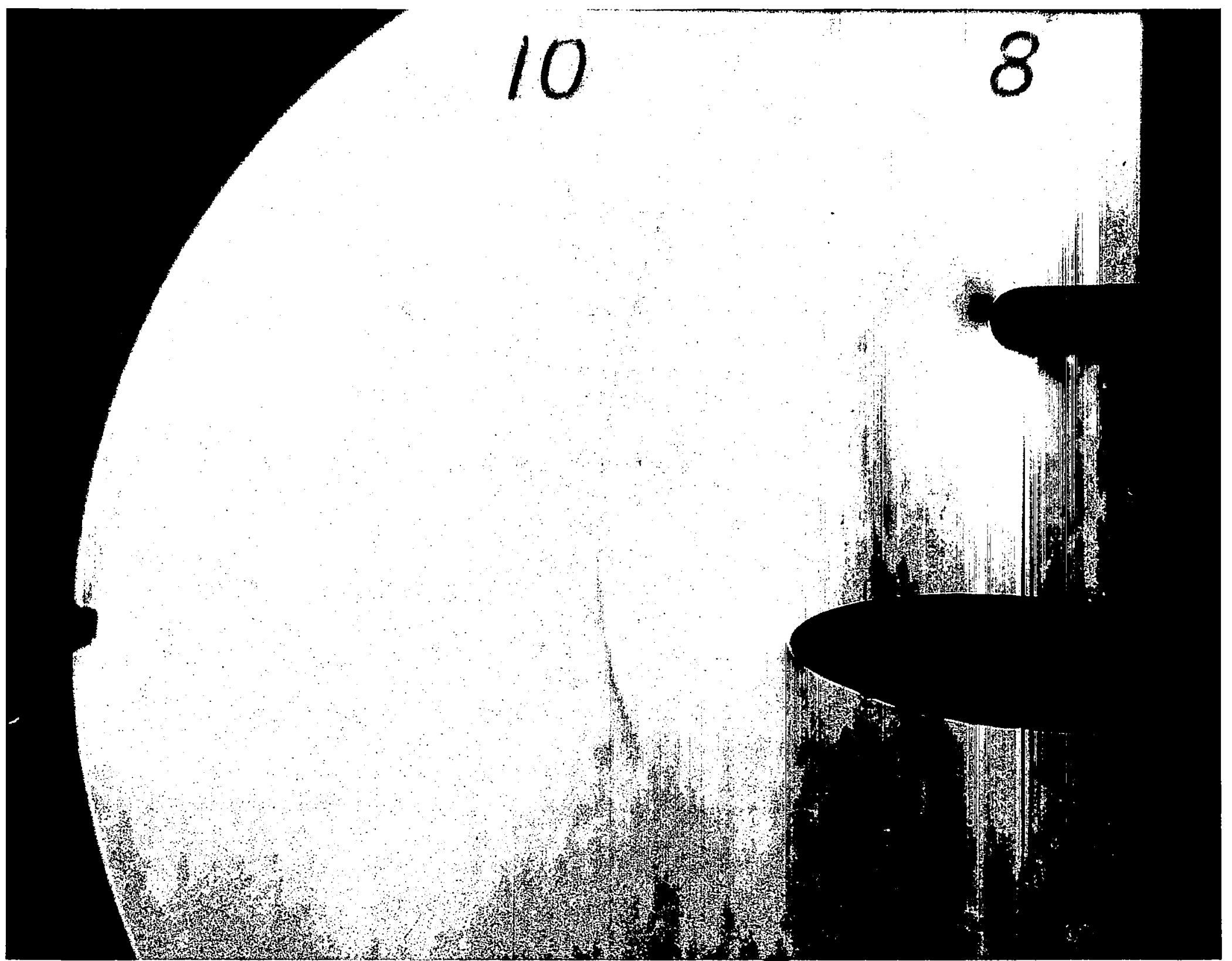


The results from configuration N3-06 are not presented here, but did show how a configuration containing a centerbody can also cause large changes in the direction of wave propagation.

Part 4.--Examination of the sets of Schtieren photographs obtained for configurations N4-01 through N4-06 showed that for each of the two contraction sections used, the preferred value of the approach length ratio, $A_{R}$, was unity. This qualitative judgment was based on the extent to which waves were reflected from the surface of the dividers upstream of the throat. Approach length ratios of zero were entirely insufficient, while a value of 2.2 would be unnecessarily long. 


\section{PHASE II: THE INFLUENCE OF REFRACTION \\ ON THE EFFECTIVENESS OF ACOUSTIC LININGS}

\section{General Description}

This phase of the contract was concerned with a possible method of improving the attenutation characteristics of acoustic linings by refracting the sound waves prior to their entry into the lined section. The effect has been experimentally examined in a duct of rectangular cross-section using the double reverberation chamber flow duct technique. The refraction has been obtained in this study by use of suitably shaped contours on the downstream side of the 1 ined section. Only the inlet mode was considered in this test program.

The insertion loss spectra for six linings were measured with a uniform duct and with three different contours at three different flow conditions. Figure 17 shows a typical test configuration.

The Test Facility

The test was performed on the Boeing-Wichita Acoustic Flow Duct facility. A schematic diagram of the facility is shown in figure 18 .

The two acoustic reverberation chambers act as plena for the air flow through the test section and provide a relatively uniform internal sound field. Each chamber is fabricated from double-walled 16-mm steel plate with a 100-mm sand inner liner.

The noise generators consist of impending air jets and nozzles which form a high-level broad-band sound source.

The procedure for measuring the insertion loss due to an acoustic panel is described below: 


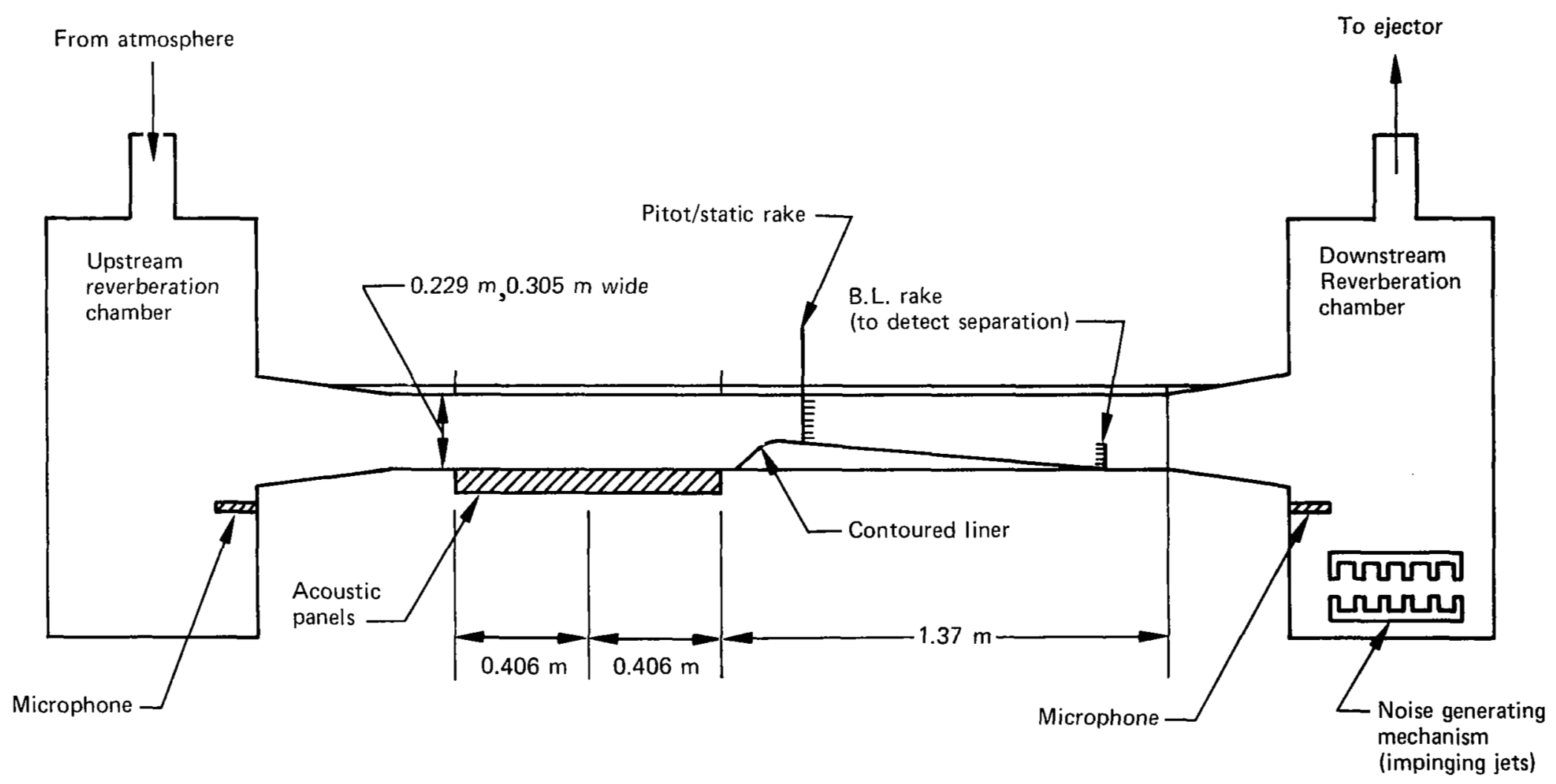

Figure 17. Schematic of the Test Facility for Phase // (The Boeing Wichita Flow Duct) 


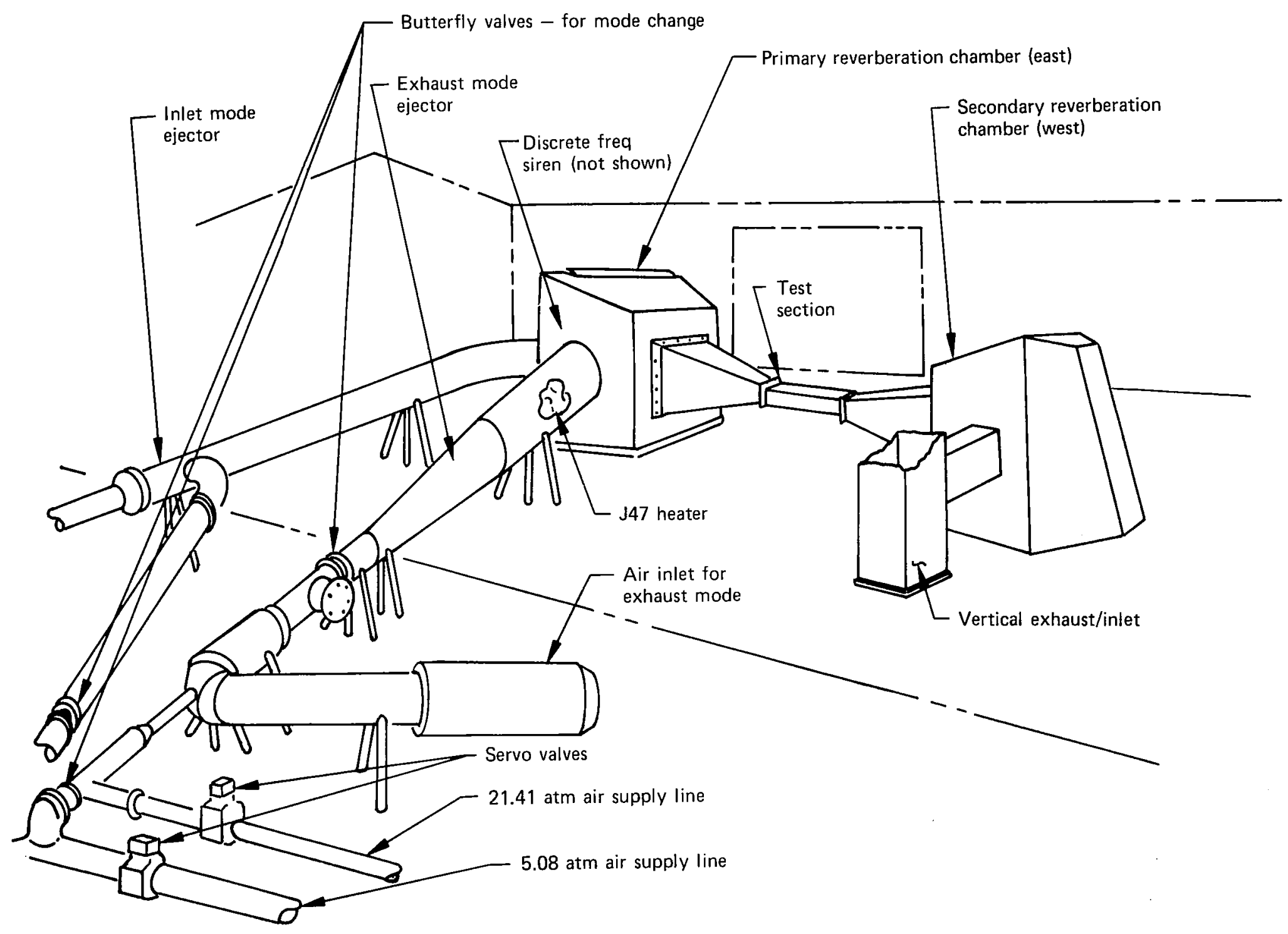


A baseline test is performed using hardwall blanking panels. The acoustic sound pressure levels are measured in both the primary and secondary reverberation chambers for the test series of flow conditions. The difference in levels between the two chambers is called the transmissibility. The blanks are replaced by acoustic lining panels and the levels in the chambers measured again for the same test flow conditions. The insertion loss is then the difference between the two transmissibilities. That is,

$$
\begin{aligned}
I L= & \left(S P L_{\text {secondary }}-S P L_{\text {primary }}\right)_{\text {hardwal1 }} \\
& -\left(S P L_{\text {secondary }}-S P L_{\text {primary }}\right)_{\text {softwa } 11}
\end{aligned}
$$

When measuring the lining insertion loss in the presence of a refracting contour, the hardwall baseline also includes the contour. In this way, the insertion loss obtained corresponds to the incremental effect of inserting the lining into a configuration which already has the contour. The insertion loss is then supplemental to any "sonic inlet" effects.

Figure 19 shows typical spectra for the primary and secondary reverberation chambers.

Estimates made at the time of initial calibration of the system indicated that insertion loss data should have a 90 percent confidence level of being in error by less than $\pm 1 \mathrm{~dB}$.

\section{Model Design}

Duct contours.--The contours selected for Phase II of this test program were based on the information obtained in Phase I, Part 1. These results are described in the Phase I section of this report and summarized in figure 11. This shows regions of relatively weak, medium, or strong refraction on a plot of length ratio of the contraction versus contraction ratio. For the Phase II test, one contraction section was selected to generate flow corresponding to each of these levels of refraction. Consequentiy, the contours of configurations $\mathrm{Cl}, \mathrm{C} 2$, and $\mathrm{C} 3$ of the Phase II 


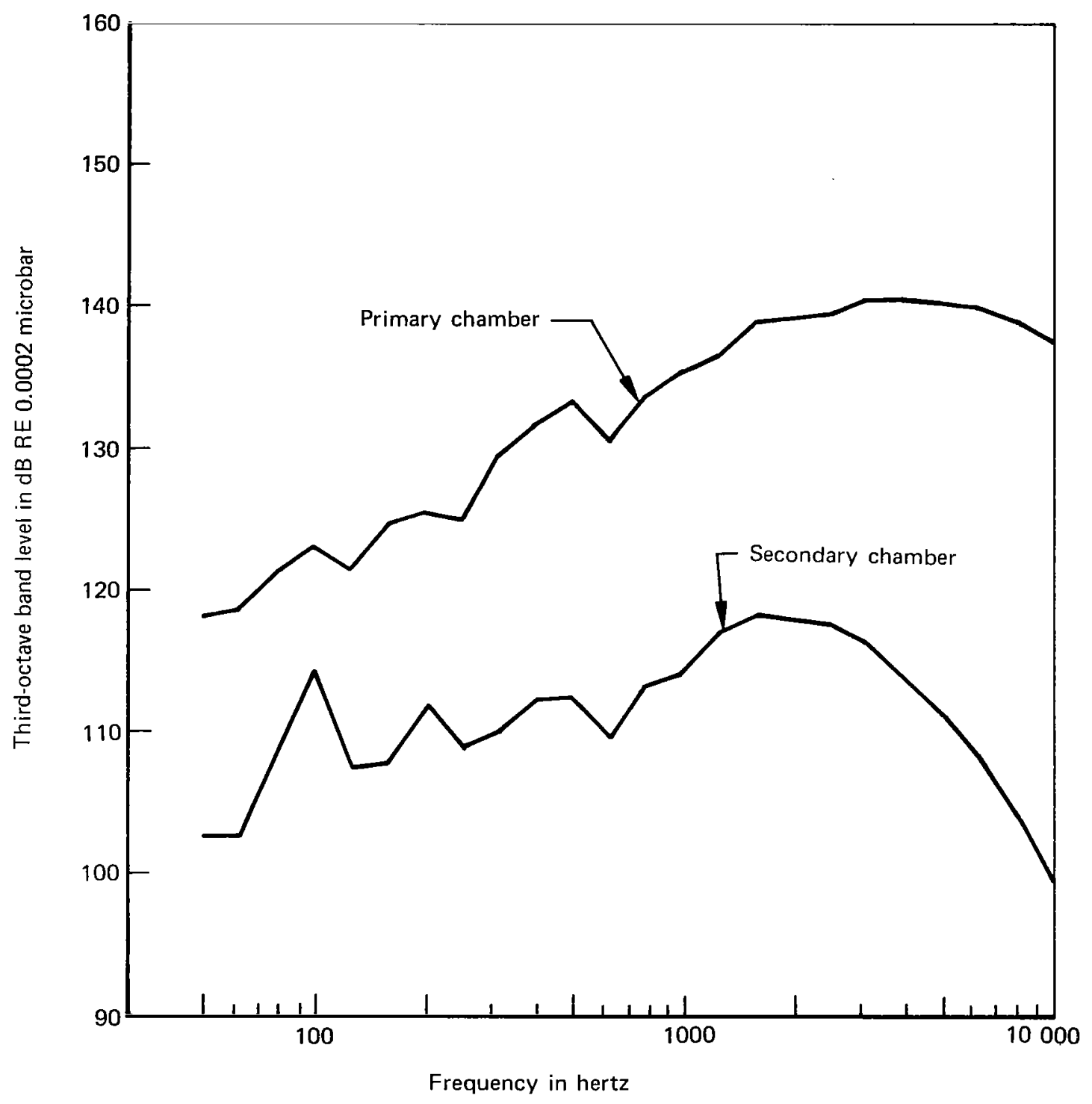

Figure 19. Typical SPL's in the Primary and Secondary. Reverberation Chambers. (Lining L1, Uniform Section, $M=0.351$ ) 
program were geometrically similar to the configurations $\mathrm{N1}-02, \mathrm{~N} 1-03$, and N7-04 from Phase I. These profiles were all cubic curves and are shown in figure 20 together with the static pressure tap locations used to establish the required flow conditions. Contour $\mathrm{Cl}$ was expected to cause relatively weak refraction, contour $\mathrm{C} 2$ medium refraction, and contour $\mathrm{C} 3$ strong refraction.

Acoustic lining materials.--The lining face sheet material selected was a metal felt. This material type was chosen because some of its properties are helpful in a test environment. Metal felts have a low nonlinearity factor and consequently the acoustic resistance is quite insensitive to variation in the sound pressure level. The small characteristic pore size has the effect of making the impedance almost independent of the grazing flow speed. Because of these desirable physical properties, the impedance of the liners practically depends only on the frequency. In this way, comparison between test conditions with different flow and SPL becomes possible.

Table 5 shows the flow resistance and depth for each of the test pane1s. A simple model was used to calculate the impedances of the liners, i.e.,

$$
z=1.1 R-i \cot (k d)
$$

where $Z$ is the impedance of the assembled liner, $R$ is the flow resistance at the appropriate particle velocity, $k$ is the wave number, and $d$ is the backing depth. SPL measurements were made at three axial locations along the 1 ined section during the tests. The operating particle velocities were calculated with these spectra using an iterative technique. As a consequence of the low nonlinearity of the face sheets, the range of SPL's encountered during the test introduced only a small variation in resistance (on the order of one percent). Tables $6,7,8$, and 9 show the predicted impedance properties for linings $L 1, L 2, L 5$, and $L 6 . A 11$ impedances have been normalized to duct conditions. 


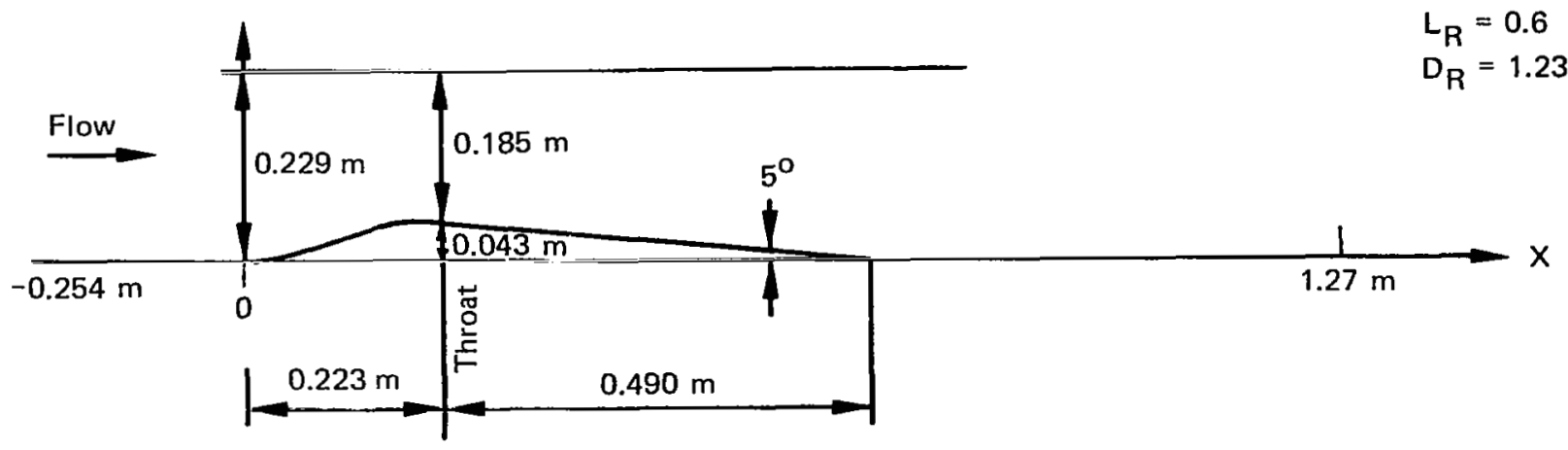

Contour $\mathrm{C} 1$, lower surface static pressure taps (12) at:

$X=-0.254,-0.127,0,0.064,0.127,0.191,0.224,0.254,0.381,0.635,1.02,1.37 \mathrm{~m}$

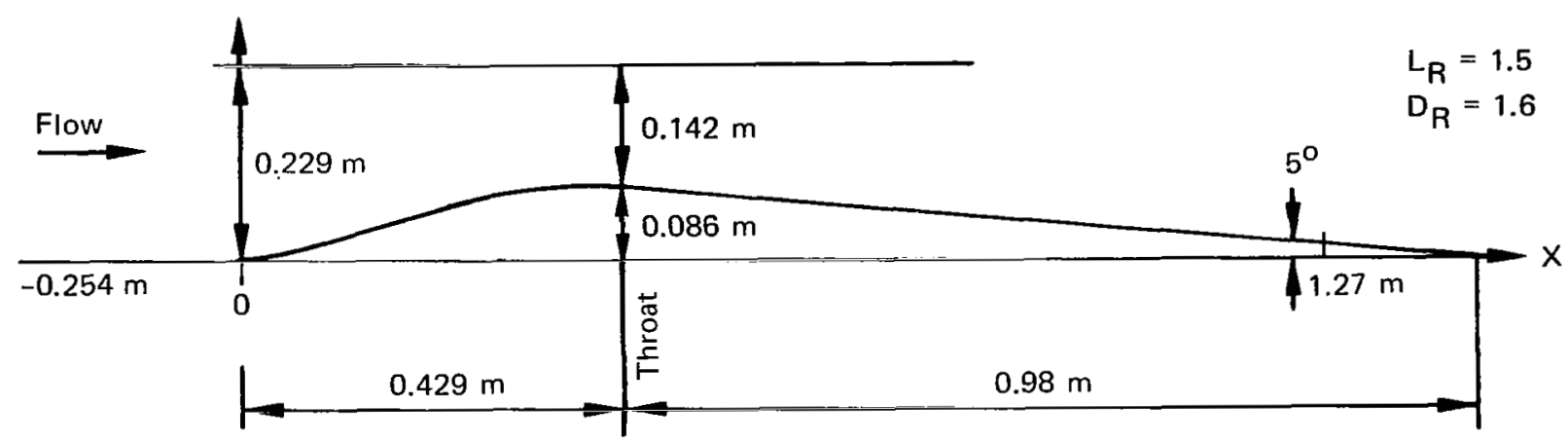

Contour $\mathrm{C2}$, lower surface static pressure taps (12) at:

$X=-0.254,-0.127,-0,0.127,0.254,0.381,0.429,0.508,0.635,1.02,1.27,1.37 \mathrm{~m}$

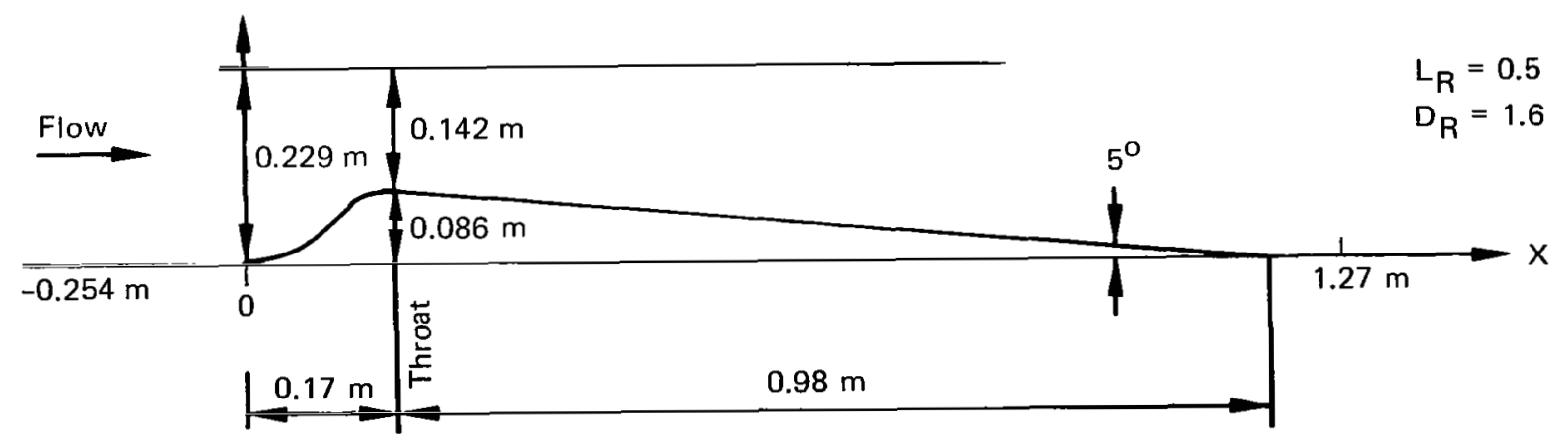

Contour C3, lower surface static pressure taps (12) at:

$X=-0.254,-0.127,0,051,0.102,0.152,0.170,0.203,0.254,0.635,1.02,1.37 \mathrm{~m}$

Faired in linear diffuser section at throat to form smooth contour (C1, C2, \& C3)

Upper surface static pressure taps (10) at:

$X=-0.254,-0.127,0,0.064,0.170,0.224,0.429,0.635,1.02,1.37 \mathrm{~m} \pm 0.001 \mathrm{~m}$

(for all contours $\mathrm{C} 1, \mathrm{C} 2 \& \mathrm{C} 3$ )

Figure 20. Configuration Contours \& Pressure Tap Locations for Phase II of NASA Contract No. NAS 1-14187 
TABLE 5

DEFINITION OF THE ACOUSTIC LININGS

\begin{tabular}{|c|c|c|c|}
\hline \multirow[b]{2}{*}{$\begin{array}{l}\text { Panel } \\
\text { I.D. }\end{array}$} & \multicolumn{2}{|c|}{ Standard Day Flow Resistance } & \multirow[b]{2}{*}{$\begin{array}{l}\text { Core } \\
\text { Depth } \\
\mathrm{cm}\end{array}$} \\
\hline & $\begin{array}{l}\text { Intercept } \\
\text { cgs Rayls }\end{array}$ & $\begin{array}{l}\text { Slope } \\
\mathrm{cgs} \text { Rayls } \\
\mathrm{cm} / \mathrm{sec}\end{array}$ & \\
\hline $\begin{array}{l}\text { LIN } \\
\text { LIF }\end{array}$ & $\begin{array}{l}75.1 \\
66.2\end{array}$ & $\begin{array}{l}0.54 \\
0.50\end{array}$ & $\begin{array}{l}0.635 \\
0.635\end{array}$ \\
\hline $\begin{array}{l}\mathrm{L} 2 \mathrm{~N} \\
\mathrm{~L} 2 \mathrm{~F}\end{array}$ & $\begin{array}{l}88.0 \\
87.2\end{array}$ & $\begin{array}{l}0.21 \\
0.22\end{array}$ & $\begin{array}{l}1.27 \\
1.27\end{array}$ \\
\hline $\begin{array}{l}\text { L3N } \\
\text { L3F }\end{array}$ & $\begin{array}{l}86.1 \\
89.0\end{array}$ & $\begin{array}{l}0.21 \\
0.21\end{array}$ & $\begin{array}{l}1.27 \\
1.27\end{array}$ \\
\hline $\begin{array}{l}\angle 4 N \\
\angle 4 F\end{array}$ & $\begin{array}{l}91.3 \\
90.4\end{array}$ & $\begin{array}{l}0.22 \\
0.21\end{array}$ & $\begin{array}{l}1.27 \\
1.27\end{array}$ \\
\hline $\begin{array}{l}\text { L5N } \\
\text { L5F }\end{array}$ & $\begin{array}{r}95.7 \\
111.9\end{array}$ & $\begin{array}{l}0.22 \\
0.23\end{array}$ & $\begin{array}{l}2.54 \\
2.54\end{array}$ \\
\hline $\begin{array}{l}\text { L6N } \\
\text { L6F }\end{array}$ & $\begin{array}{l}44.0 \\
42.4\end{array}$ & $\begin{array}{l}0.12 \\
0.12\end{array}$ & $\begin{array}{l}1.27 \\
1.27\end{array}$ \\
\hline
\end{tabular}


TABLE 6

IMPEDANCE CHARACTERISTICS OF LINING L1 $(\mathrm{Mp}=0.0007)$

\begin{tabular}{|c|c|c|c|c|c|}
\hline \multirow{2}{*}{ Frequency } & \multicolumn{2}{|c|}{ Impedance } & \multicolumn{3}{c|}{ Absorption Coefficient } \\
\hline $\mathrm{Hz}$ & $\mathrm{R} / \rho \mathrm{C}$ & $\mathrm{X} / \rho \mathrm{C}$ & Normal & $30^{\circ}$ & $45^{\circ}$ \\
\hline 630 & 2.12 & -15.1 & 0.035 & 0.041 & 0.050 \\
\hline 800 & 2.12 & -11.9 & 0.056 & 0.064 & 0.078 \\
\hline 1000 & 2.12 & -9.5 & 0.085 & 0.098 & 0.117 \\
\hline 1250 & 2.12 & -7.5 & 0.128 & 0.146 & 0.174 \\
\hline 1600 & 2.12 & -5.8 & 0.196 & 0.222 & 0.261 \\
\hline 2000 & 2.12 & -4.5 & 0.280 & 0.313 & 0.363 \\
\hline 2500 & 2.12 & -3.5 & 0.385 & 0.426 & 0.484 \\
\hline 3150 & 2.12 & -2.6 & 0.510 & 0.556 & 0.619 \\
\hline 4000 & 2.12 & -1.86 & 0.643 & 0.691 & 0.752 \\
\hline 5000 & 2.12 & -1.24 & 0.752 & 0.799 & 0.855 \\
\hline 6300 & 2.12 & -0.67 & 0.834 & 0.877 & 0.927 \\
\hline 8000 & 2.12 & -0.10 & 0.871 & 0.913 & 0.960 \\
\hline 10000 & 2.12 & 0.43 & 0.855 & 0.898 & 0.946 \\
\hline
\end{tabular}


TABLE 7

IMPEDANCE CHARACTERISTICS OF LINING L2 $(\mathrm{Mp}=0.0007)$

\begin{tabular}{|c|c|c|c|c|c|}
\hline Frequency & \multicolumn{2}{|c|}{ Impedance } & \multicolumn{3}{c|}{ Absorption Coefficient } \\
\hline $\mathrm{Hz}$ & $\mathrm{R} / \rho \mathrm{c}$ & $\mathrm{X} / \mathrm{\rho C}$ & Norma 1 & $30^{\circ}$ & $45^{\circ}$ \\
\hline 630 & 2.38 & -7.5 & 0.141 & 0.160 & 0.191 \\
\hline 800 & 2.38 & -5.8 & 0.209 & 0.236 & 0.278 \\
\hline 1000 & 2.38 & -4.6 & 0.292 & 0.327 & 0.379 \\
\hline 1250 & 2.38 & -3.6 & 0.392 & 0.433 & 0.494 \\
\hline 1600 & 2.38 & -2.7 & 0.512 & 0.559 & 0.624 \\
\hline 2000 & 2.38 & -2.0 & 0.618 & 0.667 & 0.732 \\
\hline 2500 & 2.38 & -1.41 & 0.709 & 0.759 & 0.821 \\
\hline 3150 & 2.38 & -0.88 & 0.780 & 0.828 & 0.887 \\
\hline 4000 & 2.38 & -0.38 & 0.823 & 0.870 & 0.926 \\
\hline 5000 & 2.38 & 0.09 & 0.833 & 0.879 & 0.935 \\
\hline 6300 & 2.38 & 0.60 & 0.808 & 0.855 & 0.912 \\
\hline 8000 & 2.38 & 1.25 & 0.733 & 0.782 & 0.843 \\
\hline 10000 & 2.38 & 2.22 & 0.582 & 0.630 & 0.696 \\
\hline
\end{tabular}


TABLE 8

IMPEDANCE CHARACTERISTICS OF LINING L5 $(\mathrm{Mp}=0.0006)$

\begin{tabular}{|c|c|c|c|c|c|}
\hline Frequency & \multicolumn{2}{|c|}{ Impedance } & \multicolumn{3}{|c|}{ Absorption Coefficient } \\
\hline $\mathrm{Hz}$ & $R / \rho c$ & $X / \rho c$ & Norma 1 & $30^{\circ}$ & $45^{\circ}$ \\
\hline 630 & 2.91 & -3.6 & 0.411 & 0.455 & 0.519 \\
\hline 800 & 2.91 & -2.75 & 0.509 & 0.558 & 0.627 \\
\hline 1000 & 2.91 & -2.09 & 0.592 & 0.644 & 0.714 \\
\hline 1250 & 2.91 & -1.53 & 0.660 & 0.713 & 0.782 \\
\hline 1600 & 2.91 & -0.99 & 0.715 & 0.767 & 0.836 \\
\hline 2000 & 2.91 & -0.56 & 0.746 & 0.798 & 0.866 \\
\hline 2500 & 2.91 & -0.14 & 0.760 & 0.812 & 0.879 \\
\hline 3150 & 2.91 & 0.31 & 0.756 & 0.808 & 0.875 \\
\hline 4000 & 2.91 & 0.89 & 0.724 & 0.776 & 0.845 \\
\hline 5000 & 2.91 & 1.78 & 0.632 & 0.684 & 0.754 \\
\hline 6300 & 2.91 & 6.8 & 0.190 & 0.215 & 0.254 \\
\hline 8000 & 2.91 & -0.5 & 0.747 & 0.799 & 0.866 \\
\hline 10000 & 2.91 & 1.3 & 0.685 & 0.737 & 0.807 \\
\hline
\end{tabular}


TABLE 9

IMPEDANCE CHARACTERISTICS OF LINING L6 $(M p=0.0012)$

\begin{tabular}{|c|c|c|c|c|c|}
\hline \multirow{2}{*}{ Frequency } & \multicolumn{2}{|c|}{ Impedance } & \multicolumn{3}{c|}{ Absorption Coefficient } \\
\hline $\mathrm{Hz}$ & $\mathrm{R} / \rho \mathrm{C}$ & $\mathrm{X} / \textrm{C}$ & Norma & $30^{\circ}$ & $45^{\circ}$ \\
\hline 630 & 1.23 & -7.5 & 0.080 & 0.097 & 0.109 \\
\hline 800 & 1.23 & -5.9 & 0.124 & 0.141 & 0.167 \\
\hline 1000 & 1.23 & -4.7 & 0.185 & 0.208 & 0.243 \\
\hline 1250 & 1.23 & -3.7 & 0.268 & 0.298 & 0.341 \\
\hline 1600 & 1.23 & -2.8 & 0.389 & 0.425 & 0.475 \\
\hline 2000 & 1.23 & -2.1 & 0.522 & 0.560 & 0.608 \\
\hline 2500 & 1.23 & -1.56 & 0.665 & 0.701 & 0.739 \\
\hline 3150 & 1.23 & -1.06 & 0.807 & 0.834 & 0.857 \\
\hline 4000 & 1.23 & -0.60 & 0.922 & 0.939 & 0.946 \\
\hline 5000 & 1.23 & -0.20 & 0.982 & 0.992 & 0.990 \\
\hline 6300 & 1.23 & 0.24 & 0.978 & 0.989 & 0.987 \\
\hline 8000 & 1.23 & 0.80 & 0.877 & 0.898 & 0.912 \\
\hline 10000 & 1.23 & 1.65 & 0.638 & 0.674 & 0.715 \\
\hline
\end{tabular}




\section{Test Conditions}

Each lining-contour combination was tested at three flow conditions. These corresponded closely to mean flow Mach numbers in the throat of 0.40 , 0.55 , and 0.70 .

The approach flow conditions at which data were taken are shown in the table below:

\begin{tabular}{|l|l|l|l|}
\hline $\begin{array}{l}\text { Contour } \\
\text { No. }\end{array}$ & \multicolumn{3}{|c|}{$\begin{array}{l}\text { Mach Number Condition } \\
\text { (Upstream of Contraction) }\end{array}$} \\
\hline 0 & 0.30 & 0.40 & 0.50 \\
1 & 0.30 & 0.40 & 0.50 \\
2 & 0.23 & 0.30 & 0.35 \\
3 & 0.23 & 0.30 & 0.35 \\
\hline
\end{tabular}

\section{Results}

Aerodynamic data.--The calculated variation of Mach number, using reference 4 , along both walls of the duct for each of the contours is shown in figures $21(\mathrm{a}), 21(\mathrm{~b})$, and $21(\mathrm{c})$, when the mean Mach number in the throat was $0.40,0.55,0.70$. Also shown are the measured values of Mach number at the static pressure tap locations determined using both the measured static pressure and the stagnation pressure of the flow. The measured flow conditions generally agreed well with the predicted values, although there was some discrepancy where the velocity gradients were high close to the throat region. This was due mainly to the influence of the boundary layer in moving the effective throat of the duct slightly downstream from the geometric throat.

Acoustic data.--The acoustic data are presented here as insertion loss spectra for each 1 ined test condition. Figures $22(\mathrm{a})$ through $22(\mathrm{f})$ show the measured spectra. The only obvious problem with the data was an apparent resonance in the $800 \mathrm{~Hz}$ band which switched on and off unpredictably. 


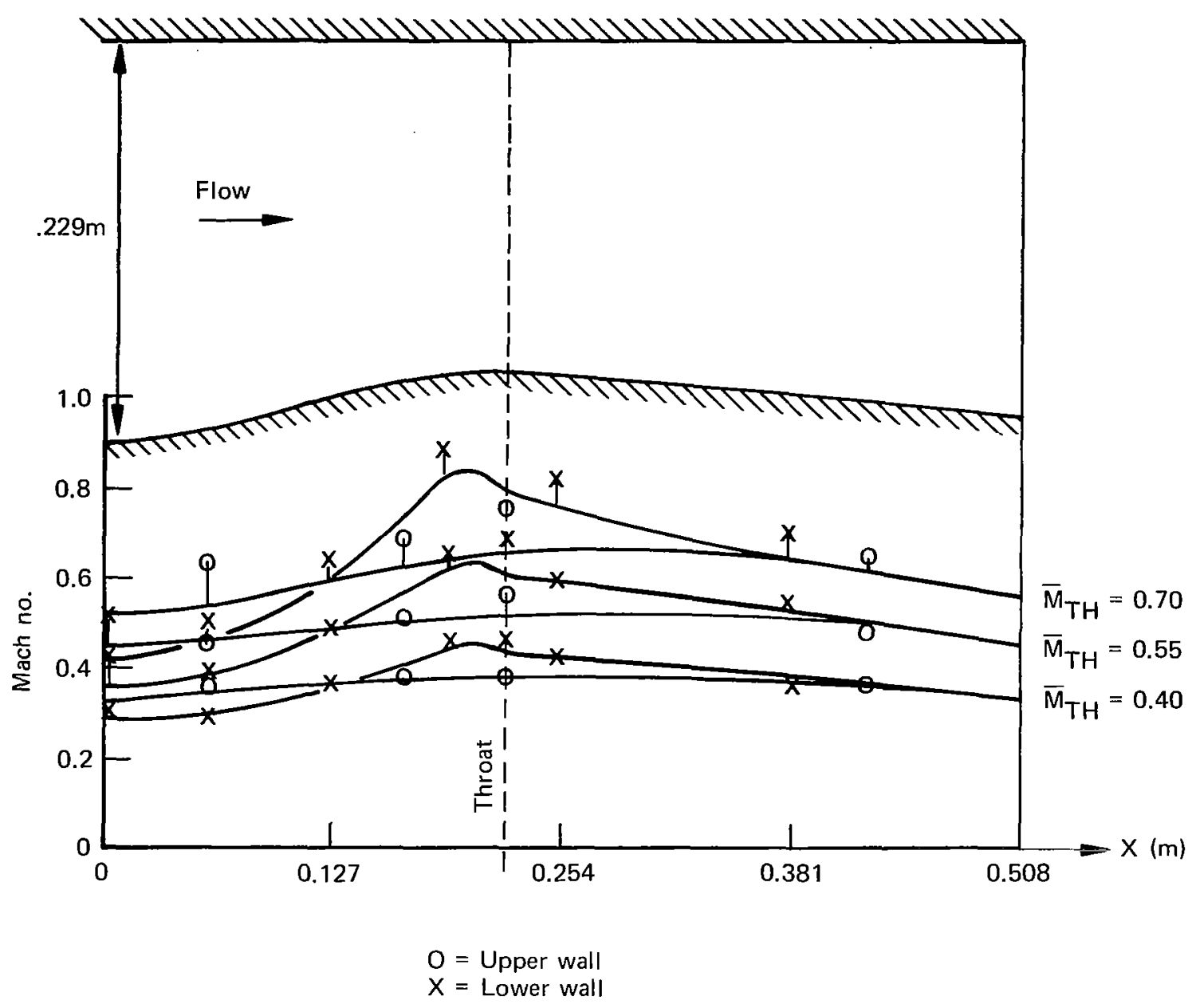

Figure 21(a). Mach No. Variation Along Upper and Lower Walls and Across the Throat of Configuration C1. 


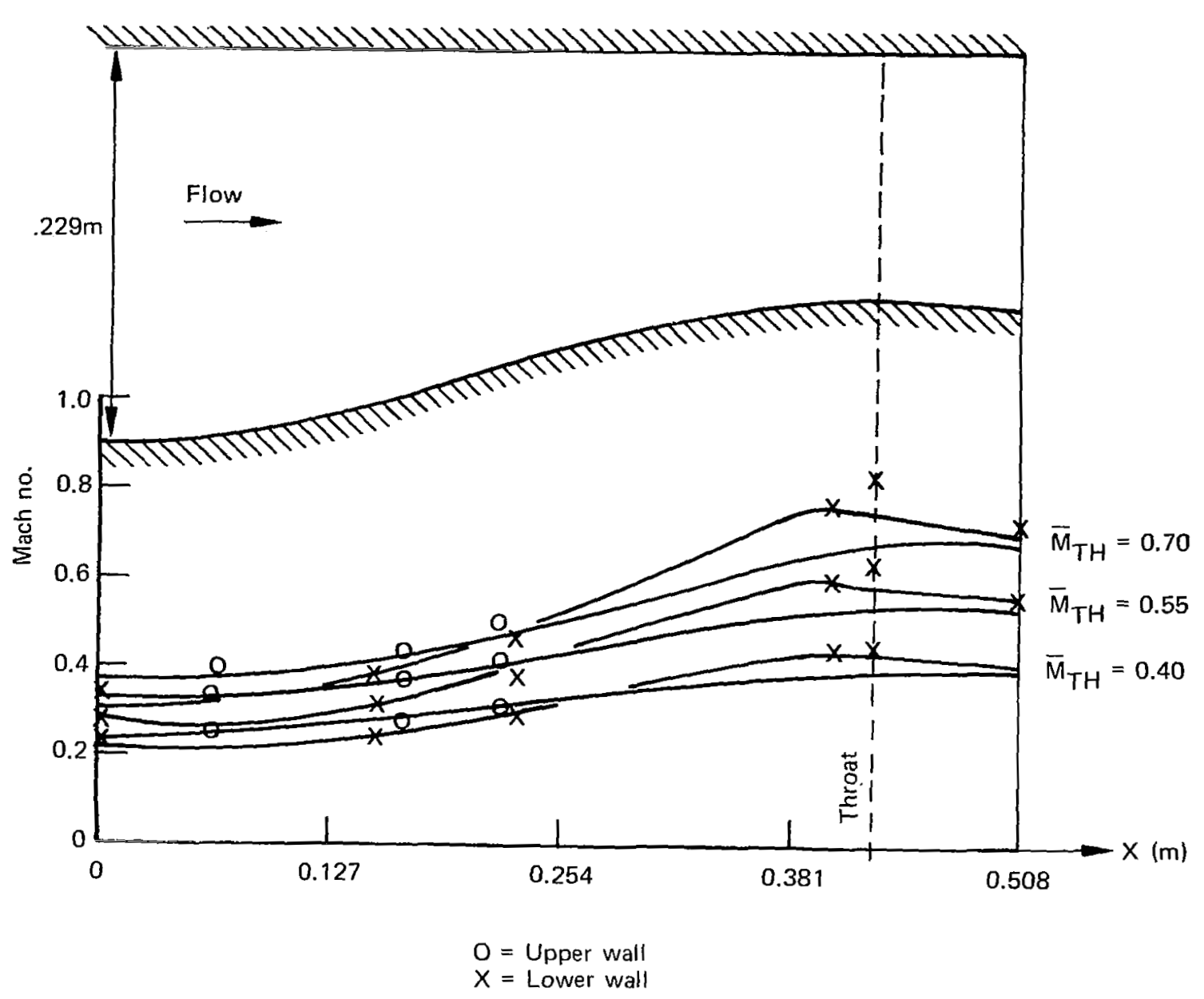

Figure 21(b). Mach No. Variation Along Upper and Lower Walls and Across the Throat of Configuration C2. 


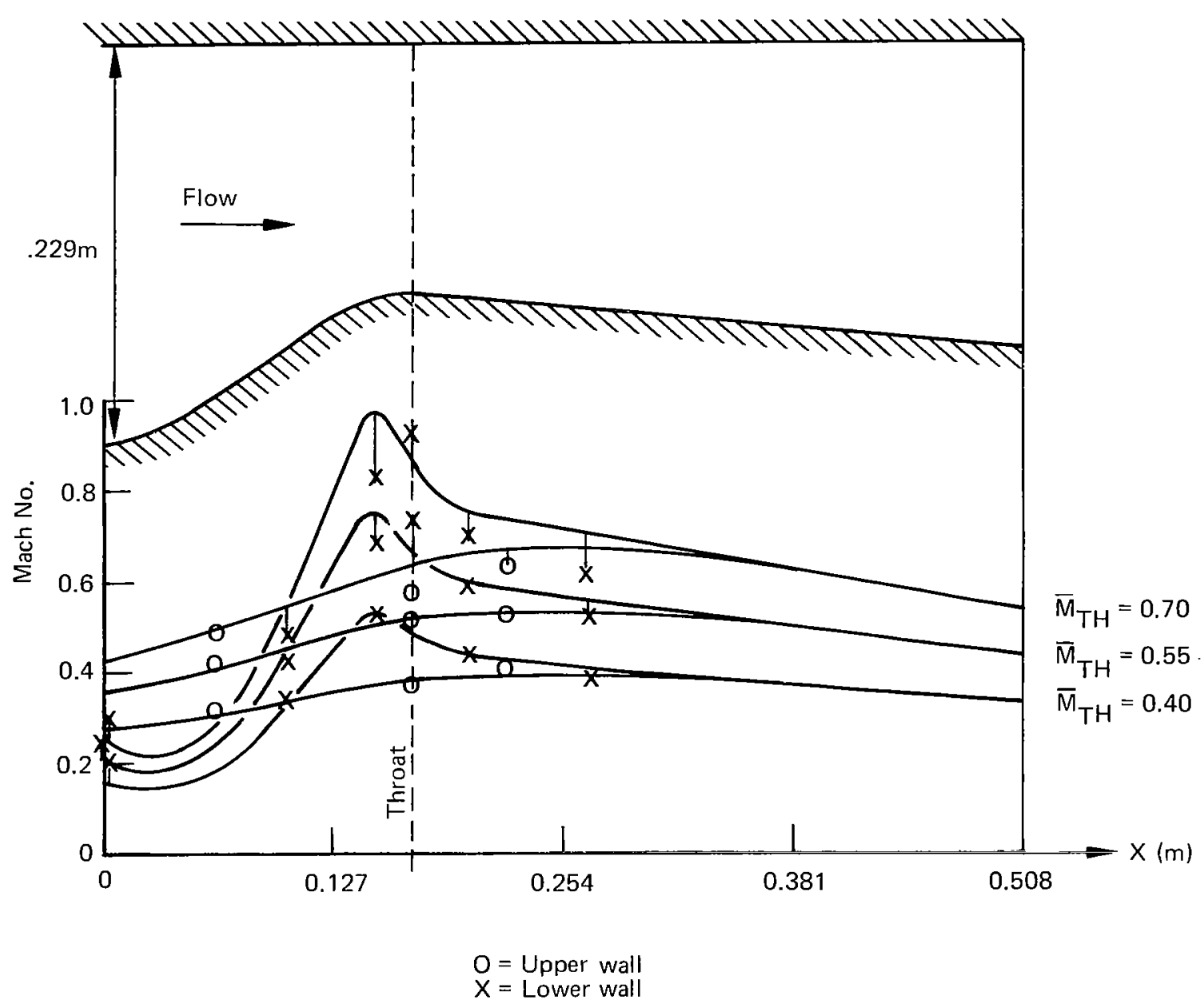

Figure 21(c). Mach No. Variation Along Upper and Lower Walls and Across the Throat of Configuration C3. 

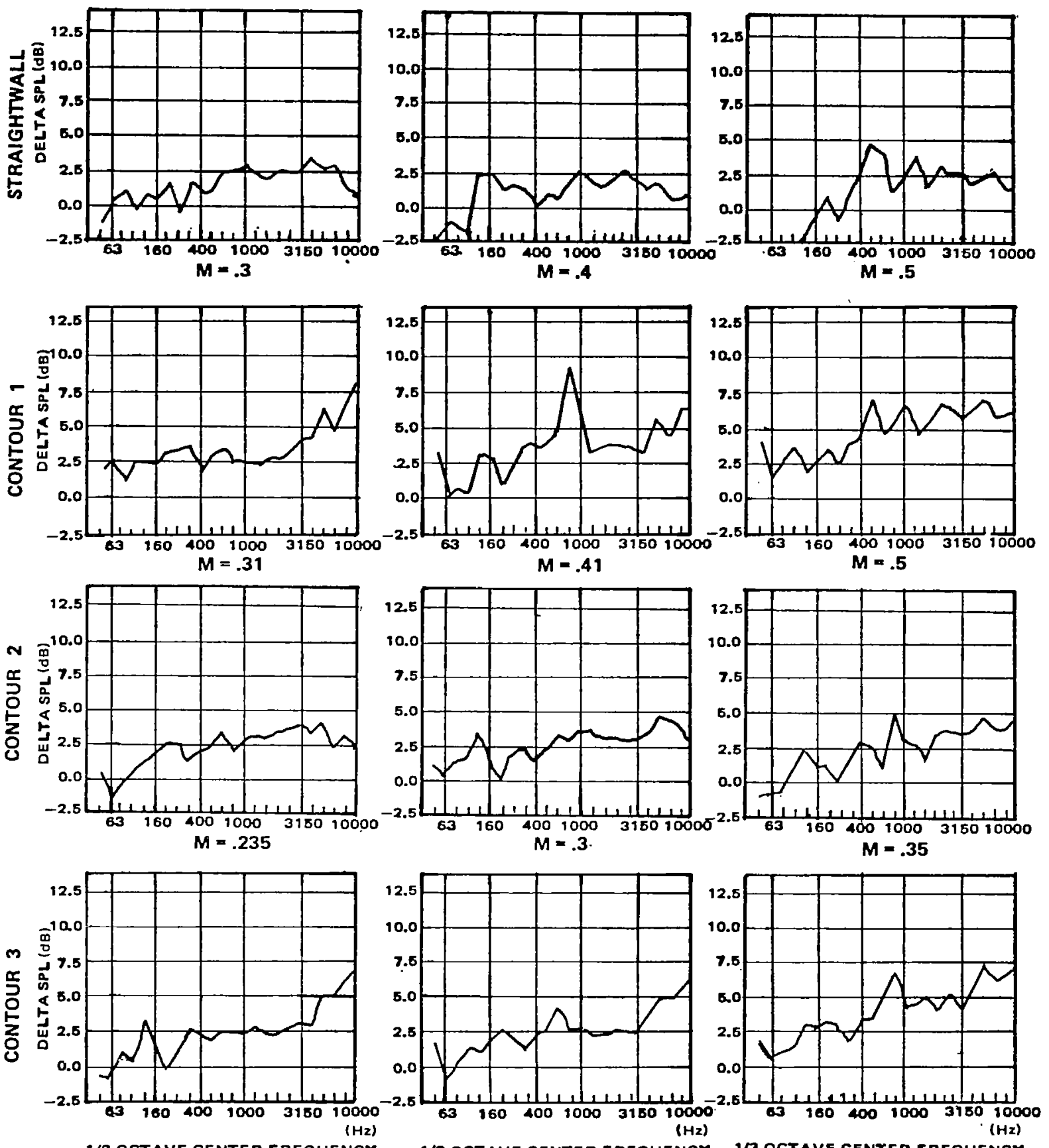

$M=.235$

$M=.3$

$M=.35$

Figure 22(a) Attenuation Spectra for Lining L1 

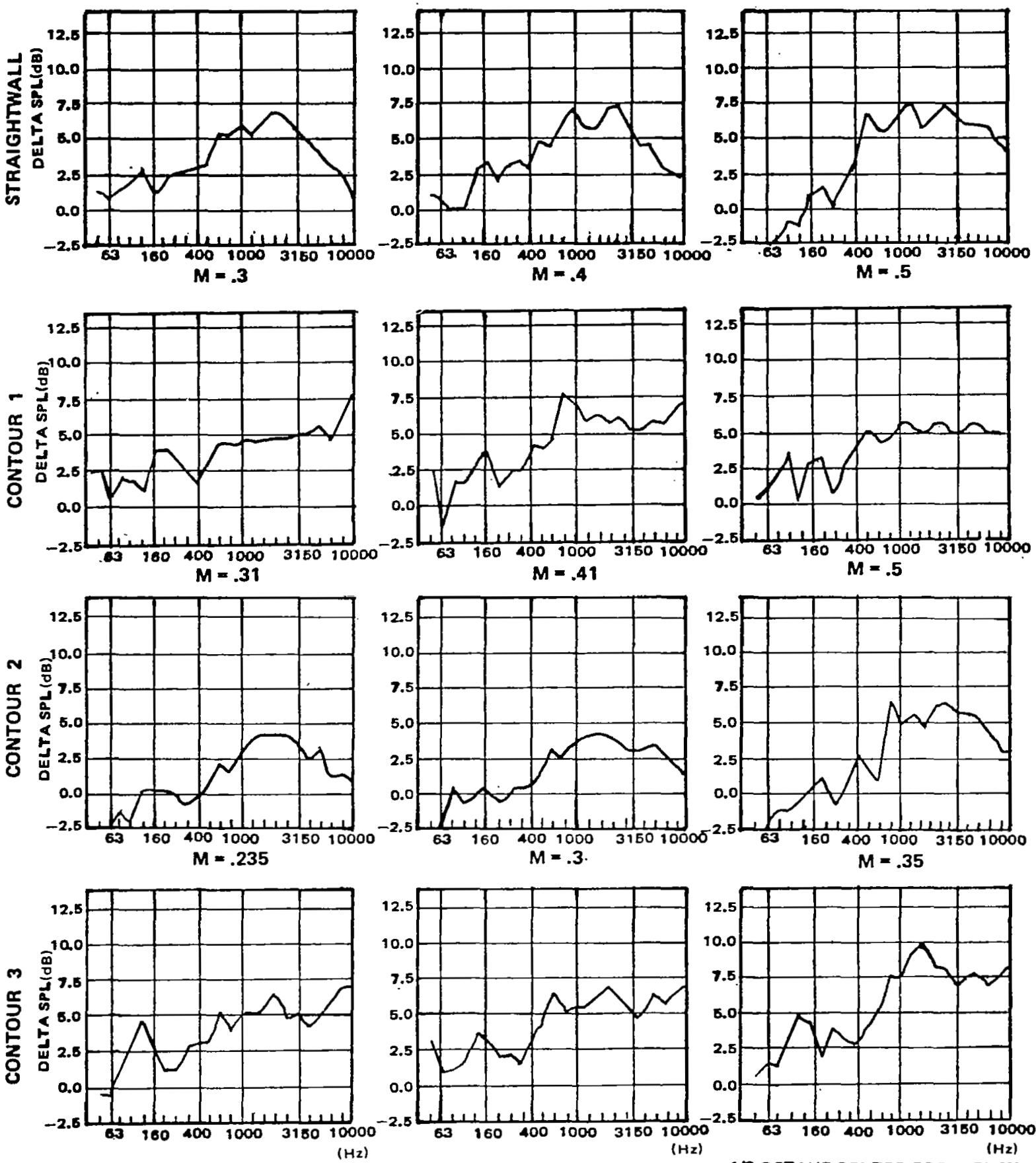

1/3 OCTAVE CENTER FREQUENCY

$M=.235$

1/3 OCTAVE CENTER FREQUENCY

$M=.3$

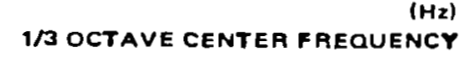

$M=.35$

Figure 22(b) Attenuation Spectra for Lining $L 2$ 

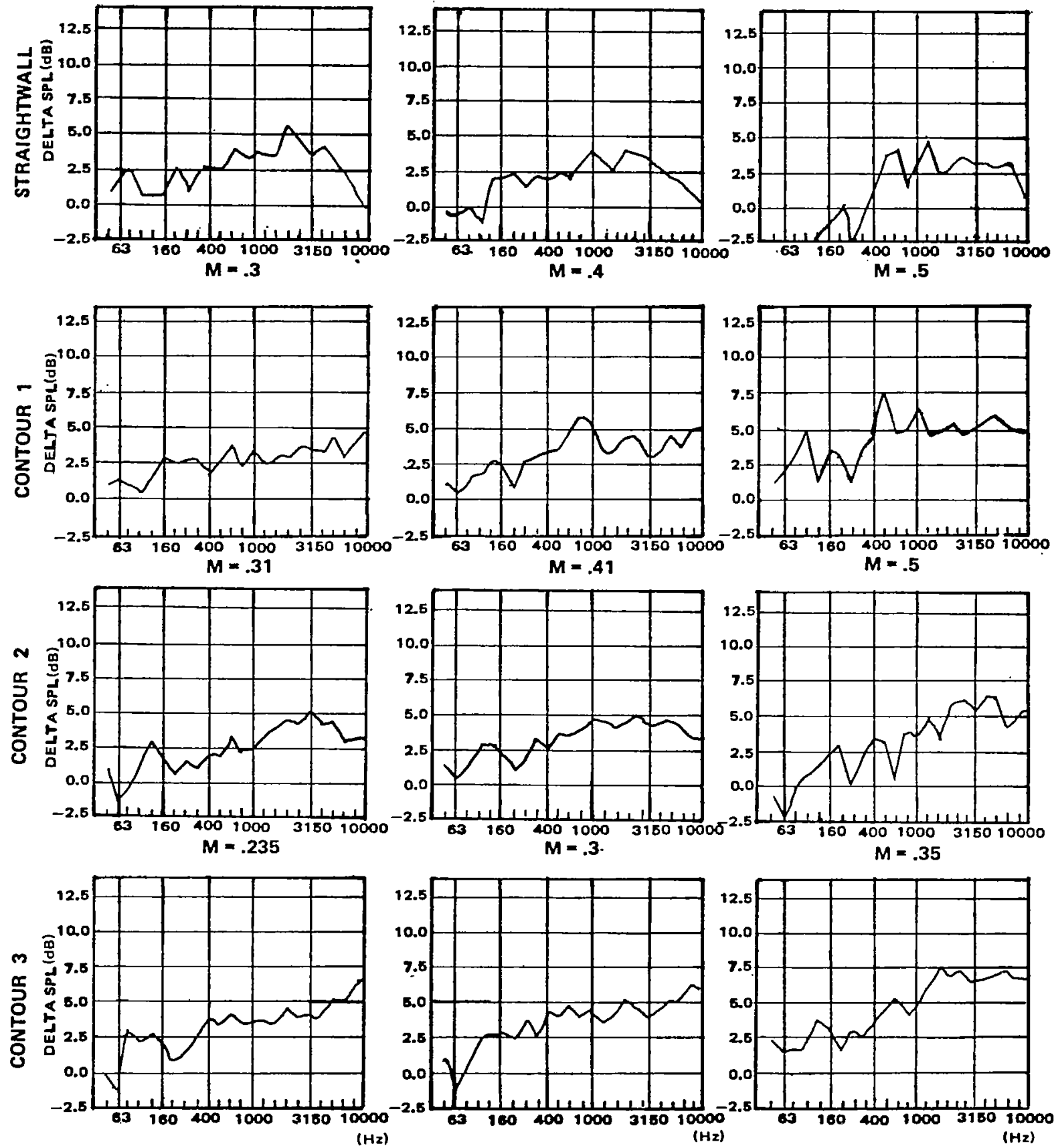

$M=.235$

$M=.3$

$M=.35$

Figure 22(c) Attenuation Spectra for Lining L3 

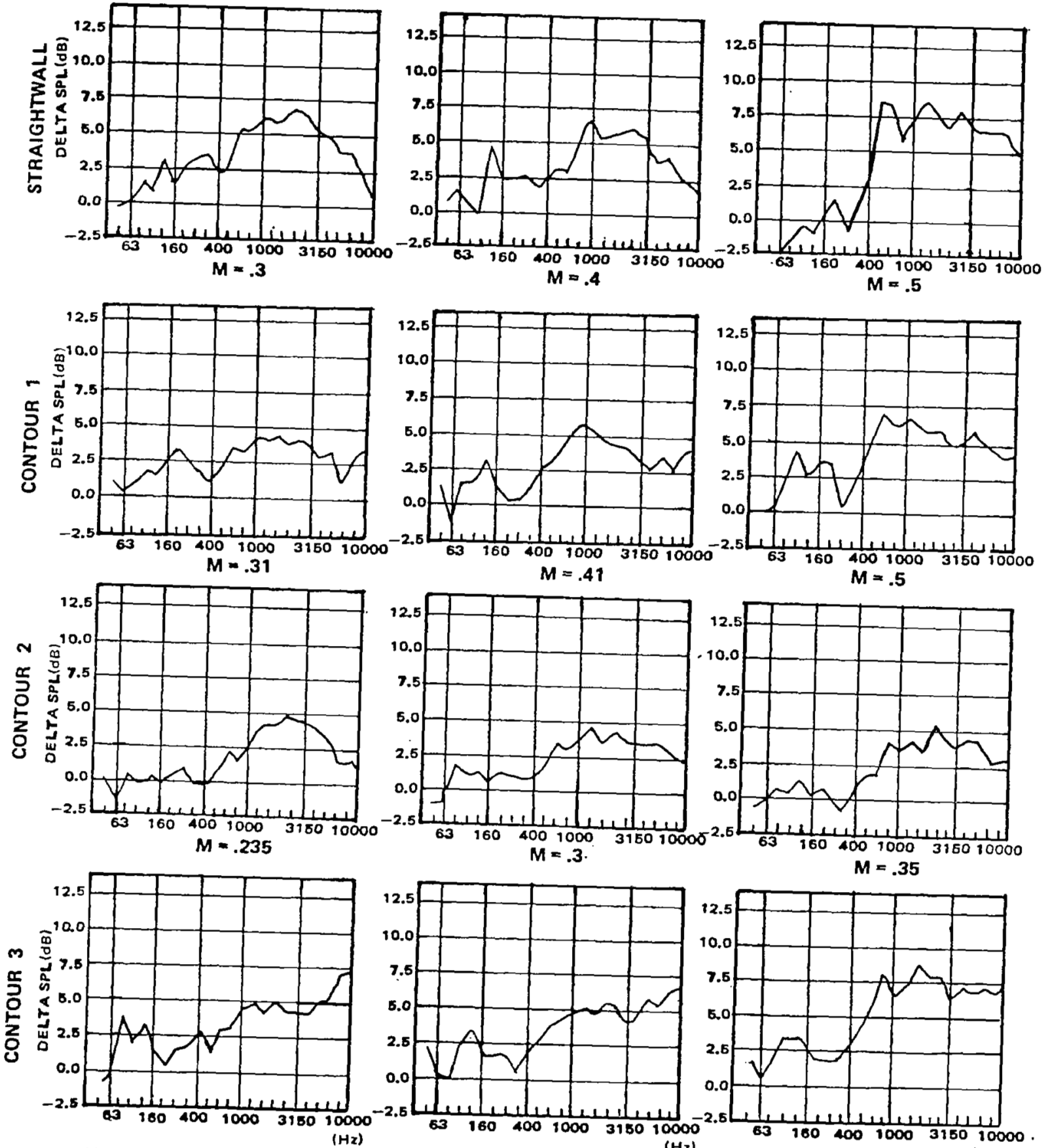

1/3 OCTAVE CENTER FREOUENCY

$M=.235$

(Hz) $M=.3$

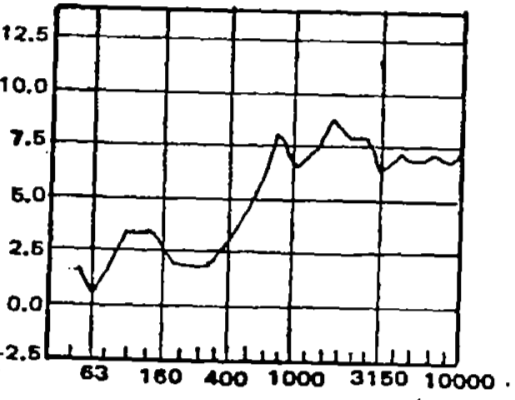

I/3 OCTAVE CENTER FREOUENCY

$M=.35$

Figure 22(d) Attenuation Spectra for Lining $L 4$ 

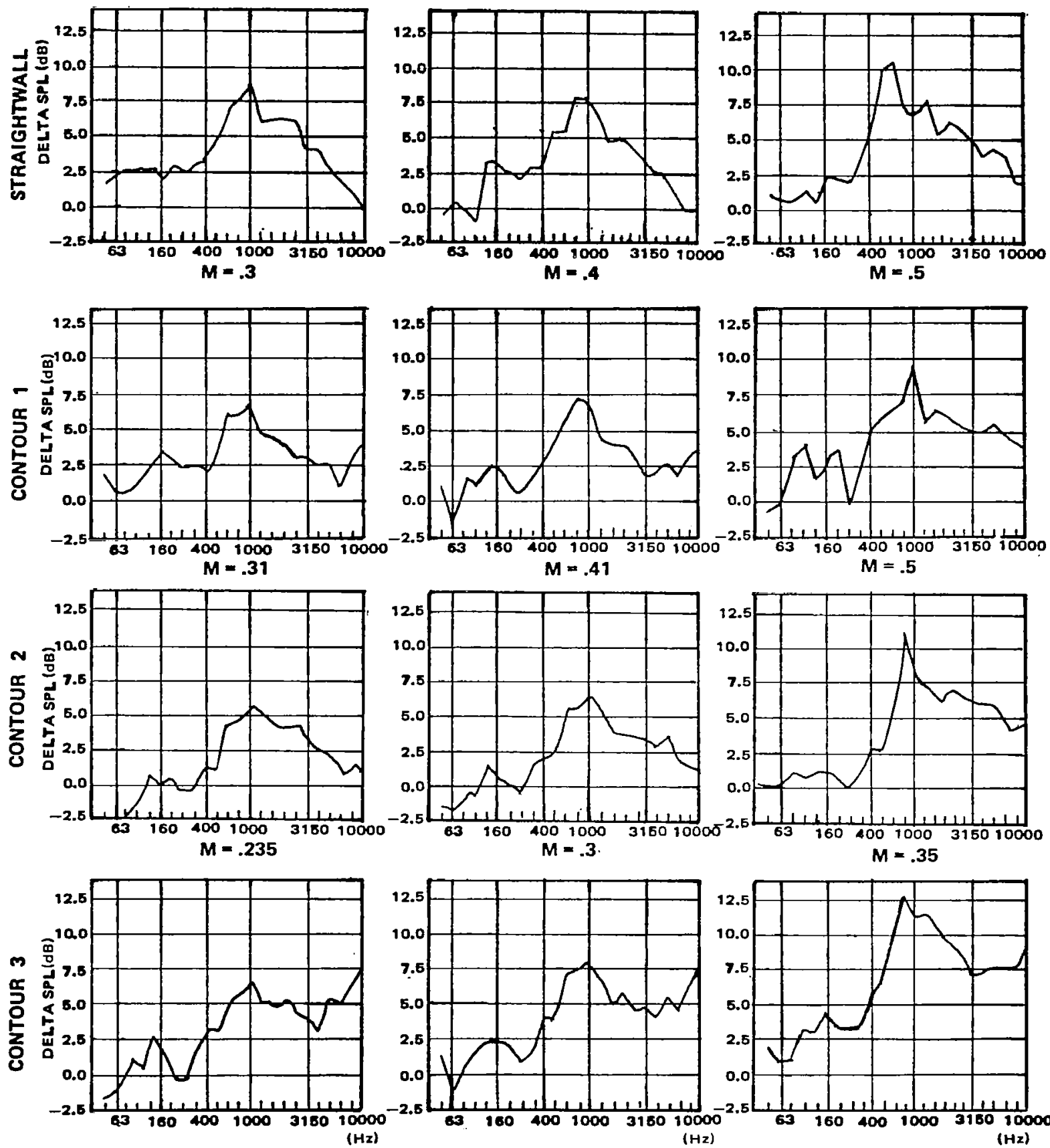

1/3 OCTAVE CENTER F REOUENCY

$M=.3$

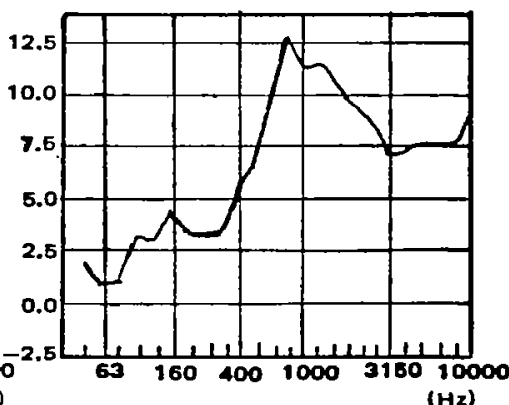

1/3 OCTAVE CENTEA FREQUENCY

$M=.235$

$M=.35$

Figure 22(e) Attenuation Spectra for Lining L5 

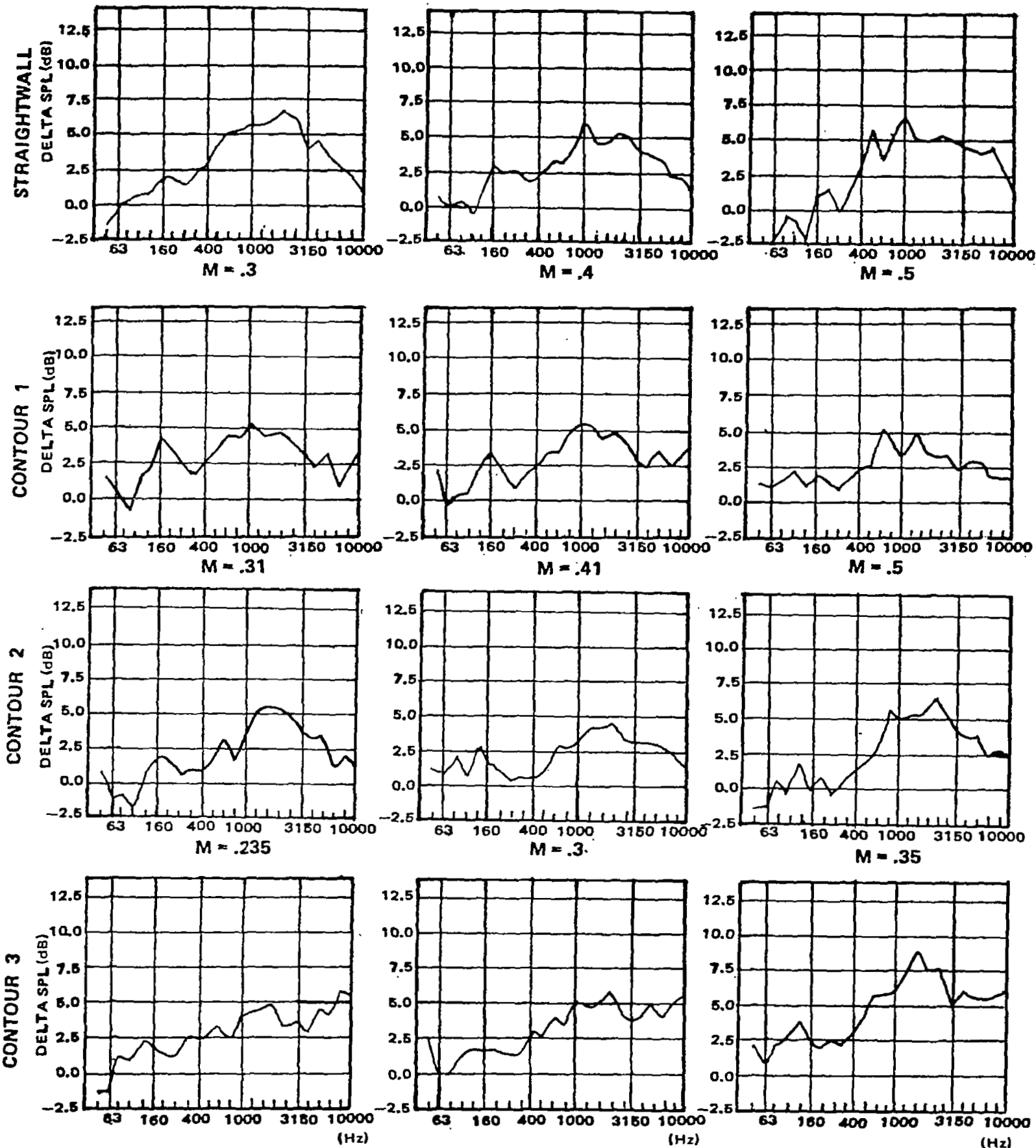

1T OCTAYE CENTER FREOUENCY

$M=.235$

$M=.3$

$M=.35$

Figure 22(f) Attenuation Spectra for Lining $L 6$ 
Repeat runs were made with contour $C 3$ and lining $L 1$ to verify repeatability. Figure 23 shows the comparison. Above $1000 \mathrm{~Hz}$, the difference between the repeats is generaliy not greater than $1 \mathrm{~dB}$.

As a check on the presence of noise floors, a configuration was run with lining on two walls ( $L 2$ and L4). The measured attentuation in this case peaked at $12.5 \mathrm{~dB}$, indicating that there was no serious noise floor problem for measured attenuations in the 6-8 $\mathrm{dB}$ range.

Some configurations were run with only one acoustic panel installed. The measured attenuations did not show any systematic benefit to placing the panel near to the contour rather than in the farther position.

The item of greatest interest in this study was the change in attenuation of a lining due to refraction effects. Figure 24 shows this change for each lining and contour at $M=0.35$. The results for contour $\mathrm{Cl}$ were obtained by interpolation. Although there was a wide scatter range, some trends are quite evident:

(1) Alt contours improved attentuation at high frequencies.

(2) Improvement sometimes occurred in the low frequency range.

(3) There was generally least change in the mid-frequency range. 

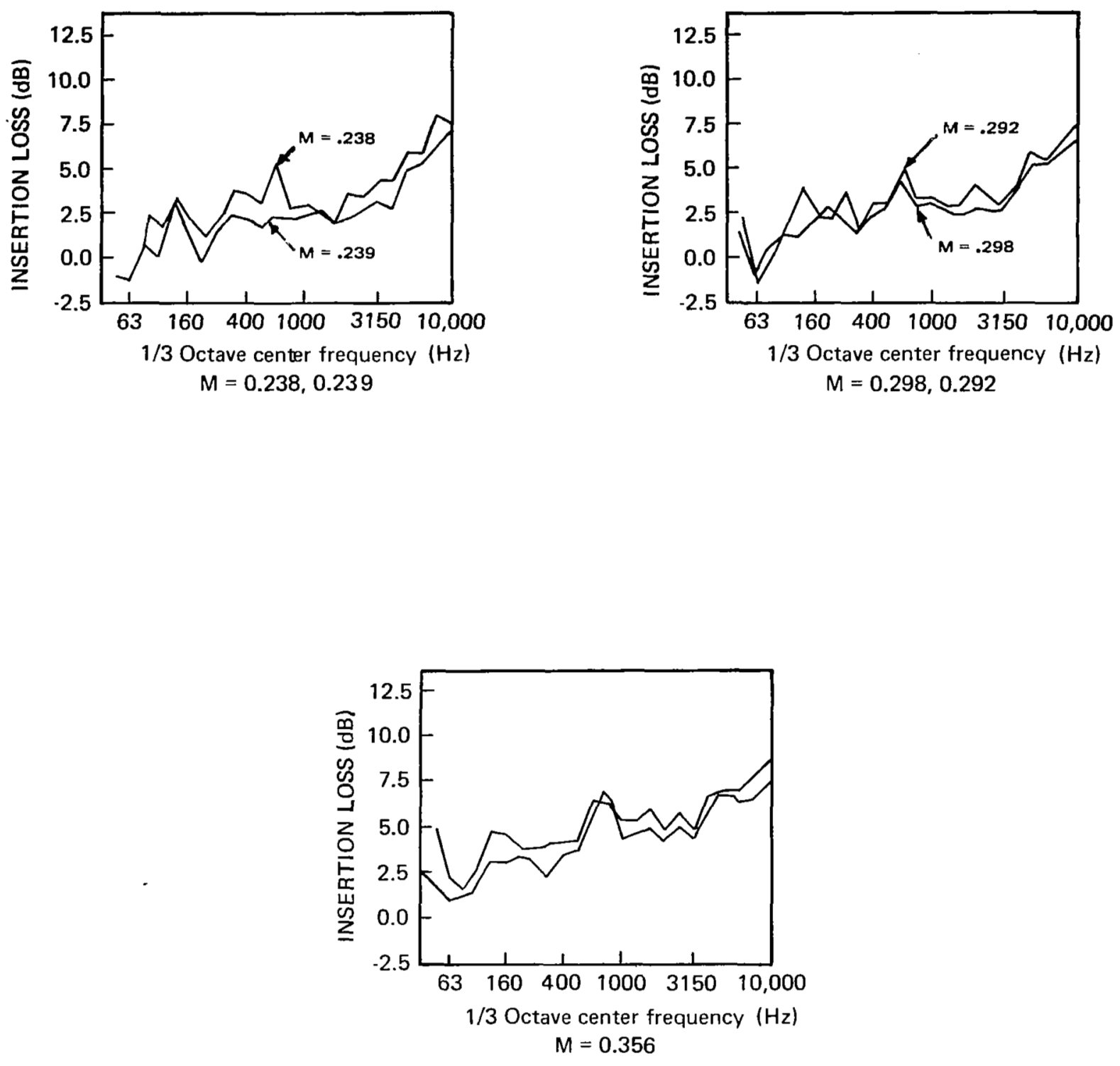

Figure 23. Repeatability Comparison Insertion Loss Spectra for Contour C3, Lining L1 


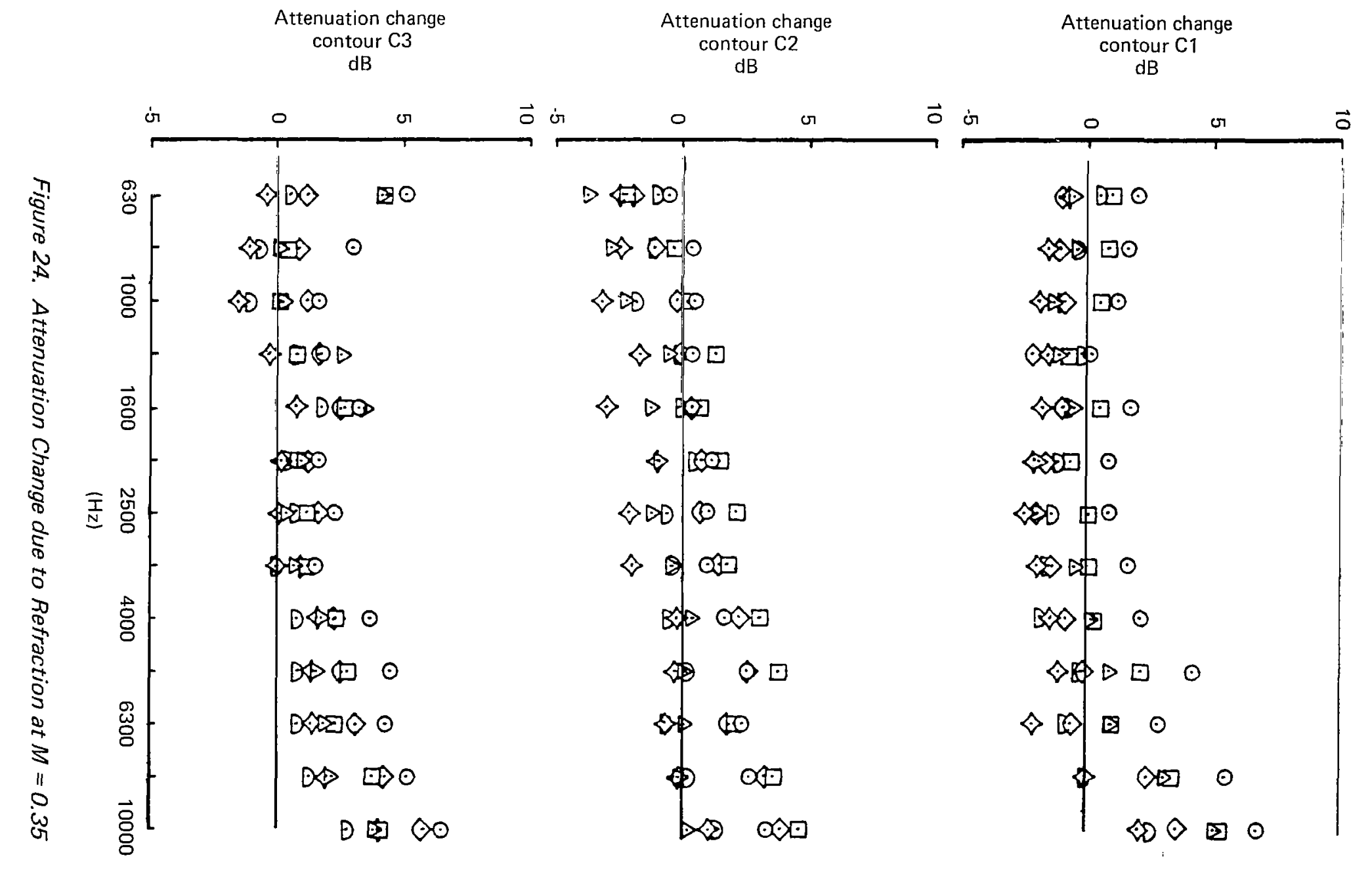

Attenuation change contour $\mathrm{C} 2$

$$
\mathrm{dB}
$$
contour $\mathrm{Cl}$

$\mathrm{dB}$ 


\section{CONCLUSIONS}

\section{Phase I}

(1) Comparison of the behavior of weak shock waves with that of highfrequency acoustic waves in refracting flowfields has shown them to be closely similar.

(2) Test results have been obtained which relate the comparative levels of wave refraction in duct flow to the shape of the duct. These data can be used in the design of refracting inlets which direct acoustic waves to intercept the duct wall where their energy can be absorbed by suitable lining material.

(3) Observations of the motion of weak shock waves traveling upstream from simulated inlet configurations have shown the relationship between the direction of wave propagation and the shape of the profile. The behavior of the waves was found to be strongly dependent on the curvature of the wall close to the throat region.

(4) Refraction effects can be used to cause waves to propagate in a favored direction away from the centerline of simulated inlet configurations which are nonsymmetrical. Two quite different types of contours caused large changes in directivity, one having a large hilite-to-throat ratio and the other a small ratio. In a real inlet, these refraction effects could be used to propagate noise above the inlet and away from the ground.

(5) Observations of wave behavior have suggested a preferred length for the portion of the duct towards which acoustic waves are directed in a refracting inlet configuration. 


\section{Phase II}

(1) Results showed that refraction can be used to induce large improvements in acoustic lining attenuation, especially at high frequencies.

(2) The principal benefits should be for broadband noise. The effect of refraction is to widen the bandwidth of the attenuation spectrum. 



\section{RECOMMENDATIONS}

(1) The information obtained on the influence of refraction effects on the direction of wave propagation should be incorporated into the design of directional inlets which cause inlet noise to be radiated in a favored direction. These should be tested at model scale using a fan rig test facility to determine the extent to which directivity patterns can be controlled.

(2) If the model scale test of the directional inlets demonstrates the potential useful application of refraction effects to control directivity, this type of inlet should be designed and ground tested at full scale using a gas turbine engine.

(3) The information obtained both on the behavior of waves in refracting flows and on the influence of refraction on acoustic lining effectiveness should be applied to the design of a refracting inlet for full-scale test.

(4) Analytic procedures should be developed for the design of refracting contours and for the attentuation of duct linings in the presence of refraction.

(5) A study should be initiated to determine how refraction effects could be applied to suppress noise in the fan ducts of high bypass ratio engines. 


\section{REFERENCES}

1. Sloan, D.; and Farquhar, B. W.: The Refracting Inlet: A New Concept for Aircraft Inlet Noise Suppression. ASME Paper No. 75-GT-21, March 2-6, 1975.

2. Hartmann, J.; and Trolle, B.: A New Acoustic Generator: The Air Jet Generator. J. Sci. Instr., vo1. 4, 1927, pp. 101-111.

3. Martlew, D. L.: The Use of Hartmann Generators as Sources of High Intensity Sound in a Large Absorption Flow Duct Facility. AIAA Paper No. 75-529, March 24-26, 1975.

4. Colehour, J. L.: Transonic Flow Analysis Using a Streamline Coordinate Transformation Procedure. AIAA Paper No. 73-667. Paper presented at AIAA 6th Fluid and Plasma Dynamics Conference (Palm Springs, Calif.), July 16-18, 1973. 